\title{
¿El ingreso influye en la felicidad de las poblaciones? Los casos de Colombia, Brasil y México*
}

\author{
Does Income Influence the Reported Happiness of Populations? \\ The Cases of Colombia, Brazil and Mexico
}

Oscar Mauricio Poveda Bermudez

\begin{abstract}
RESUMEN
Este trabajo busca las variables que inciden sobre la probabilidad de reportar ser feliz en Colombia, Brasil y México para el periodo 2010-2014. Para ello, se emplea una especificación logística ordenada por país cuya variable dependiente es el nivel de felicidad reportado expresado en categorías. Las conclusiones de esta aproximación empírica sustentan que el nivel de ingresos no tiene una incidencia notable sobre la felicidad reportada. En contraste, variables como el estado civil, la salud o el número de hijos tienen significativa relevancia sobre la probabilidad de reportar ser feliz. Un hecho sobresaliente en el caso colombiano es el incremento de la probabilidad de reportar ser feliz a medida que aumenta la libertad de elección; en Brasil, la felicidad aumenta en cuanto mejora el estado de salud y en México, la probabilidad de reportar ser feliz es levemente mayor en las mujeres. Por último, la probabilidad de reportar ser feliz a lo largo de la vida tiene forma de "U" en Brasil y México.
\end{abstract}

Palabras clave: Felicidad, América Latina, nivel de ingresos, libertad de elección, salud, edad, modelo logístico ordenado.

Clasificación JEL: I31, D87, C25, J28

\begin{abstract}
This paper researches the variables that impact the likelihood to report being happy in Colombia, Brazil and Mexico in the period 2010-2014. For this aim, it estimates an ordered logistic model by country where the dependent variable is the reported happiness. The results indicate that income level does not have relevant incidence over reported happiness. Conversely, variables such as civil or health status and number of offspring have a significant influence on the likelihood to be happy. An outstanding fact the Colombian case is the swift growth in the probability of being happy when freedom of choice increases. The Brazilian happiness increases inasmuch as health status soars, whilst Mexican women seem to be slightly happier than males. Finally, the likelihood to report being happy throughout life is U-shaped in Brazil and Mexico.
\end{abstract}

Keywords: Happiness, Latin America, income level, freedom of choice, health status, age, ordered logit model.

JEL Classification: I31, D87, C25, J28

\footnotetext{
* Fecha de recepción: 29/06/2017. Fecha de aceptación: 03/12/2018.

** Universidad Externado de Colombia, Colombia. E-mail: oscar.poveda01@est.uexternado.edu.co ORCID: 0000-0002-0001-4539.
} 


\section{INTRODUCCIÓN}

La felicidad puede tomar diversos matices a la hora de ser definida, desde la satisfacción de necesidades fisiológicas, hasta la máxima plenitud de las personas mediante la consecución de propósitos. Es así que este artículo toma la definición expuesta por Maslow (1943) quien define la felicidad como la autorrealización que alcanzan los individuos después de satisfacer, parcial o totalmente, ciertas necesidades jerárquicamente ordenadas.

Desde Smith ([1776], 1958) y Bentham ([1776], 2007), quienes estudiaban las emociones que gobernaban el actuar humano y la búsqueda de la máxima utilidad posible, ${ }^{1}$ respectivamente, hasta Edgeworth $([1881], 2009)$ y la formalización matemática de la utilidad de los agentes, los intentos por estudiar la utilidad sensible de los individuos han sido una preocupación de la ciencia económica, con miras a realizar mejores aproximaciones sobre la toma de decisiones (Gilbert, 2006). Por lo anterior, la pertinencia y contribución de este trabajo radica en una aproximación a los factores sociodemográficos que pueden incurrir sobre la probabilidad de reportar ser feliz para algunos países de la región latinoamericana. Con esto se espera enriquecer la búsqueda de elementos que permitan entender los niveles de felicidad reportados y, eventualmente, servir de instrumento para desarrollar políticas públicas que permitan incluir este factor (i.e. la felicidad) en el paradigma de desarrollo económico.

El objetivo del mismo es identificar las variables sociodemográficas ${ }^{2}$ que inciden sobre la probabilidad de reportar ser feliz en Colombia, México y Brasil para el periodo 2010-2014. La hipótesis preliminar del documento surge de Kahneman \& Deaton (2010), quienes concluyen que la influencia del ingreso, sobre la felicidad, sólo es significativa si este es menor o igual a USD $\$ 75.000$ anuales. ${ }^{3}$ En consecuencia, la existencia de variables con mayor incidencia que el ingreso sobre la probabilidad de reportar ser feliz es un hecho latente que resulta apropiado comprobar.

Este trabajo consta de cuatro secciones. La primera contempla la introducción y la revisión de la literatura, donde aborda desde la definición de felicidad, hasta las variables explicativas empleadas y la justificación de América Latina como región de estudio. La segunda sección expone la conveniencia de la base

\footnotetext{
1 Término original: The greatest happiness principle. En este concepto se expone la búsqueda de la máxima utilidad posible a través del placer, por encima del dolor, así como se encapsula la premisa del actuar humano basado en lograr la máxima felicidad posible entre los seres sensibles -dentro de los parámetros razonables.

Estadísticamente significativas.

Durante dos años, en Estados Unidos, se obtuvieron 450,000 observaciones del índice de bienestar Gallup-Healthways (Gallup-Healthways Well-Being Index) donde se captura la felicidad como experiencias emocionales del día previo a la entrevista.
} 
de los datos empleada, así como los países escogidos y algunos estadísticos descriptivos. La sección tres enmarca el desarrollo metodológico y sus resultados. El trabajo finaliza con la sección cuatro donde se presentan las conclusiones.

\section{UNA BREVE DEFINICIÓN DE FELICIDAD}

Desde la óptica de Maslow (1943), la felicidad es el resultado de la satisfacción de un conjunto de necesidades, las cuales jerárquicamente anteceden a ésta. Desde las necesidades fisiológicas y de seguridad, hasta las de reconocimiento, satisfacer cada uno de estos niveles conlleva a que el individuo pueda lograr ambas, la autorrealización y la máxima felicidad posible. Sin embargo, resulta apropiado exponer visiones alternas que permitan enriquecer dicho concepto. Autores como Argyle (1992), Bradburn \& Noll (1969) y Seligman (2002) concuerdan en que la felicidad es el resultado de la interacción de las emociones y su efecto sobre las habilidades cognitivas y sensoriales. Esto permite inferir que la felicidad puede estar asociada a factores no tangibles que afectan a los individuos y que pueden proceder de la interacción de éstos con su entorno.

\section{I.1. Ingreso: literatura indagada}

En el imaginario social la relación causal entre ingreso y felicidad parece regir las decisiones de los agentes. Sin embargo, desde la revisión de la literatura esta asociación parece desvirtuarse. A la luz de Stutzer (2004), mayores niveles de ingreso no garantizan mayores niveles de felicidad puesto que los individuos adaptan su contexto a los cambios en el ingreso. Este fenómeno es denominado por Layard (2011) como treadmill effect ${ }^{4}$ o efecto marea. ${ }^{5}$ Asimismo, la mejora en la sensación de necesidades satisfechas, producto del ingreso, sí parece tener un efecto notable sobre la felicidad, pero el efecto directo del ingreso sobre la felicidad es débil (Fuentes \& Rojas, 2001).

La escasa correlación entre ingreso y felicidad no es del todo concluyente, puesto que parece tomar dos sendas divergentes en función del tipo de ingresos

\footnotetext{
El efecto total del ingreso sobre la felicidad es nulo si el grupo de referencia en el cual el individuo se desenvuelve sufre el mismo cambio. La traducción del término treadmill es trotadora. Sin embargo, para este artículo, la analogía hará referencia a que un estímulo sobre un individuo llevará a éste a terminar justo donde él inició (i. e. reportar el mismo nivel de felicidad, antes y después de un estímulo).

5 Cuando las sociedades experimentan tasas particularmente altas de crecimiento económico, las personas experimentan un incremento de la felicidad gracias al aumento de sus ingresos. Sin embargo, este efecto se ve contrarrestado por el mismo aumento en el ingreso de los demás. En otras palabras, todos disfrutan de mayores ingresos absolutos, pero las diferencias preexistentes (ingreso relativo) entre un individuo y otro, se mantienen.
} 
que se considere: absoluto o relativo. ${ }^{6}$ Respecto a la relación del primero con la felicidad, McBride (2010) sostiene que incrementos en la felicidad producto del incremento en el ingreso absoluto son contrarrestados por las expectativas futuras sobre este último.

Sin embargo, la analogía felicidad e ingreso relativo parece tener una mayor relevancia en la literatura indagada, encontrándose una correlación estadísticamente significativa entre estas variables en los trabajos realizados por Clark \& Oswald (1996), Ferrer-i-Carbonell (2005) y Tsui (2014). Autores y evidencia adicional correspondiente al nivel de ingresos se exponen en la tabla 1.

Tabla 1. Referentes revisión literatura I.

\begin{tabular}{|c|c|c|c|}
\hline Variable & Descripción & $\begin{array}{l}\text { Efecto sobre } \\
\text { felicidad }\end{array}$ & Referente \\
\hline \multirow{5}{*}{$\begin{array}{l}\text { Nivel } \\
\text { Ingresos }\end{array}$} & $\begin{array}{l}\text { El ingreso absoluto parece no estar correlacionado } \\
\text { con la felicidad reportada. }{ }^{1}\end{array}$ & Neutro & $\begin{array}{l}\text { (Ahuvia, 2008; } \\
\text { Easterlin, 1973; } \\
\text { Tsui, 2014) }\end{array}$ \\
\hline & $\begin{array}{l}\text { Un incremento generalizado en los ingresos absolutos } \\
\text { de una sociedad no genera un incremento significativo } \\
\text { de la felicidad. }{ }^{2}\end{array}$ & Neutro & $\begin{array}{l}\text { (Bartolini \& } \\
\text { Sarracino, 2014; } \\
\text { Easterlin, 1974) }\end{array}$ \\
\hline & $\begin{array}{l}\text { Los individuos tienden a comparar su nivel de ingresos } \\
\text { con el de sus congéneres (ingreso relativo). } .^{3}\end{array}$ & Positivo & $\begin{array}{l}\text { (Ferrer-i-Carbo- } \\
\text { nell, 2005) }\end{array}$ \\
\hline & $\begin{array}{l}\text { Mayores ingresos se asocian a menores niveles } \\
\text { promedio de felicidad reportada. }{ }^{4}\end{array}$ & Negativo & $\begin{array}{l}\text { (Blanchflower \& } \\
\text { Oswald, 2004b) }\end{array}$ \\
\hline & $\begin{array}{l}\text { El nivel de ingresos es utilizado como una herramienta } \\
\text { social para establecer mejores relaciones sociales que } \\
\text { inciden sobre la felicidad reportada. }\end{array}$ & Positivo & $\begin{array}{l}\text { (Ahuvia, 2008; } \\
\text { Easterlin, 1995; } \\
\text { Tsui, 2014) }\end{array}$ \\
\hline \multicolumn{4}{|c|}{$\begin{array}{l}{ }^{1} \text { En Taiwán entre } 1999-2002 \text { (Tsui, 2014). } \\
2 \text { Incluso, para aquel autor, en el corto plazo la felicidad puede disminuir. En } 27 \text { países en el periodo 1980-2009. } \\
{ }^{3} \text { En Alemania para el periodo 1992-1997. } \\
{ }^{4} \text { Para Estados Unidos y Reino Unido. }\end{array}$} \\
\hline
\end{tabular}

\section{I.2. Elementos adicionales al ingreso para explicar la felicidad}

Dadas las definiciones de felicidad hechas por Argyle (1992), Bradburn \& Noll (1969) y Seligman (2002), es pertinente incluir variables como la importancia de relaciones sociales, el tiempo libre y la libertad de elección, de forma tal que permitan capturar componentes emocionales de los individuos.

\footnotetext{
6 Tomando como ingreso absoluto el monto total de pagos que reciben los individuos y el ingreso relativo como la proporción de pagos que recibe un individuo con relación al monto de ingresos que reciben los demás individuos de la sociedad.
} 
Para sintetizar los referentes utilizados en la revisión de la literatura, la tabla 2 expone cada una de las variables que se emplean como explicativas de la felicidad reportada, ${ }^{7}$ a partir de una breve descripción de su relevancia en la literatura, su efecto esperado y el referente a partir del cual se consideran.

Tabla 2. Referentes revisión literatura II.

\begin{tabular}{|c|c|c|c|}
\hline Variable & Descripción & $\begin{array}{l}\text { Efecto sobre } \\
\text { felicidad }\end{array}$ & Referente \\
\hline \multirow{4}{*}{ Edad } & $\begin{array}{l}\text { A lo largo de la vida la felicidad es constante } \\
\text { (hedonic treadmill). }\end{array}$ & Neutro & $\begin{array}{l}\text { (Brickman \& } \\
\text { Campbell, 1971) }\end{array}$ \\
\hline & $\begin{array}{l}\text { La felicidad presenta una forma parabólica a lo largo } \\
\text { de la vida. }{ }^{1}\end{array}$ & Neutro & (Easterlin, 2006) \\
\hline & $\begin{array}{l}\text { En la región latinoamericana la felicidad a lo largo } \\
\text { de la vida puede tener forma de " } U \text { ". }\end{array}$ & Neutro & $\begin{array}{l}\text { (Gerstenblüth, } \\
\text { Melgar \& Rossi, } \\
\text { 2013) }\end{array}$ \\
\hline & La felicidad a lo largo de la vida tiene forma de " $U$ ". ${ }^{3}$ & Neutro & $\begin{array}{l}\text { (Gerdtham \& } \\
\text { Johannesson, } \\
\text { 2001; Lelkes, } \\
\text { 2006; Peiró, } \\
\text { 2006) }\end{array}$ \\
\hline $\begin{array}{l}\text { Relaciones } \\
\text { sociales }\end{array}$ & $\begin{array}{l}\text { La importancia de la familia y las amistades parece } \\
\text { asociarse a niveles altos de felicidad. }{ }^{4}\end{array}$ & Positivo & $\begin{array}{l}\text { (Becchetti \& } \\
\text { Rossetti, 2009) }\end{array}$ \\
\hline \multirow{3}{*}{ Consumo } & $\begin{array}{l}\text { La pertenencia de los individuos a un grupo social } \\
\text { se asocia a alcanzar mayores niveles de felicidad. }\end{array}$ & Positivo & (Maslow, 1943) \\
\hline & $\begin{array}{l}\text { El consumo ajeno se vincula a menores niveles } \\
\text { de felicidad propios. }\end{array}$ & Negativo & (McBride, 2010) \\
\hline & $\begin{array}{l}\text { Mayores niveles de consumo se correlacionan } \\
\text { con menores niveles de felicidad. }{ }^{5}\end{array}$ & Negativo & $\begin{array}{l}\text { (Cryder, Lerner, } \\
\text { Gross \& Dahl, } \\
\text { 2008) }\end{array}$ \\
\hline $\begin{array}{l}\text { Condición } \\
\text { laboral }\end{array}$ & $\begin{array}{l}\text { La satisfacción por la tenencia de trabajo puede } \\
\text { explicar la felicidad reportada. }{ }^{6}\end{array}$ & Positivo & $\begin{array}{l}\text { (Oswald, 1999; } \\
\text { Stutzer \& Frey, } \\
\text { 2006) }\end{array}$ \\
\hline \multirow{3}{*}{$\begin{array}{l}\text { Tiempo } \\
\text { libre }\end{array}$} & $\begin{array}{l}\text { Mayores horas laborales implican menor tiempo } \\
\text { de ocio para entablar relaciones sociales. }{ }^{7}\end{array}$ & Negativo & (Kaun, 2005) \\
\hline & $\begin{array}{l}\text { Existe una correlación positiva entre el tiempo } \\
\text { de ocio y la felicidad reportada. }{ }^{8}\end{array}$ & Positivo & $\begin{array}{l}\text { (Guven, 2012; } \\
\text { Prinz \& Bünger, } \\
\text { 2012) }\end{array}$ \\
\hline & $\begin{array}{l}\text { Ambos, saturar los cronogramas diarios de actividades } \\
\text { y la sobreoferta de opciones }{ }^{10} \text { inciden negativamente } \\
\text { sobre la felicidad. }\end{array}$ & Negativo & (Peiró, 2006) \\
\hline
\end{tabular}

Estas variables pueden tener distintas formas de ser medidas. 
ECONOMÍA TEORÍA Y PRÁCTICA [ISSN: 2448-7481] • Nueva Época, año 27, número 50, enero-junio 2019

Oscar Mauricio Poveda Bermudez

Tabla 2. Continuación.

\begin{tabular}{|c|c|c|c|}
\hline Variable & Descripción & $\begin{array}{l}\text { Efecto sobre } \\
\text { felicidad }\end{array}$ & Referente \\
\hline \multirow{3}{*}{$\begin{array}{l}\text { Libertad } \\
\text { elección }\end{array}$} & $\begin{array}{l}\text { Percepción de elementos desencadenantes sobre } \\
\text { las elecciones y acontecimientos en la vida de los } \\
\text { individuos }^{11} \text { puede segmentarlos entre internos }{ }^{12} \\
\text { y externos. }{ }^{13}\end{array}$ & Positivo & (Verme, 2009) \\
\hline & $\begin{array}{l}\text { Existe una diferencia entre la oportunidad de elegir } \\
\text { y la capacidad de elegir. }\end{array}$ & Positivo & $\begin{array}{l}\text { (Veenhoven, } \\
\text { 2000) }\end{array}$ \\
\hline & $\begin{array}{l}\text { La libertad de elección podría ser un determinante } \\
\text { relevante de la felicidad reportada. }\end{array}$ & Positivo & $\begin{array}{l}\text { (Helliwell, } \\
\text { Layard \& Sachs, } \\
\text { 2015; Inglehart, } \\
\text { Foa, Peterson } \\
\text { \& Welzel, 2008; } \\
\text { Lelkes, 2006) }\end{array}$ \\
\hline \multirow{3}{*}{ Religión } & $\begin{array}{l}\text { Existe una relación inversa entre la espiritualidad } \\
\text { (como aproximación de la religión) y consumo, con un } \\
\text { subsecuente efecto sobre la felicidad reportada. }\end{array}$ & Positivo & $\begin{array}{l}\text { (Stillman, } \\
\text { Fincham, Vohs, } \\
\text { Lambert \& Phi- } \\
\text { llips, 2012) }\end{array}$ \\
\hline & $\begin{array}{l}\text { La importancia de la religión podría comportarse mejor } \\
\text { que el ingreso para explicar de forma significativamente } \\
\text { estadística la felicidad reportada. }{ }^{14}\end{array}$ & Positivo & (Lelkes, 2006) \\
\hline & $\begin{array}{l}\text { Los estudiantes cristianos de economía reportan } \\
\text { mayores niveles de felicidad que los estudiantes de } \\
\text { otras religiones. } .^{15}\end{array}$ & Positivo & $\begin{array}{l}\text { (Haucap \& Hei- } \\
\text { meshoff, 2014) }\end{array}$ \\
\hline \multirow{6}{*}{$\begin{array}{l}\text { Estado } \\
\text { civil }\end{array}$} & $\begin{array}{l}\text { Mayor diversidad religiosa dentro de un grupo social } \\
\text { se asocia con menores niveles de felicidad. }{ }^{16}\end{array}$ & Negativo & $\begin{array}{l}\text { (Mookerjee \& } \\
\text { Beron, 2005) }\end{array}$ \\
\hline & $\begin{array}{l}\text { La felicidad reportada después del matrimonio es } \\
\text { elevada en los primeros años, posteriormente regresa } \\
\text { a los niveles previos al compromiso. }\end{array}$ & Neutro & $\begin{array}{l}\text { (Loewenstein, } \\
\text { O’Donoghue \& } \\
\text { Rabin, 2003) }\end{array}$ \\
\hline & $\begin{array}{l}\text { La felicidad en el matrimonio es mayor -de forma } \\
\text { permanente- que la reportada cuando se es soltero. }{ }^{17}\end{array}$ & Positivo & (Qari, 2014) \\
\hline & $\begin{array}{l}\text { El matrimonio se correlaciona con la felicidad } \\
\text { reportada por los individuos en América del sur. }\end{array}$ & Positivo & $\begin{array}{l}\text { (Triunfo, } \\
\text { Gerstenbluth \& } \\
\text { Rossi, 2008) }\end{array}$ \\
\hline & $\begin{array}{l}\text { El divorcio afecta negativamente la felicidad reportada } \\
\text { por los agentes. }\end{array}$ & Negativo & Negativo \\
\hline & $\begin{array}{l}\text { Una vida sexual más activa en el matrimonio } \\
\text { se asocia a mayores niveles de felicidad reportada. }{ }^{18}\end{array}$ & Positivo & $\begin{array}{l}\text { (Blanchflower \& } \\
\text { Oswald, 2004a; } \\
\text { Loewenstein, } \\
\text { Krishnamurti, } \\
\text { Kopsic \& Mcdo- } \\
\text { nald, 2015) }\end{array}$ \\
\hline
\end{tabular}


Tabla 2. Continuación.

\begin{tabular}{|c|c|c|c|}
\hline Variable & Descripción & $\begin{array}{l}\text { Efecto sobre } \\
\text { felicidad }\end{array}$ & Referente \\
\hline Hijos & $\begin{array}{l}\text { El número de hijos se correlaciona positivamente } \\
\text { con la felicidad de las familias. }\end{array}$ & Positivo & (Tsui, 2014) \\
\hline \multirow{2}{*}{$\begin{array}{l}\text { Nivel } \\
\text { educativo }\end{array}$} & $\begin{array}{l}\text { Un nivel educativo más alto no asegura el nivel más } \\
\text { elevado de felicidad, ni garantiza los mayores ingresos. }{ }^{19}\end{array}$ & Neutro & $\begin{array}{l}\text { (Hartog \& Oos- } \\
\text { terbeek, 1998) }\end{array}$ \\
\hline & $\begin{array}{l}\text { La felicidad puede reducirse a medida que se eleva } \\
\text { el nivel educativo. }\end{array}$ & Negativo & $\begin{array}{l}\text { (Clark \& Oswald, } \\
\text { 1996) }\end{array}$ \\
\hline \multirow{2}{*}{$\begin{array}{l}\text { Nivel } \\
\text { educativo }\end{array}$} & $\begin{array}{l}\text { La educación no explica de forma significativa } \\
\text { la felicidad reportada. }\end{array}$ & Neutro & (Peiró, 2006) \\
\hline & $\begin{array}{l}\text { Estudiar economía }{ }^{20} \text { se correlaciona positivamente } \\
\text { con mayores niveles de felicidad. } .^{21}\end{array}$ & Positivo & $\begin{array}{l}\text { (Haucap \& Hei- } \\
\text { meshoff, 2014) }\end{array}$ \\
\hline \multirow{3}{*}{ Sexo } & $\begin{array}{l}\text { Las mujeres reportan mayores niveles de felicidad } \\
\text { que los hombres. }{ }^{22}\end{array}$ & Positivo & $\begin{array}{l}\text { (Gerdtham \& } \\
\text { Johannesson, } \\
2001 \text { y Peiró, } \\
\text { 2006) }\end{array}$ \\
\hline & $\begin{array}{l}\text { Las mujeres obtienen menores ingresos que los } \\
\text { hombres, son igualmente saludables, pero más felices } \\
\text { que ellos. }{ }^{23}\end{array}$ & Positivo & $\begin{array}{l}\text { (Hartog \& Oos- } \\
\text { terbeek, 1998) }\end{array}$ \\
\hline & $\begin{array}{l}\text { Mayor participación femenina en el Senado aumenta } \\
\text { de forma estadísticamente significativa la felicidad } \\
\text { de una sociedad. }\end{array}$ & Positivo & $\begin{array}{l}\text { (Mookerjee \& } \\
\text { Beron, 2005) }\end{array}$ \\
\hline $\begin{array}{l}\text { Justifica- } \\
\text { ción acu- } \\
\text { mulación } \\
\text { riqueza }\end{array}$ & $\begin{array}{l}\text { Incrementos en el ingreso relativo tienen mayores } \\
\text { efectos sobre la felicidad reportada en grupos con baja } \\
\text { equidad distributiva. }{ }^{24}\end{array}$ & Positivo & $\begin{array}{l}\text { (Bjørnskov, } \\
\text { Dreher, Fischer, } \\
\text { Schnellenbach \& } \\
\text { Gehring, 2013) }\end{array}$ \\
\hline \multirow[b]{2}{*}{$\begin{array}{l}\text { Orgullo } \\
\text { patrio }\end{array}$} & $\begin{array}{l}\text { Los agentes buscan tener una mayor cantidad de } \\
\text { riqueza con respecto a quienes conforman su grupo } \\
\text { social (Upward comparisons). }{ }^{25}\end{array}$ & Positivo & $\begin{array}{l}\text { (Ferrer-i-Carbo- } \\
\text { nell, 2005) }\end{array}$ \\
\hline & $\begin{array}{l}\text { Eventos que eleven el orgullo patrio como ser } \\
\text { sede de eventos deportivos o ganar competiciones } \\
\text { internacionales pueden contribuir al incremento } \\
\text { de la felicidad. }\end{array}$ & Positivo & $\begin{array}{l}\text { (Hallmann, Breu- } \\
\text { er \& Kühnreich, } \\
\text { 2013; Pawlows- } \\
\text { ki, Downward \& } \\
\text { Rasciute, 2014) }\end{array}$ \\
\hline Salud & $\begin{array}{l}\text { La salud es una variable altamente correlacionada } \\
\text { con la felicidad reportada en América del sur. }{ }^{26}\end{array}$ & Positivo & $\begin{array}{l}\text { (Dolan et al., } \\
\text { 2008; Triunfo } \\
\text { et al., 2008) }\end{array}$ \\
\hline
\end{tabular}

${ }^{1}$ En la cual, a partir de los 18 años hasta la mitad de la vida, la felicidad crece ligeramente, para decrecer posteriormente. Explicada esencialmente por la pérdida de salud y la insatisfacción laboral. No obstante, aquel efecto es atenuado por las relaciones sociales que el individuo pudiera tener.

2 Para el año 2008.

${ }^{3}$ En Suecia, para el año 1991.

${ }^{4}$ Para Alemania en el periodo 1992-2004.

${ }^{5}$ En comparación con personas con menores niveles de consumo quienes reportaron ser felices. Evaluado mediante la habilidad cognitiva del autoenfoque (término original del inglés: self-focus), en la cual se evalúa la prioridad que se le brindan a las necesidades básicas y cómo éstas son satisfechas. 
ECONOMÍA TEORÍA Y PRÁCTICA [ISSN: 2448-7481] • Nueva Época, año 27, número 50, enero-junio 2019

Oscar Mauricio Poveda Bermudez

${ }^{6}$ En el Reino Unido.

7 En Estados Unidos.

8 En Holanda para el periodo 1993-2006.

9 Término original: time-saving treadmill. Ejemplo: los individuos tienden a saturar sus cronogramas de otras obligaciones cuando disponen de tiempo libre, pudiendo destinarlo a actividades de ocio que eleven sus niveles de felicidad. En suma, el tiempo ahorrado en formas más eficientes de realizar actividades es empleado en realizar un mayor número de éstas.

10 Término original: multi-option treadmill. La conclusión es que no se logra el objetivo de hacer lo que se desea, ya que quedará la sensación de no hacer todo lo que se desea.

${ }^{11}$ El locus de control responde al grado de reconocimiento de un individuo frente a las causas de eventos y decisiones que toma en su vida. Así, el origen de estos eventos, desde la visión del agente, puede ser interno, donde el individuo puede controlar o incidir sobre los resultados (e. $g$. esfuerzo personal); o externo a él, donde el entorno ejerce una mayor influencia en los resultados que lo que el individuo puede hacer (e. $g$. azar o dificultad intrínseca).

${ }^{12}$ Categoría que enmarca a los individuos quienes consideran que los resultados de sus acciones dependen del esfuerzo individual.

${ }^{13}$ Categoría que enmarca a los individuos quienes consideran que los resultados de sus acciones dependen de las condiciones de su entorno.

14 En Hungría entre 1991-1998.

15 Para el año 2005 en la universidad alemana de Ruhr-University of Bochum a los estudiantes de Introducción a la Microeconomía.

1660 países entre industrializados y en vías de desarrollo. Para el año 2000.

17 En Alemania para el periodo 1984-2006.

18 Encuesta realizada a 16,000 estadounidenses adultos.

19 En Holanda para el periodo 1940-1998.

${ }^{20} \mathrm{El}$ autor hace una diferencia entre economía y finanzas.

${ }^{21}$ Para el año 2005 en la universidad alemana de Ruhr-University of Bochum a los estudiantes de Introducción a la Microeconomía.

22 En Suecia para 1991 (Gerdtham \& Johannesson, 2001).

23 En Holanda para el periodo 1940-1998.

24 Para Polonia en el periodo 1992-1996.

${ }^{25}$ Este concepto captura el comportamiento de los individuos quienes no valoran lo que poseen, sino que envidian aquello que no tienen.

${ }^{26}$ Para el caso uruguayo, un buen nivel de salud puede incrementar la felicidad entre 31 y 46 puntos porcentuales. Y para el caso argentino la felicidad puede incrementar entre 15 y 27 puntos porcentuales producto de tener un buen nivel de salud. Ambos resultados para el año 2004.

Fuente: elaboración del autor a partir de la revisión de la literatura consultada.

De forma complementaria a lo expuesto en la tabla 2, es preciso agregar dos elementos. El primero corresponde al contexto particular de la felicidad en América Latina, vinculada con la condición laboral, puesto que el 82 por ciento de la fuerza laboral activa en 2007 reportó sentirse feliz con su puesto de trabajo, a pesar de los bajos niveles de formalización laboral (Lora, 2008). El segundo elemento busca reforzar la hipótesis de que la felicidad a lo largo de la vida tiene forma de "U". Lo anterior es expuesto por Becchetti \& Rossetti (2009), quienes encuentran que los jóvenes profesionales son menos felices, en comparación con personas de mayor edad realizando actividades similares, pero reportan niveles de consumo muy por encima que sus antecesores. Aquello puede ser explicado por la disparidad entre los ideales en el ámbito laboral y la realidad de este. ${ }^{8}$

8 Término original: Frustrated Achievement. 


\section{I.3. Por qué Latinoamérica}

La delimitación de la región latinoamericana está sustentada por la Real Academia Española (RAE, 2005) que define a Latinoamérica como "el conjunto de países del continente americano en los que se hablan lenguas derivadas del latín (español, portugués y francés), en oposición a la América de habla inglesa”.

De esta forma, la región latinoamericana constituye una de las regiones lingüísticas más grandes y culturalmente más cohesionadas del mundo, a pesar de su pluralidad poblacional y sus contrastes geográficos (Colburn, 2002). Siendo así un actor relevante en el contexto internacional.

Asimismo, América Latina representa el 13 por ciento de la superficie emergida de la tierra y sobresale en diversos indicadores, los cuales se describen a continuación:

1. Alberga a cerca de 630 millones de habitantes ${ }^{9}$ (Organización de las Naciones Unidas [ONU], 2015).

2. Representó el 8.49 por ciento de la producción mundial durante el 2010 (Banco Mundial [BM], 2012).

3. Desde la Organización para la Cooperación y el Desarrollo Económicos (OCDE \& Santiso, 2009), la región latinoamericana ha experimentado condiciones favorables ${ }^{10}$ para el aumento de la felicidad durante el primer lustro del siglo XXI.

En términos de felicidad, esta zona del mundo ocupa el tercer puesto en índices de felicidad, sólo por detrás de Norteamérica y Europa Occidental durante el periodo 2012-2014. Desde la clasificación realizada por Helliwell et al. (2015), el primer país latinoamericano en el escalafón es Costa Rica en el puesto $12,{ }^{11} \mathrm{se}$ guido de México y Brasil en los puestos $14^{12}$ y $16^{13}$ respectivamente; y Colombia en el puesto 33. ${ }^{14}$ A partir de esto, y contemplando la disponibilidad de datos que permitan cumplir con el objetivo de este trabajo, se escoge a Colombia, Brasil y México como países de estudio.

\footnotetext{
9 Cerca del 9 por ciento de la población mundial (ONU, 2015).

${ }^{10}$ Elevado crecimiento económico, baja inflación y finanzas fiscales saludables; todas las variables como promedios a lo largo de la región.

${ }^{11}$ Reporta un nivel de 7,226 en una escala de 0 a 10, siendo cero (0) el nivel más bajo de felicidad y 10 el máximo nivel reportado.

${ }^{12}$ Reporta un nivel de 7,187 en una escala de 0 a 10.

${ }^{13}$ Reporta un nivel de 6,983 en una escala de 0 a 10.

${ }^{14}$ Reporta un nivel de 6,477 en una escala de 0 a 10.
} 
De esta manera, elementos como la correlación existente en América Latina entre crecimiento económico y felicidad reportada (Lora, 2008), así como el elevado PIB-PPA ${ }^{15}$ para el año 2013 que presentan estos países al interior de la región latinoamericana (FMI, 2014), los catalogan como países relevantes para ser analizados. La justificación de emplear la Encuesta Mundial de Valores Longitudinal (WVS, 2015), así como la escogencia de países con elevados niveles de felicidad se expone en el siguiente apartado.

\section{DATOS}

\section{II.1. Encuesta mundial de valores versión 6}

Recordando que el objetivo de este trabajo es identificar las variables sociodemográficas que inciden sobre la probabilidad de reportar ser feliz para el periodo 2010-2014, es factible emplear a Colombia, Brasil y México -aun teniendo los mayores niveles de felicidad en la región- ya que no se busca una muestra heterogénea de naciones con diversos niveles de felicidad. En su lugar, se desea reconocer cuáles factores pueden incidir sobre elevados niveles de felicidad reportados en los países.

Para esto, se indagan los factores estadísticamente significativos que incurren en la probabilidad de reportar ser feliz en cada país, a miras de encontrar elementos al interior de cada sociedad que se asocien positivamente con los niveles de felicidad reportados. En suma, dado el análisis individual (por países) que se lleva a cabo en este trabajo, la homogeneidad de la felicidad, antes bien, es un elemento a favor de éste, ya que refuerza la búsqueda de elementos que expliquen la felicidad reportada.

Con la finalidad de realizar una aproximación empírica que satisfaga el objetivo descrito previamente, se emplean los micro-datos en la tabla 6 (periodo 2010-2014) de la Encuesta Mundial de Valores Longitudinal (WVS, 2015) ${ }^{16}$ porque esta versión en particular, a diferencia de otros periodos, contiene un número importante de variables subjetivas como el orgullo patrio, la importancia individual del tiempo libre y la libertad de elección. Este tipo de encuestas

\footnotetext{
${ }^{15}$ Producto Interno Bruto (PIB) evaluado a Valores de Paridad de Poder Adquisitivo (PPA).

${ }^{16}$ La encuesta mundial de valores es un proyecto de investigación llevado a cabo por World Value Survey Association, que busca recolectar las opiniones y creencias de las personas y cómo éstas cambian a lo largo del tiempo. Entre los principales campos que abarca están la democracia, el medio ambiente, la política, la familia, la cultura, la inseguridad y el bienestar subjetivo, entre otros. Ésta se lleva a cabo desde 1981 y es aplicada en el 90 por ciento de los países, con una muestra mínima de 1,000 encuestados mayores de 18 años, entrevistados personalmente o telefónicamente -para áreas remotas- y escogidos aleatoriamente a partir de georreferenciación de distritos de votación o unidades censadas.
} 
de opinión resulta conveniente ya que permiten capturar de una manera desagregada elementos puntuales de cada individuo que permiten una mejor aproximación a definiciones subjetivas como la felicidad.

\section{II.2. Datos acerca de la felicidad: qué dicen}

Las cuatro categorías de felicidad, ${ }^{17}$ a partir de las cuales se fundamentará la aproximación empírica de este trabajo, fueron capturadas mediante la pregunta $\mathrm{A}_{008}{ }^{18}$ disponible en la encuesta previamente descrita. Partiendo de ello, la muestra tiene un total de 4,414 observaciones repartidas así: 1,324 observaciones de Colombia, ${ }^{19} 1,288$ para Brasil ${ }^{20}$ y 1,802 observaciones para México. ${ }^{21}$

Las categorías de algunas de las variables escogidas como explicativas de la probabilidad de reportar ser feliz se explican en la tabla 3 y, posteriormente, los niveles de felicidad son tabulados en función de éstas para cada uno de los países. ${ }^{22}$

Tabla 3. Variables explicativas y sus categorías. ${ }^{1}$

\begin{tabular}{|c|c|}
\hline Variable & Categorías \\
\hline Nivel ingresos & Nivel I, nivel II, nivel III, nivel IV y nivel V. \\
\hline Libertad elección (percepción)² & Nivel I, nivel II, nivel III, nivel IV y nivel V. \\
\hline Estado civil & Casado, unión libre, divorciado, separado, viudo y soltero. \\
\hline Consumo (proporción del ingreso) & $\begin{array}{l}\text { Inferior al nivel de ingresos, igual al nivel de ingresos y superior } \\
\text { al nivel de ingresos. }\end{array}$ \\
\hline Salud (subjetivo) & Malo, regular, bueno y muy bueno. \\
\hline Edad & $18-20$ años, $21-30,31-40,41-50,51-60,61-70,71-80,81-90$ y $91-99$. \\
\hline Sexo & 1=hombre, 2=Mujer \\
\hline $\begin{array}{l}\text { Tiempo libre } \\
\text { (importancia individual) }\end{array}$ & $\begin{array}{l}\text { Nada importante, poco importante, levemente importante, muy } \\
\text { importante. }\end{array}$ \\
\hline \multirow{2}{*}{\multicolumn{2}{|c|}{$\begin{array}{l}{ }^{1} \text { Las categorías para las variables explicativas restantes se encuentran en el anexo I (tabla A.1). } \\
2 \text { La variable libertad de elección corresponde a una variable de } 10 \text { categorías, en la cual el nivel mínimo (Nivel I) correspon- } \\
\text { de a tener nula autodeterminación para tomar decisiones cotidianas, mientras que el máximo nivel (Nivel X) implica tener } \\
\text { plena autonomía sobre las decisiones que se toman. }\end{array}$}} \\
\hline & \\
\hline & \\
\hline
\end{tabular}

\footnotetext{
${ }^{17}$ Las opciones de respuesta van desde Muy Feliz (Felicidad=4), pasando por Feliz (Felicidad=3), Poco feliz (Felicidad=2) hasta Infeliz (Felicidad=1). Por facilidades metodológicas no se tuvieron en cuenta las respuestas en las categorías "no sabe" y "no responde", ya que ambos sólo alcanzan el 0,15 por ciento y el 0,18 por ciento de la muestra, respectivamente.

${ }^{18}$ La formulación de la pregunta es: "Evaluando todo en conjunto, usted diría que su sentimiento de felicidad es..."

19 Obtenidas en el año 2012.

${ }^{20}$ Obtenidas en el año 2014.

${ }^{21}$ Obtenidas en el año 2012.

${ }^{22}$ Las tabulaciones completas para las demás variables se encuentran en el anexo II (tabla A.2).
} 
La primera de estas variables es el nivel de ingresos, al respecto se evidencia que, para cada nivel de ingresos, en los tres países, la mayoría de las personas reportaron ser felices (Brasil) o muy felices (Colombia y México); destacándose México, donde el 65.7 por ciento de los pertenecientes al nivel de ingresos más bajo reportaron ser muy felices, al igual que el 79.01 por ciento de los pertenecientes al nivel de ingresos más alto. Aquello permite inferir levemente la escasa relación entre nivel de ingresos y felicidad reportada.

\section{Gráfica 1. Felicidad reportada por nivel de ingresos.}

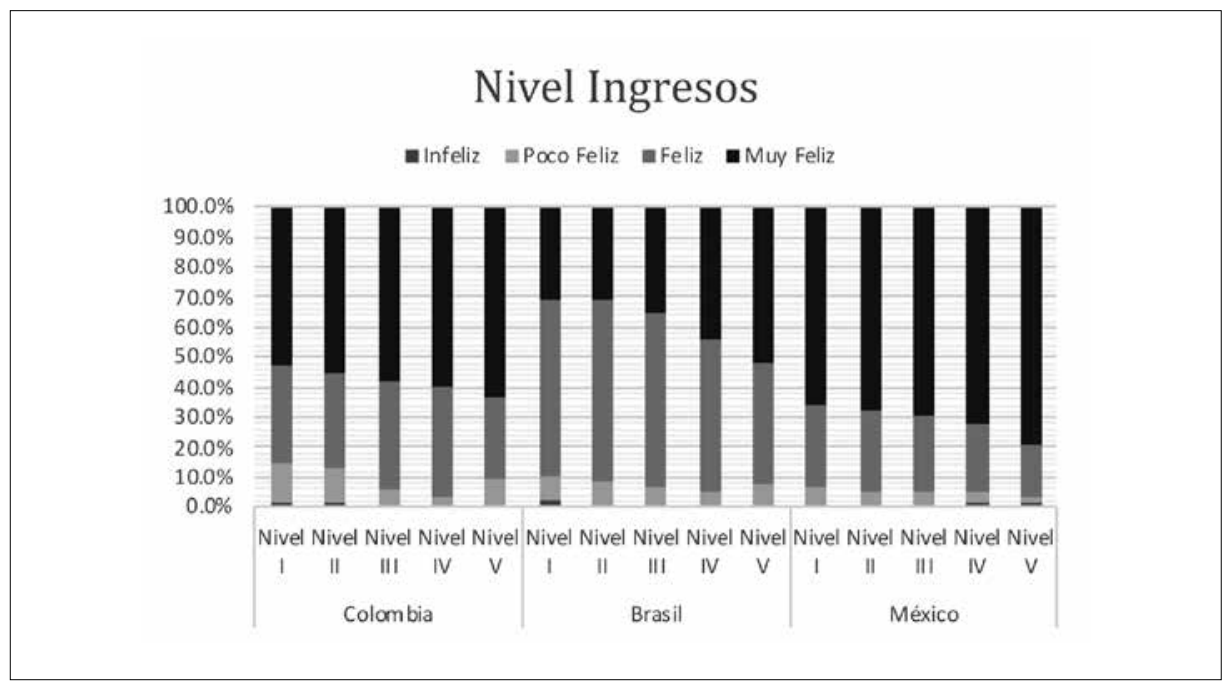

Fuente: elaboración del autor a partir de WVS-LONG WAVE 6.

El porcentaje de individuos que reporta mayores niveles de felicidad parece incrementar a medida que incrementa la percepción de libertad de elección. Para Colombia, mientras que el 27.78 por ciento de quienes reportan nula libertad de elección declaran ser muy felices, el 63.20 por ciento de quienes reportan plena libertad de elección declaran el mismo nivel de felicidad. Esta tendencia se repite en Brasil, donde el 27.91 por ciento de quienes tienen nula libertad de elección y el 43.38 por ciento de quienes tienen plena libertad de elección reportan ser muy felices. Esto plantea un tenue escenario donde mayor percepción de libertad de elección puede estar correlacionado con mayores niveles de felicidad. 
Gráfica 2. Felicidad reportada por percepción de libertad de elección.

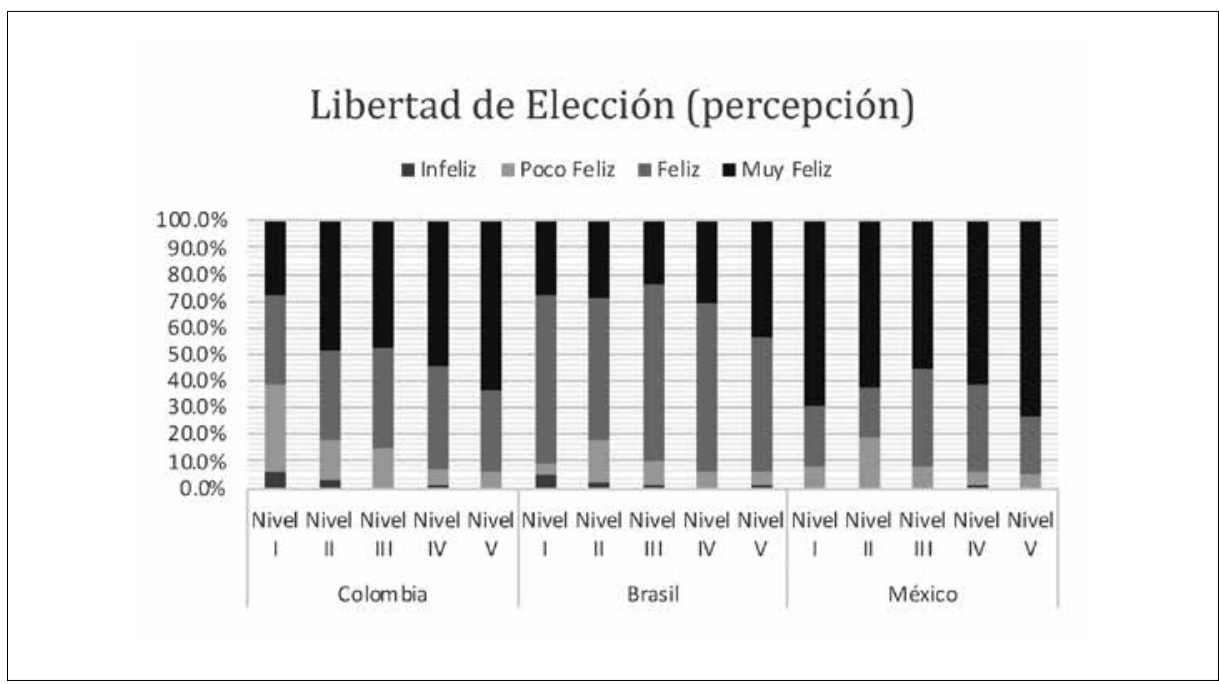

Fuente: elaboración del autor a partir de WVS-LONG WAVE 6.

Gráfica 3. Felicidad reportada por nivel de consumo.

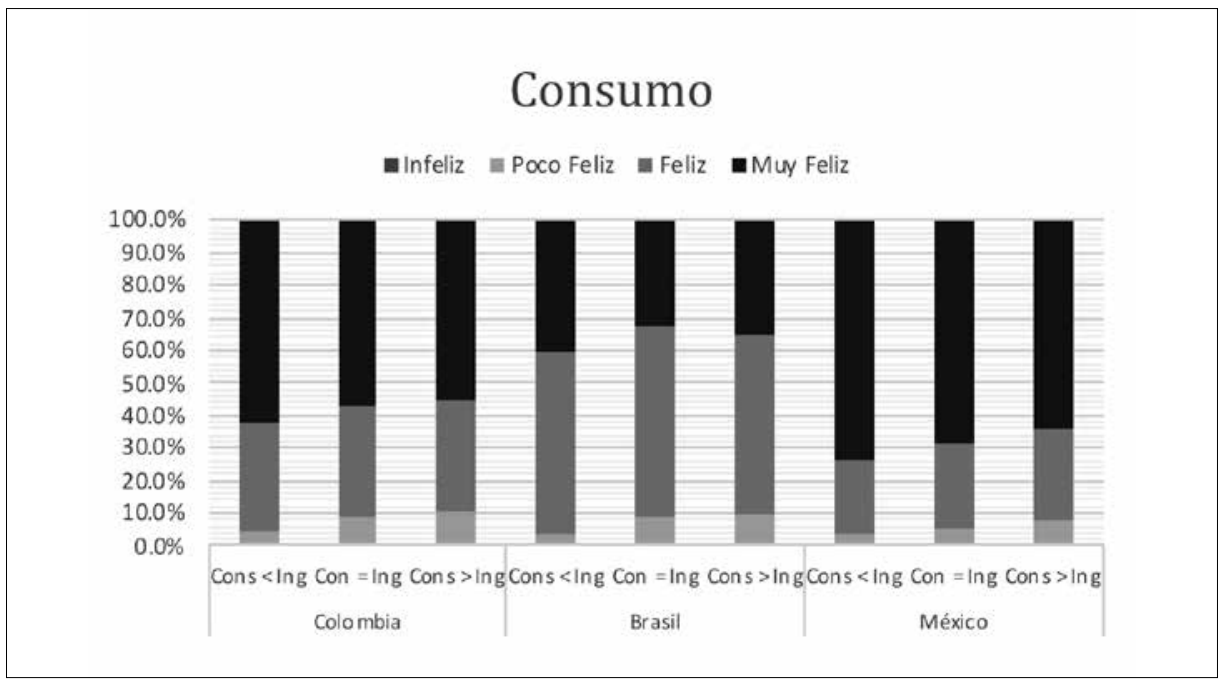

Fuente: elaboración del autor a partir de WVS-LONG WAVE 6. 
Los individuos cuyo consumo es menor al nivel de ingresos reportan mayores niveles de felicidad. Para el caso mexicano, el 73.44 por ciento de quienes consumen menos que su ingreso reportan ser muy felices, en contraste con el 64.22 por ciento de quienes consumen por encima de su ingreso; la misma tendencia se repite en Colombia donde el 62.14 por ciento de quienes consumen por debajo de su ingreso reportan ser muy felices, frente al 55.25 por ciento de quienes reportan la misma categoría de felicidad, pero consumen por encima de su ingreso.

Con relación a la edad, a lo largo de la vida los individuos reportan mayoritariamente ser muy felices. Para el caso de Colombia, el 59.56 por ciento de quienes pertenecen al grupo de edad 41-50 reportan ser muy felices. En tanto, en Brasil el 44 por ciento de los pertenecientes al grupo 18-20 reportan ser muy felices, mientras que en México el 69.23 por ciento de este mismo grupo reporta la máxima categoría de felicidad, también.

Gráfica 4. Felicidad reportada por grupos de edad.

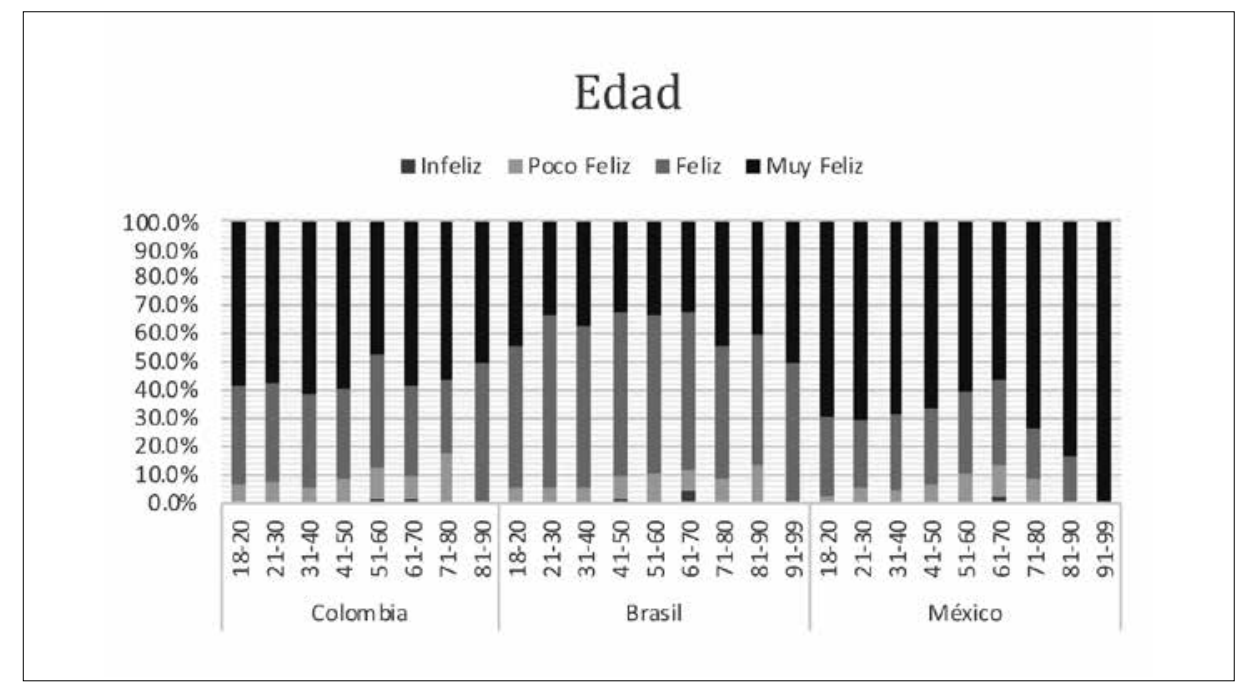

Fuente: elaboración del autor a partir de WVS-LONG WAVE 6. 
La relación entre felicidad y tiempo libre parece tener una correlación positiva. Esto se hace evidente, ya que el 63.03 por ciento de los colombianos que consideran el tiempo libre muy importante reportaron ser muy felices, frente al 0.45 por ciento de quienes reportan ser infelices valorando en la misma medida el tiempo libre. Análogo a esto, para Brasil, un 43.46 por ciento de los que valoran el tiempo libre reportaron ser muy felices, frente al 0.93 por ciento de quienes valoran el tiempo en la misma medida, pero reportaron ser infelices.

Mejores niveles de salud parecen asociarse a mayores niveles de felicidad. En Colombia, el 13.64 por ciento de quienes reportaron un mal estado de salud reportaron ser muy felices, mientras que el 66.48 por ciento de quienes responden al mismo nivel de felicidad, tienen un estado de salud muy bueno. Esta tendencia creciente de la felicidad reportada asociada al estado de salud se repite en México, ya que el 54.55 por ciento de quienes tienen un estado de salud malo reportaron ser muy felices, sin embargo, quienes reportaron el mismo nivel de felicidad, pero con un estado de salud muy bueno fueron el 81.61 por ciento.

Gráfica 5. Felicidad reportada por importancia del tiempo libre.

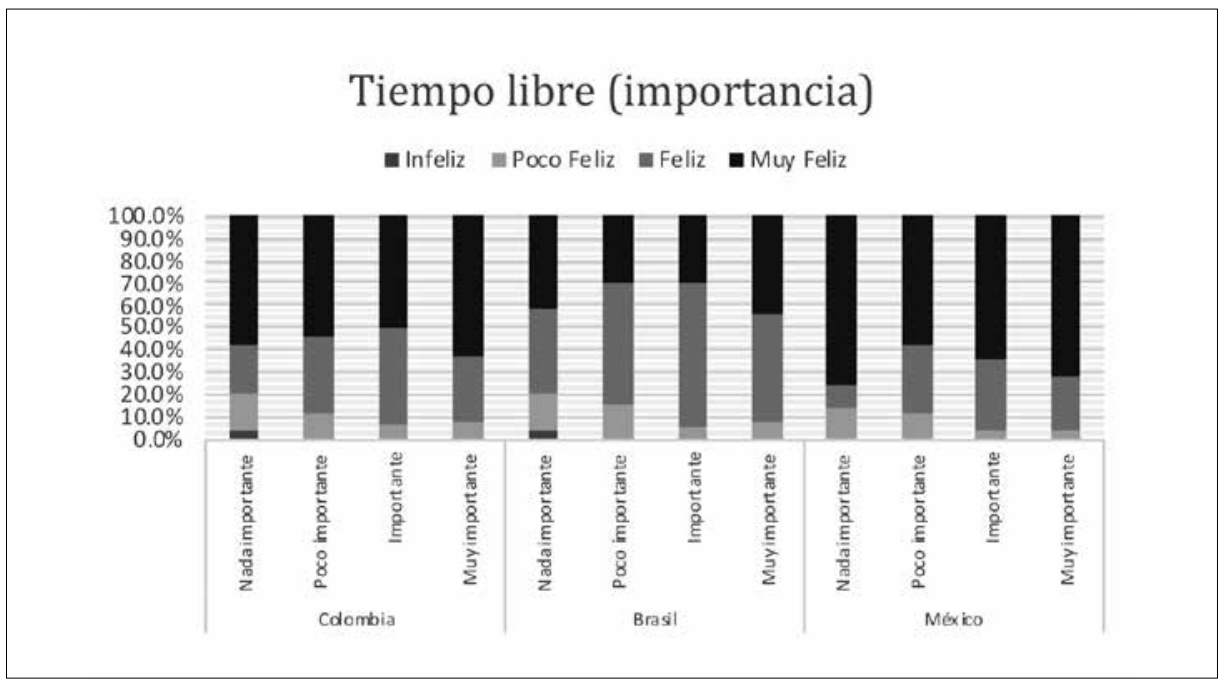

Fuente: elaboración del autor a partir de WVS-LONG WAVE 6. 


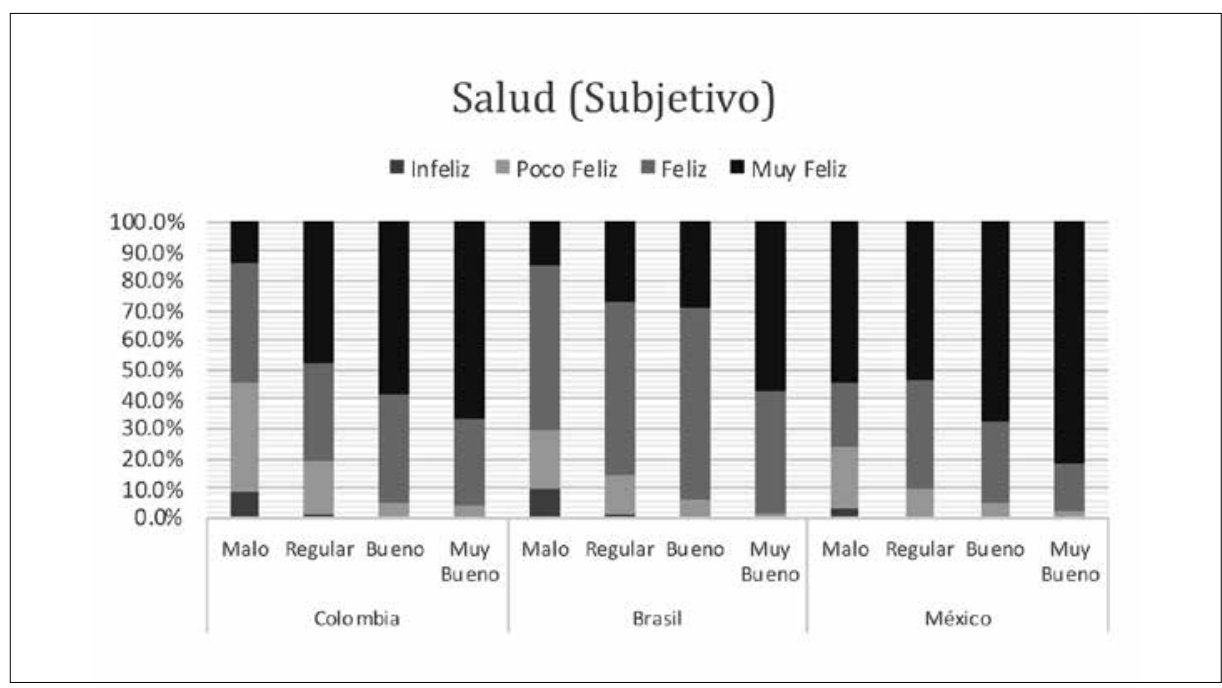

Fuente: elaboración del autor a partir de WVS-LONG WAVE 6.

Las personas que mayores niveles de felicidad reportan son los casados, seguido por los solteros, en los tres países. Al respecto, el 59.44 por ciento de los casados colombianos afirman ser muy felices al igual que el 57.96 por ciento de los solteros colombianos. En Brasil el 41.39 por ciento de los casados responden a ser muy felices, seguidos por el 33.76 por ciento de los solteros. Por su parte, el 72.46 por ciento de los casados mexicanos reportan ser muy felices, en línea con el 66.30 por ciento de los solteros mexicanos que corresponden a la misma categoría de felicidad. 
Gráfica 7. Felicidad reportada por estado civil.

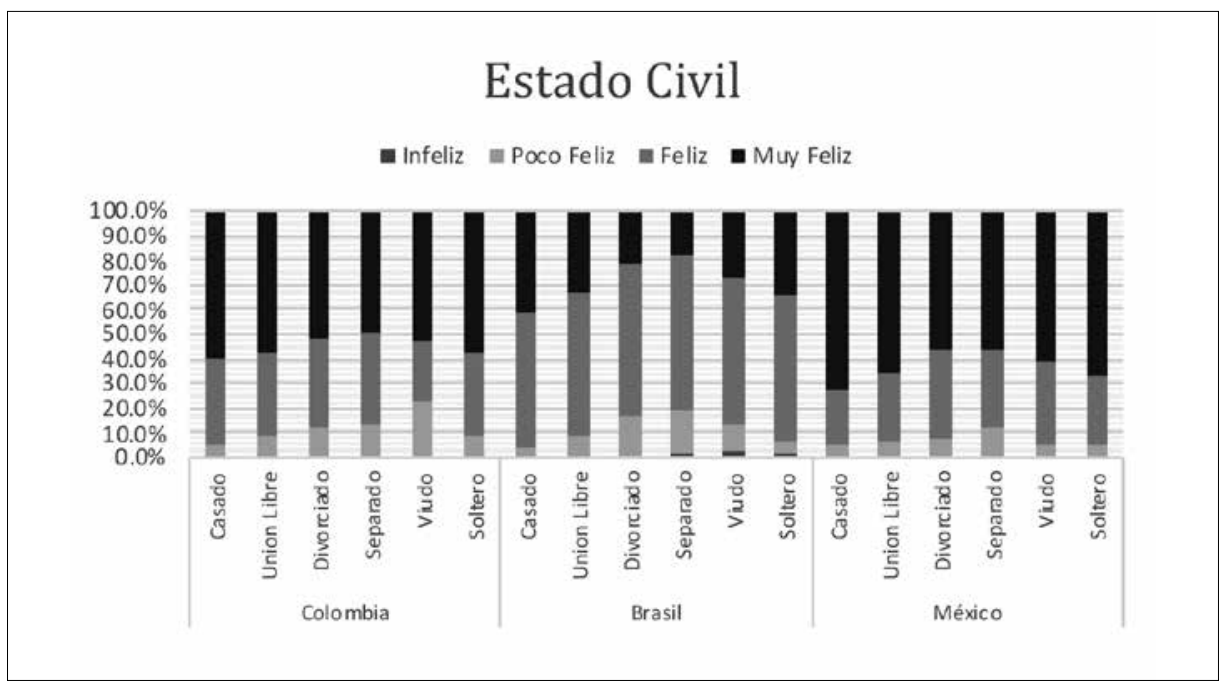

Fuente: elaboración del autor a partir de WVS-LONG WAVE 6.

Gráfica 8. Felicidad reportada por género.

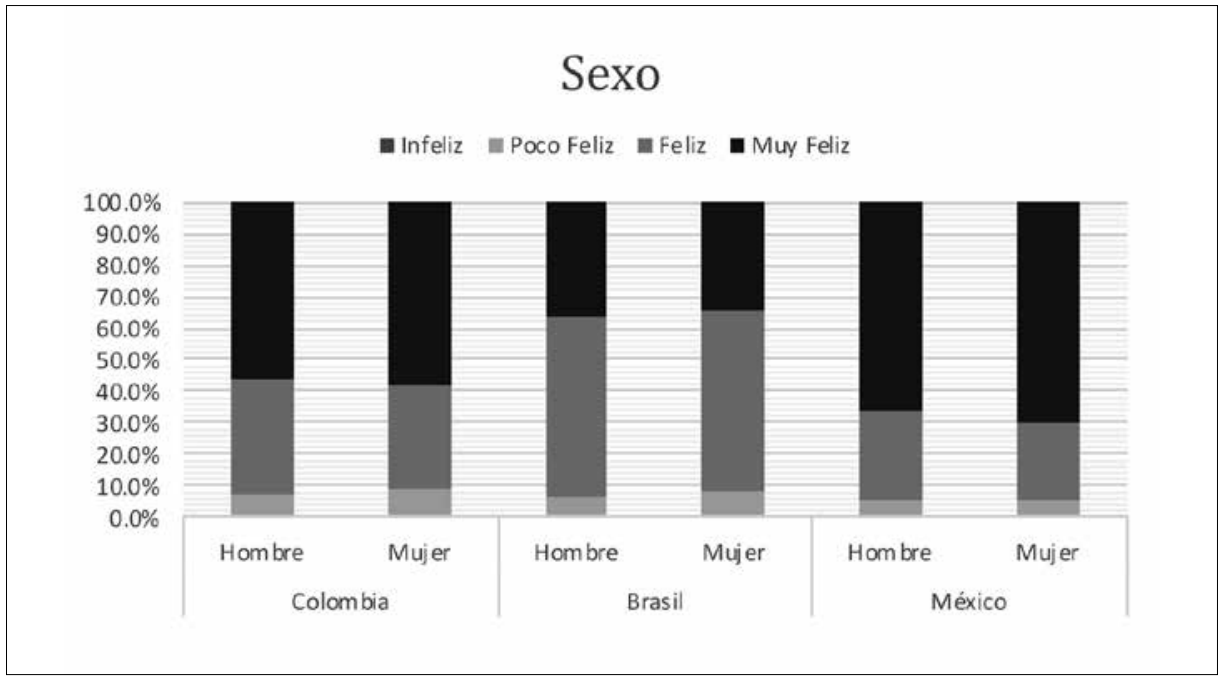

Fuente: elaboración del autor a partir de WVS-LONG WAVE 6. 
La proporción entre hombres y mujeres que reportan ser felices indica que las mujeres son levemente más felices que los hombres, al menos en Colombia y México. Es así como el 56.65 por ciento de los hombres colombianos afirman ser muy felices frente al 58.31 por ciento de las mujeres que reportan lo mismo. En México esta proporción alcanza el 66.23 por ciento para los hombres y el 69.75 por ciento para las mujeres quienes reportan ser muy felices.

\section{METODOLOGÍA Y RESULTADOS}

En este apartado se elige la aproximación logística ordenada a partir de la metodología propuesta por Cameron \& Trivedi (2005) como desarrollo más apropiado para responder la pregunta de investigación, la cual fue planteada en la introducción de este documento, junto con la hipótesis inicial. A fin de garantizar robustez en los resultados obtenidos es pertinente analizar metodologías alternativas que eventualmente pudieran generar aproximaciones alternas. Como preludio a las subsecuentes especificaciones es imperativo aclarar que las variables explicativas, incluidas en éstas, se encuentran sustentadas por la revisión de la literatura expuesta en la sección uno. ${ }^{23}$

Preliminarmente se realizaron especificaciones para la metodología regresión lineal y logística multinomial, las cuales se presentan en los anexos III y IV, respectivamente; tanto sus coeficientes como una breve descripción de los resultados son expuestos allí. No obstante, se prescindió de dichas metodologías en el cuerpo del documento puesto que presentan ciertas limitaciones que se exponen a continuación.

La regresión lineal carece de elementos para capturar la subordinación de la variable dependiente, así como las variaciones no lineales que se puedan presentar frente a cambios en las variables explicativas (Winship \& Mare, 1984). Por su parte, la aproximación logística multinomial, si bien puede capturar variaciones no lineales por cambios en variables independientes, impide incluir la jerarquía intrínseca de la variable dependiente ${ }^{24}$ (Cameron $\&$ Trivedi, 2005; Winship \& Mare, 1984).

En este escenario, resulta conveniente recurrir a una especificación logística ordenada, la cual se define como "una modelización de una variable latente - no observada- en función de la relación observada entre la variable categórica observada - explicada- y las variables independientes incluidas en el modelo" (Escobar, Bernardi, \& Macías, 2012, p. 422).

\footnotetext{
${ }^{23}$ Siempre y cuando los datos disponibles permitan capturarlas.

${ }^{24}$ La no inclusión de la información que aporta el orden de las alternativas de la variable dependiente en la especificación del modelo podría sesgar los resultados obtenidos.
} 
En términos formales, la relación entre la variable latente - no observada-de los niveles de felicidad en función de las variables independientes escogidas, se denota así:

$$
Y_{i}^{*}=X_{i} \beta+\varepsilon_{i}
$$

Donde $Y_{i}^{*}$ es una variable continua subyacente al modelo que toma los valores de la felicidad reportada, $X_{i}$ es un vector de características explicativas observables de cada individuo, $\beta$ es el vector de parámetros de los efectos de cada una de las características contenidas en $X_{i}$ que determinan el nivel de felicidad y $\varepsilon_{i}$ captura el término de error sobre la felicidad.

Cabe destacar que la distribución del término de error no es conocida, por tanto se ha de recurrir a una distribución teórica que permita estimar la especificación anterior. En este caso se asume que se distribuye de manera logística y por consiguiente se puede estimar un modelo logístico ordenado ${ }^{25}$ (Cameron \& Trivedi, 2005).

Entretanto, la relación entre la variable dependiente observada y la variable subyacente se puede expresar mediante cuatro intervalos - uno por cada nivel de felicidad reportada-. Éstos se encuentran acotados por los umbrales de categoría, ${ }^{26} \pi_{m-1}$, donde $m$ es el número de categorías de la variable dependiente.

$$
Y_{i}=\left\{\begin{array}{l}
1(\text { Infeliz }) \text { si }-\infty \leq Y_{i}^{*}<\pi_{1} \\
2\left(\text { Poco feliz) si } \pi_{1} \leq Y_{i}^{*}<\pi_{2}\right. \\
3\left(\text { Feliz)si } \pi_{2} \leq Y_{i}^{*}<\pi_{3}\right. \\
4\left(\text { MuyFeliz)si } \pi_{3} \leq Y_{i}^{*}<\infty\right.
\end{array}\right\}
$$

\footnotetext{
${ }^{25}$ Dada la similitud que existe entre las curvas de las distribuciones normal y la logística, los resultados estimados por ambas metodologías (Probit y Logit, respectivamente) no difieren mucho entre sí. Éstas sólo discrepan en la velocidad con que cada una converge a los valores extremos, siendo el modelo Probit - por su función de distribución normal- más veloz para alcanzar los valores extremos ( 0 y 1), mientras que el modelo Logit resulta más adecuado para su solución computacional. En suma, utilizar un modelo u otro depende más de las preferencias del investigador (Bravo \& Vásquez, 2008; Escobar et al., 2012).

${ }^{26}$ Para este caso, al haber cuatro niveles de felicidad $(m=4)$ existen $m-1$ umbrales.
} 
Definiendo estos intervalos para cada categoría, ahora es posible formular la probabilidad de ocurrencia de cada uno de los niveles de felicidad, ${ }^{27}$ dado un conjunto de valores contenidos en $X_{i}$ y encontrándose que la probabilidad conjunta de reportar un nivel de felicidad estará acotada por la resta entre las funciones de distribución acumulada $(F)$ de los umbrales actual y anterior, evaluadas en las características $X_{i}$.

El proceso de estimación se realiza mediante máxima verosimilitud $;{ }^{28}$ no obstante, debido a que los coeficientes estimados no capturan los efectos marginales ${ }^{29}$ buscados (Bravo \& Vásquez, 2008) se debe realizar una transformación para poderlos obtener ${ }^{30}$ (Cameron \& Trivedi, 2009).

Por conveniencia, ambos, los coeficientes y los efectos marginales de la estimación logística ordenada, se encuentran en los anexos V y VI, respectivamente. En su lugar, a continuación, se muestran los efectos marginales estadísticamente significativos con mayor incidencia sobre la probabilidad de reportar ser feliz para cada país.

Adicionalmente, es pertinente definir un sujeto base de comparación a partir del cual se analizan los cambios en la probabilidad de reportar ser feliz. Es por esto por lo que en la tabla 4 se exponen las categorías base de las variables explicativas incluidas en la especificación logística ordenada, para cada país.

${ }^{27} \operatorname{Pr}\left(Y_{i}=m \mid X_{i}\right)=\operatorname{Pr}\left(\pi_{m-1} \leq Y_{i}^{*}<\pi_{m} \mid X_{i}\right)$. Reordenando y reemplazando, se obtiene la función de probabilidad predicha para el modelo logístico ordenado, así $\operatorname{Pr}\left(Y_{i}=m \mid X_{i}\right)=\operatorname{Pr}\left(\varepsilon_{i}<\pi_{m}-X_{i} \beta\right)-\operatorname{Pr}\left(\varepsilon_{i}<\pi_{m-1}-X_{i} \beta\right)$. Recordando el supuesto de distribución sobre el error de la variable latente se obtiene $\operatorname{Pr}\left(Y_{i}=m \mid X_{i}\right)=F\left(\pi_{m}-X_{i} \beta\right)-F\left(\pi_{m-1}-X_{i} \beta\right)$.

${ }^{28}$ Esta metodología busca obtener los valores $\operatorname{de} \beta$, tal que maximicen el logaritmo de la diferencia entre las funciones acumuladas del umbral actual y el umbral inmediatamente anterior para las condiciones contenidas en $X_{i}$, desde primer umbral $Y_{i}=j=1$ hasta el umbral correspondiente a la categoría máxima de la variable explicada $Y_{i}=J$. Lo anterior se encuentra denotado por: $\ln (\beta, \pi \mid Y, X)=\sum_{j=1}^{J} \sum_{Y_{i}=1} \ln \left[F\left(\pi_{j}-X_{i} \beta\right)-F\left(\pi_{j-1}-X_{i} \beta\right)\right]$

${ }^{29}$ Definiendo un efecto marginal como el cambio en la probabilidad de ocurrencia de la variable explicada, por cambios en la n-sima variable explicativa.

30 $\frac{\partial \operatorname{Pr}\left(Y_{i}=m \mid X_{i}\right)}{\partial X_{i}}=\frac{\partial F\left(X_{i} \beta\right)}{\partial X_{i}} \cdot \beta_{i}=f\left(X_{i} \beta\right) \cdot \beta_{i}$ Donde $f\left(X_{i} \beta\right)$ revela la función de densidad evaluada en el parámetro para cada uno de los niveles de felicidad reportada $Y_{i}=m$. 
Tabla 4. Categorías base por variable explicativa.

\begin{tabular}{|c|c|c|c|}
\hline Variable & Categoría base & Variable & Categoría base \\
\hline Nivel ingresos & Nivel I & Sexo & Hombre \\
\hline $\begin{array}{l}\text { Libertad elección } \\
\text { (percepción) }^{1}\end{array}$ & Nivel I & Mujer ingresos & Mujer Nivel Ingresos I \\
\hline Condición laboral & Desempleado & $\begin{array}{l}\text { Tiempo libre } \\
\text { (importancia individual) }\end{array}$ & Nada importante \\
\hline Estado civil & Soltero & $\begin{array}{l}\text { Trabajo (importancia } \\
\text { individual) }\end{array}$ & Nada importante \\
\hline $\begin{array}{l}\text { Consumo (proporción } \\
\text { del ingreso) }\end{array}$ & $\begin{array}{l}\text { Por debajo del nivel de } \\
\text { ingresos }\end{array}$ & $\begin{array}{l}\text { Familia (importancia } \\
\text { individual) }\end{array}$ & Nada importante \\
\hline Nivel educativo & Primaria incompleta & Hijos & Sin hijos \\
\hline Salud (subjetivo) & Malo & $\begin{array}{l}\text { Justificación de la } \\
\text { riqueza }\end{array}$ & Inaceptable \\
\hline Edad & 18-20 años & Orgullo patrio & Nada orgulloso \\
\hline Religión (importancia) & Nada importante & $\begin{array}{l}\text { Satisfacción ingresos } \\
\text { del hogar }{ }^{2}\end{array}$ & Totalmente insatisfecho \\
\hline \multicolumn{4}{|c|}{$\begin{array}{l}{ }^{1} \text { La variable libertad de elección corresponde a una variable de } 10 \text { categorías, en la cual el nivel mínimo (Nivel I) correspon- } \\
\text { de a tener nula autodeterminación para tomar decisiones cotidianas, mientras que el máximo nivel (Nivel X) implica tener } \\
\text { plena autonomía sobre las decisiones que se toman. } \\
2 \text { La variable satisfacción-ingresos-hogar captura el grado de conformidad del encuestado frente a la situación financiera del } \\
\text { hogar donde habita. Para esto, dicha variable consta de } 10 \text { categorías, donde el nivel mínimo (Nivel I) corresponde a total } \\
\text { insatisfacción por las condiciones financieras del hogar del encuestado, mientras que el máximo nivel de (Nivel X) implica } \\
\text { reportar plena complacencia con las condiciones financieras del hogar. }\end{array}$} \\
\hline & & & \\
\hline
\end{tabular}

Para el caso de Brasil, la libertad de elección es estadísticamente significativa en menor medida que el país anterior. Las personas con plena libertad de elección, en contraste con aquellos con nula libertad de elección, tienen un incremento de 11.5 puntos porcentuales sobre probabilidad de reportar ser muy felices.

Reportar estar casado representa un incremento en la probabilidad de reportar ser feliz de 3.82 puntos porcentuales para Colombia, de 6.52 para Brasil y de 5.43 puntos porcentuales para México; todos en comparación con las personas solteras. En contraste, las personas divorciadas tienen una disminución de 18.2 y 13 puntos porcentuales en la probabilidad de reportar ser muy feliz, para Brasil y México, respectivamente, en comparación con alguien soltero. El mismo comportamiento se repite para las personas viudas en ambos países, con una reducción en la probabilidad de reportar ser muy feliz de 10.5 puntos porcentuales en Brasil y 12.4 puntos porcentuales en México.

El estado de salud tiene una correlación positiva con la felicidad reportada para el caso de Colombia y Brasil. En el primer país, tener un estado de salud regular eleva la probabilidad de reportar ser muy feliz en 28.8 puntos porcentuales, hecho que aumenta hasta los 47.7 puntos porcentuales cuando se reporta 
un estado de salud muy bueno; ambos en comparación con los individuos que reportaron un estado de salud malo.

Para el caso de Brasil, un estado de salud regular, en comparación con un estado de salud malo, aumenta la probabilidad de reportar ser muy feliz en 13.6 puntos porcentuales. Sin embargo, aquella probabilidad aumenta en 41.8 puntos porcentuales cuando el estado de salud reportado es muy bueno. Con relación a México, las personas con un estado de salud muy bueno, en comparación con alguien con un mal estado de salud, tienen un incremento de 23.9 puntos porcentuales en la probabilidad de reportar ser muy feliz.

Respecto a la edad, en Colombia las personas entre 51-60 años tienen una reducción de 10.8 puntos porcentuales sobre la probabilidad de reportar ser muy feliz en comparación con las personas entre 18-20 años. En Brasil, la probabilidad de reportar ser feliz decrece a medida que se es mayor, ya que las personas entre 41-50 años tienen 11.6 puntos porcentuales menos de probabilidad de reportar ser muy feliz si se comparan con los individuos en la franja 18-20 años. Para el caso mexicano las personas entre 61-70 años tienen 23.3 puntos porcentuales menos de probabilidad de reportar ser muy felices, en comparación con el mismo grupo base, siguiendo el patrón del país anterior. 
Tabla 5. Efectos marginales-Metodología logística ordenada. ${ }^{31}$

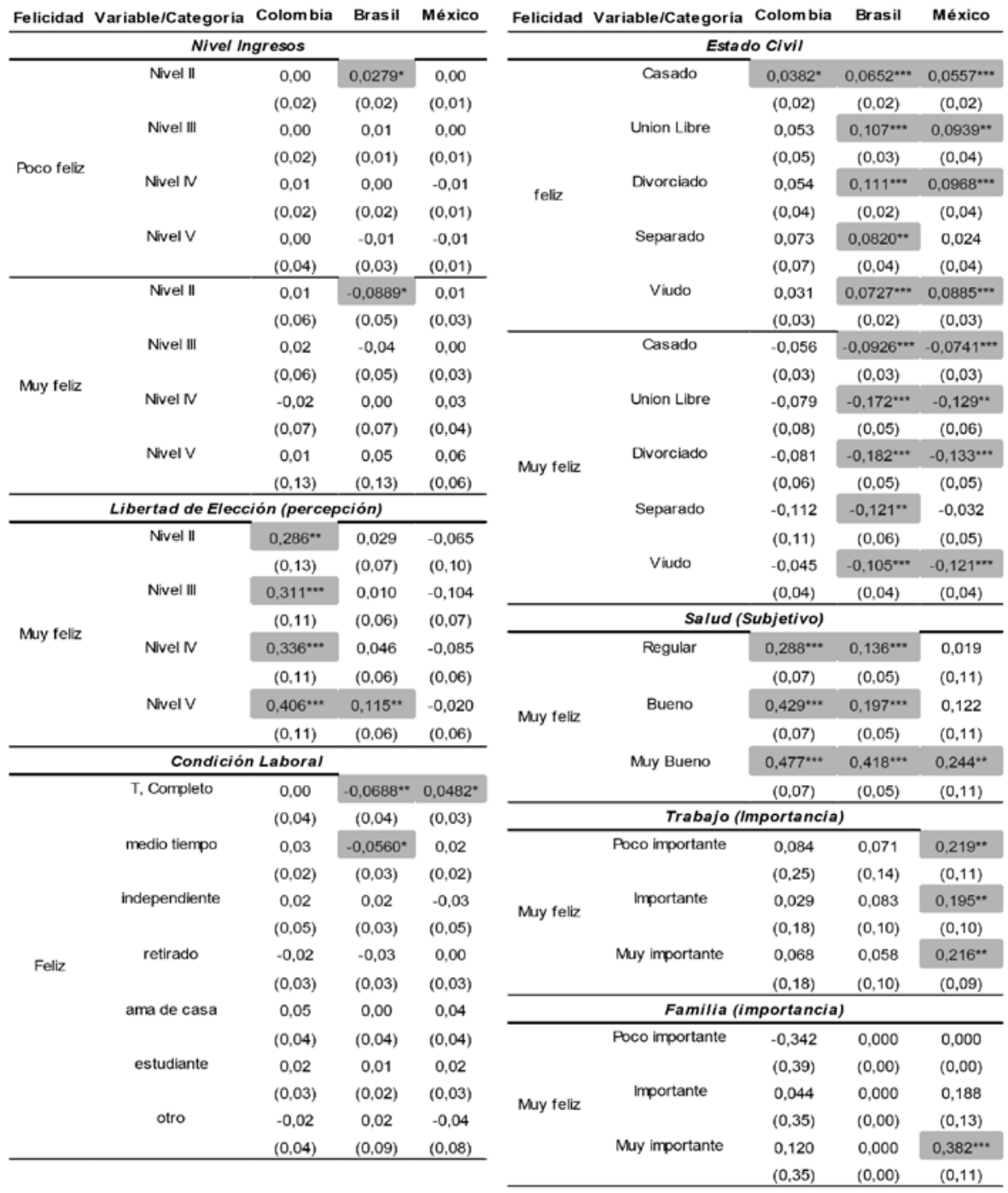

Fuente: elaboración del autor a partir de wVS- 6. Un asterisco indica que la estimación es estadísticamente significativa a un nivel de significancia del 10 por ciento. Dos asteriscos a una significancia del 5 por ciento y tres asteriscos a una significancia del 1 por ciento. El valor en paréntesis indica el error estándar.

${ }^{31}$ Los efectos marginales adicionales de la especificación logística ordenada por país se encuentran en el anexo VI (tabla A.6). 
ECONOMÍA TEORÍA Y PRÁCTICA [ISSN: 2448-7481] • Nueva Época, año 27, número 50, enero-junio 2019 Oscar Mauricio Poveda Bermudez

Tabla 5. Continuación.

\begin{tabular}{|c|c|c|c|c|c|c|c|c|c|}
\hline \multirow[t]{3}{*}{ Felicidad } & Variable/Categ & Colombia & Brasil & México & \multirow[t]{2}{*}{ Felicidad } & Variable/Categoria & Colom bia & \multirow[t]{2}{*}{ Brasil } & \multirow[t]{2}{*}{ México } \\
\hline & \multicolumn{2}{|c|}{ Edad } & & & & \multicolumn{2}{|c|}{ Hijos (Continuación) } & & \\
\hline & $21-30$ & $-0,045$ & $-0,101^{*}$ & $-0,032$ & \multirow{16}{*}{ Mury feliz } & \multirow[t]{2}{*}{1 hijo } & 0,050 & 0,025 & $-0,0677^{*}$ \\
\hline \multirow{15}{*}{ Muy feliz } & \multirow{3}{*}{$31-40$} & $(0,05)$ & $(0,06)$ & $(0,03)$ & & & $(0,04)$ & $(0,04)$ & $(0,04)$ \\
\hline & & $-0,023$ & $-0,0988^{*}$ & $-0,056$ & & \multirow[t]{2}{*}{2 hijos } & 0,004 & 0,023 & $-0,0741^{*}$ \\
\hline & & $(0,06)$ & $(0,06)$ & $(0,04)$ & & & $(0,05)$ & $(0,04)$ & $(0,04)$ \\
\hline & \multirow[t]{2}{*}{$41-50$} & $-0,043$ & $-0,116^{*}$ & $-0,057$ & & \multirow[t]{2}{*}{3 hijos } & $-0,014$ & 0,006 & $-0,0805^{*}$ \\
\hline & & $(0,06)$ & $(0,06)$ & $(0,05)$ & & & $(0,05)$ & $(0,04)$ & $(0,04)$ \\
\hline & \multirow[t]{2}{*}{$51-60$} & $-0,108^{*}$ & $-0,086$ & $-0,140^{* *}$ & & \multirow[t]{2}{*}{4 hijos } & $-0,026$ & $-0,067$ & $-0,064$ \\
\hline & & $(0,06)$ & $(0,07)$ & $(0,06)$ & & & $(0,07)$ & $(0,05)$ & $(0,05)$ \\
\hline & \multirow[t]{2}{*}{$61-70$} & $-0,047$ & $-0,127$ & $-0,236^{\mathrm{N} \cdots}$ & & \multirow[t]{2}{*}{5 hijos } & $-0,020$ & $-0,007$ & $-0,037$ \\
\hline & & $(0,08)$ & $(0,08)$ & $(0,07)$ & & & $(0,08)$ & $(0,07)$ & $(0,07)$ \\
\hline & \multirow[t]{2}{*}{$71-80$} & $-0,112$ & 0,113 & $-0,042$ & & \multirow[t]{2}{*}{6 hijos } & $-0,013$ & $-0,098$ & $-0,033$ \\
\hline & & $(0,11)$ & $(0,11)$ & $(0,09)$ & & & $(0,09)$ & $(0,08)$ & $(0,07)$ \\
\hline & \multirow[t]{2}{*}{$81-90$} & $-0,091$ & $-0,096$ & 0,102 & & \multirow[t]{2}{*}{7 hijos } & 0,121 & $-0,070$ & 0,007 \\
\hline & & $(0,17)$ & $(0,14)$ & $(0,16)$ & & & $(0,19)$ & $(0,14)$ & $(0,12)$ \\
\hline & $91-99$ & 0,000 & $0,395^{* *}$ & $0,265^{\cdots}$ & & 8 o más hijos & $0,207^{*}$ & $-0,170^{*}$ & 0,017 \\
\hline & & $(0,00)$ & $(0,11)$ & $(0,03)$ & & & $(0,12)$ & $(0,07)$ & $(0,09)$ \\
\hline & & & & & & Orgullo & Patrio & & \\
\hline Infeliz & Mujer & 0,00 & 0,001 & $-0,0012^{*}$ & & Muy poco & $0,421^{* * *}$ & 0,029 & 0,070 \\
\hline mence & & $(0,00)$ & $(0,00)$ & $(0,00)$ & & & $(0,04)$ & $(0,03)$ & $(0,07)$ \\
\hline Muy feliz & Mujer & $-0,003$ & $-0,027$ & $0,0609^{* *}$ & Feliz & Levemente & $0,397^{\cdots \cdots}$ & 0,011 & 0,021 \\
\hline & & $(0,03)$ & $(0,03)$ & $(0,03)$ & rella & & $(0,03)$ & $(0,03)$ & $(0,06)$ \\
\hline & Justifica & n Riqueza & & & & Totalmente & $0,330^{* \ldots *}$ & $-0,0596^{*}$ & $-0,032$ \\
\hline Muy feliz & Justificable & $0,0520^{*}$ & 0,023 & 0,006 & & & $(0,02)$ & $(0,03)$ & $(0,06)$ \\
\hline & & $(0,03)$ & $(0,03)$ & $(0,02)$ & & Satisfacción con & Ingresos $\mathrm{Ho}$ & ogar & \\
\hline & & & & & & Nvel II & 0,075 & $-0,012$ & $-0,085$ \\
\hline & 1 hijo & $-0,035$ & $-0,017$ & $0,0505^{*}$ & & & $(0,07)$ & $(0,04)$ & $(0,05)$ \\
\hline & & $(0,03)$ & $(0,03)$ & $(0,03)$ & & Nivel III & $0,135^{\circ}$ & 0,057 & $-0,030$ \\
\hline & 2 hijos & $-0,003$ & $-0,015$ & $0,0551^{*}$ & Muy feliz & & $(0,06)$ & $(0,04)$ & $(0,04)$ \\
\hline & & $(0,03)$ & $(0,02)$ & $(0,03)$ & & Nivel N & $0,162^{* *}$ & $0,0777^{*}$ & 0,054 \\
\hline & 3 hijos & 0,009 & $-0,004$ & $0,0597^{*}$ & & & $(0,06)$ & $(0,04)$ & $(0,04)$ \\
\hline & & $(0,04)$ & $(0,03)$ & $(0,03)$ & & Nivel V & $0,225 \cdots$ & $0,175^{\ldots}$ & $0,103^{* *}$ \\
\hline & 4 hijos & 0,017 & 0,040 & 0,048 & & & $(0,06)$ & $(0,04)$ & $(0,04)$ \\
\hline Feliz & & $(0,04)$ & $(0,03)$ & $(0,04)$ & & Religión (Im & portancia) & & \\
\hline & 5 hijos & 0,013 & 0,005 & 0,028 & & Poco importante & 0,008 & $-0,050$ & 0,045 \\
\hline & & $(0,05)$ & $(0,04)$ & $(0,05)$ & & & $(0,08)$ & $(0,07)$ & $(0,06)$ \\
\hline & 6 hijos & 0,008 & 0,053 & 0,025 & Muy feliz & Importante & $-0,014$ & 0,015 & 0,052 \\
\hline & & $(0,06)$ & $(0,04)$ & $(0,05)$ & & & $(0,08)$ & $(0,07)$ & $(0,05)$ \\
\hline & 7 hijos & $-0,086$ & 0,041 & $-0,006$ & & Muy importante & 0,064 & 0,11 & $0,0836^{*}$ \\
\hline & & $(0,14)$ & $(0,07)$ & $(0,09)$ & & & $(0,08)$ & $(0,07)$ & $(0,05)$ \\
\hline & 80 más hijos & $-0,154$ & $0,0698^{* \cdots}$ & $-0,013$ & & & & & \\
\hline & & $(0,10)$ & $(0,02)$ & $(0,07)$ & & & & & \\
\hline
\end{tabular}

Fuente: elaboración del autor a partir de wVs- 6 . Un asterisco indica que la estimación es estadísticamente significativa a un nivel de significancia del 10 por ciento. Dos asteriscos a una significancia del 5 por ciento y tres asteriscos a una significancia del 1 por ciento, El valor en paréntesis indica el error estándar. 
En adición, las personas del grupo de edad 91-99, en comparación con el grupo de edad 18-20, presentan 39.5 puntos porcentuales más de probabilidad de reportar ser muy felices para el caso de Brasil y 26.6 puntos porcentuales para el caso de México.

La importancia de la familia y el trabajo sólo resultaron estadísticamente significativos para México, donde considerar a la familia como un elemento muy importante eleva la probabilidad de reportar ser muy feliz en 37.7 puntos porcentuales, en comparación con quienes consideran que este grupo social no es nada importante. A su vez, considerar muy importante la tenencia de trabajo, en comparación con quienes no opinan así, eleva la probabilidad de reportar ser feliz en 21.7 puntos porcentuales. En relación con la condición laboral en México, tener un trabajo de tiempo completo eleva la probabilidad de reportar ser feliz en 4.97 puntos porcentuales, en contraste con un desempleado.

El número de hijos parece elevar la felicidad en México, puesto que, en comparación con personas sin hijos, tener uno, dos o tres hijos aumenta la probabilidad de reportar ser feliz en 5, 16, 5.88 o 5.99 puntos porcentuales, respectivamente. En Colombia tener ocho o más hijos eleva la probabilidad de reportar ser muy feliz en 20.7 puntos porcentuales, pero en Brasil esta misma condición reduce dicha probabilidad en 17 puntos porcentuales, ambos en comparación con personas sin hijos.

Con relación a los efectos del género sobre la probabilidad de reportar ser feliz, éstos son sólo significativos para México. Las mujeres mexicanas tienen 0.12 puntos porcentuales menos de probabilidad de reportar ser infeliz, en comparación con los hombres del mismo país. En esta misma línea, ser mujer implica tener 6.09 puntos porcentuales más de probabilidad de reportar ser muy feliz, por encima de los hombres. La relevancia de la religión sólo es significativa en México, donde considerarla muy importante representa 8.36 puntos porcentuales más de probabilidad de reportar ser muy feliz, en comparación con alguien cuya importancia de la religión sea nula.

Sentirse orgulloso de vivir en Colombia incide sobre la probabilidad de reportar ser feliz, desde un aumento de 42.1 puntos porcentuales sobre esta probabilidad para quienes reportaron sentirse muy poco orgullosos, pasando por 39.7 puntos porcentuales para los levemente orgullosos y 33 puntos porcentuales para los totalmente orgullosos, todos en comparación con alguien quien reportó sentirse para nada orgulloso de su país. En este mismo país, la justificación de la riqueza como elemento asociado a la probabilidad de reportar ser feliz, incide en 5.2 puntos porcentuales sobre la probabilidad de reportar ser muy feliz, en contraste con los individuos que consideran inaceptable la acumulación de riqueza. 
El nivel de complacencia con las finanzas del hogar igualmente incurre sobre la probabilidad de reportar ser muy feliz. Para Colombia aumentar el nivel de satisfacción con los ingresos del hogar incrementa la probabilidad de reportar ser muy feliz en $13.5,16.2$ o 22.5 puntos porcentuales para quienes se ubicaron en los niveles de satisfacción con estos ingresos III, IV y V, respectivamente, en comparación con alguien totalmente inconforme con los ingresos de su hogar. En Brasil, aquellos pertenecientes al nivel IV tienen un incremento en la probabilidad de reportar ser muy feliz en 7.77 puntos porcentuales; no obstante, estar plenamente satisfecho con los ingresos del hogar aumenta la mencionada probabilidad en 17.5 puntos porcentuales. Por último, un mexicano totalmente satisfecho con la situación financiera doméstica tiene 10.4 puntos porcentuales más de probabilidad de reportar ser muy feliz, en contraste con alguien totalmente insatisfecho con este escenario.

\section{CONCLUSIONES}

La escasa significancia estadística del nivel de ingresos sobre la probabilidad de reportar ser feliz parece corroborar la hipótesis planteada al inicio de este trabajo: existen variables con mayor incidencia que el ingreso sobre la probabilidad de reportar ser feliz. Éste, junto con los demás resultados se exponen en la tabla 6. Para el caso de Brasil, el único país con efecto marginal estadísticamente significativo del ingreso sobre la felicidad, se observa una correlación negativa entre los niveles de ingreso y felicidad. Al respecto, el ingreso es probable que no sea un fin en sí mismo, sino un instrumento para alcanzar mayores niveles de felicidad (Rojas, 2016) y cambios inesperados en el primero podrían generar un efecto opuesto en la satisfacción individual.

Con lo anterior, la recomendación más importante que este documento plantea es que los individuos no deberían buscar mayores ingresos, bajo la única premisa de mayores ingresos, mayor felicidad, puesto que este paradigma se encuentra sobrevalorado, al menos a partir de los hallazgos aquí descritos. En su lugar, sería deseable que al interior de las familias y organizaciones sociales se incentivara la toma de decisiones a partir de los efectos de éstas sobre áreas como la salud, la libertad de elección y las relaciones afectivas, más que a partir de la retribución económica subsecuente.

La condición laboral, como elemento asociado a la felicidad, sólo es estadísticamente significativa para México. Es así como tener empleo en este país, al igual que pertenecer a un grupo social -familia o trabajo-, afecta de forma 
estadísticamente significativa la probabilidad de reportar ser feliz. Lo anterior enmarca la importancia de los individuos como seres sociales, en línea con lo expuesto por Maslow (1943) y sugiere la necesidad de suplir necesidades laborales en México si se busca incrementar los niveles de felicidad reportados allí.

El estado civil incide de forma significativa sobre la probabilidad de reportar ser feliz en Brasil y México. Siguiendo lo expuesto por Qari (2014), estar casado eleva la probabilidad de reportar ser feliz, mientras que el divorcio reduce dicha probabilidad, en línea con el postulado de Dolan et al. (2008). A partir de esto, el fomento de relaciones sociales constructivas que puedan tener las personas con su entorno debe ser prioritario, tanto individual como colectivamente y de esta forma, eventualmente, elevar los niveles de felicidad reportados.

En relación con la composición de la familia, para México puede concluirse que la probabilidad de reportar ser feliz aumenta conforme aumenta el número de hijos hasta un nivel de tres, un número mayor de descendientes no es estadísticamente significativo. Para Brasil, las familias numerosas inciden negativamente sobre la probabilidad de reportar ser muy feliz, pero esta incidencia es positiva para el caso colombiano; evidenciando así, la relevancia de las unidades familiares como elementos asociados a la felicidad.

Respecto al orgullo patrio en Colombia, la probabilidad de reportar ser feliz sí es afectada positivamente por el grado de patriotismo. No obstante, a mayor nivel de éste, su efecto sobre la probabilidad de reportar ser feliz es menor. Es así como los programas y actividades encaminadas a incentivar el amor por el país de residencia, así como el sentido de pertenencia por éste, podrían tal vez elevar la felicidad colectiva reportada en países de la región latinoamericana.

Con relación al estado de salud, la probabilidad de reportar ser muy feliz aumenta conforme aumenta el estado de salud, al menos para Colombia y Brasil, mas no para México. Lo anterior permite inferir que la salud de los individuos tiene mayor incidencia (estadísticamente significativa) que el nivel de ingresos sobre la probabilidad de reportar ser feliz y es por esto por lo que los individuos deberían contemplar las consecuencias que cada decisión tiene sobre su salud, antes de considerar los posibles efectos de éstas, sobre sus ingresos. 
Tabla 6. Variables con incidencia sobre la probabilidad de reportar ser feliz.

\begin{tabular}{lccc}
\hline & Colombia & Brasil & México \\
\hline Nivel de ingresos & & + & \\
\hline Libertad elección & + & & + \\
\hline Familia & & & + \\
\hline Trabajo & & + & + \\
\hline Condición laboral & & + & + \\
\hline Estado civil & & + & \\
\hline Género & + & + &,+ \\
\hline Hijos & + & + & + \\
\hline Orgullo patrio & &,+ & \\
\hline Salud & & & \\
\hline Edad & + & & \\
\hline Religión & & & \\
\hline Justificación riqueza & & & \\
\hline
\end{tabular}

Fuente: elaboración del autor a partir de WVS-LONG WAVE 6.

El género tiene un efecto tenue sobre la felicidad y sólo valido para México. Aquello permite inferir, preliminarmente, que este factor no resulta decisivo a la hora de reportar ser feliz en los países de estudio, para el periodo analizado. Además, se concluye que la probabilidad de reportar ser feliz y muy feliz se incrementa conforme aumenta la libertad de elección, pero únicamente en Colombia. Con lo cual se insta que los contratos sociales expliciten un mayor grado de libertad para cada una de las partes y de esta forma, empoderar a los individuos frente a las elecciones que se presentan cotidianamente.

En relación con los efectos de la edad sobre la felicidad, la probabilidad de reportar ser muy feliz se reduce a medida que la edad de los individuos aumenta; para posteriormente revertirse dicha tendencia. En otras palabras, sólo para Brasil y México la probabilidad de reportar ser muy feliz a lo largo de la vida tiene forma de " $U$ ", apoyando la idea planteada por Gerdtham \& Johannesson (2001); Gerstenblüth et al. (2013); Lelkes (2006) y Peiró (2006). Con esto se busca exponer que posibles disminuciones en la felicidad reportada a lo largo de la adultez y la mediana edad, podrían compensarse con un aumento significativo de ésta en el ocaso de la vida. Así que se debería incentivar cambios individuales específicos a lo largo de estas etapas de la vida para mitigar efectos negativos sobre la felicidad.

Por último, a efectos de plantear futuros desarrollos de investigación, sería conveniente abordar la posible causalidad entre el nivel de ingresos y la libertad de elección, en su incidencia conjunta sobre la probabilidad de reportar ser feliz en América Latina; al igual que desarrollar especificaciones que permitan aislar las características que diferencian a cada género (e. g. emociones, aspiraciones, 
percepción del entorno) y de esta forma corroborar si existe alguna brecha entre hombres y mujeres al momento de reportar ser felices. Asimismo sería deseable ampliar la discusión sobre el efecto disímil del ingreso sobre diversas concepciones del bienestar -subjetivo y económico-, en línea con lo expuesto por Fuentes \& Rojas (2001).

También se motiva a mejorar los sistemas de recolección y procesamiento de datos en la región latinoamericana, de forma tal que permitan descomponer variables altamente subjetivas en elementos parsimoniosos que faciliten la obtención de conclusiones puntuales y dicientes sobre los eventuales desencadenantes de la felicidad asociados a las variables consignadas en este documento.

\section{REFERENCIAS BIBLIOGRÁFICAS}

Ahuvia, Aaron Chaim (2008), "If Money Doesn't Make us Happy, Why do we Act as if it Does?", Journal of Economic Psychology, 29 (4), pp. 491-507, https://doi. org/10.1016/j.joep.2007.11.005.

Argyle, Michael (1992), La psicología de la felicidad, Alianza, retrieved from https://books.google.com.co/books?id=XLQWOWAACAAJ.

Bartolini, Stefano \& Sarracino, Francesco (2014), "Happy for How Long? How Social Capital and Economic Growth Relate to Happiness Over Time", Ecological Economics, 108, pp. 242-256, https://doi.org/10.1016/j.ecolecon.2014.10.004.

Becchetti, Leonardo \& Rossetti, Fiammetta (2009), "When Money Does not Buy Happiness: The Case of 'Frustrated Achievers'”, Journal of Socio-Economics, 38 (1), pp. 159-167, https://doi.org/10.1016/j.socec.2008.08.009.

Bentham, Jeremy (1776), A Fragment on Government: Being an Examination of what is Delivered, on the Subject of Government in General, in the Introduction to Sir William Blackstone's Commentaries: with a Preface, in which is Given a Critique on the Work at Large, Payne, T.; Elmsly, P. and Brooke, E, London, Retrieved from https://books.google.com.co/books?id=epMIAAAAQAAJ.

Bjørnskov, Christian; Dreher, Axel; Fischer, Justina; Schnellenbach, Jan \& Gehring, Kai (2013), "Inequality and Happiness: When Perceived Social Mobility and Economic Reality do not Match", Journal of Economic Behavior and Organization, 91, pp. 75-92, https://doi.org/10.1016/j.jebo.2013.03.017.

Blanchflower, David \& Oswald, Andrew (2004a), "Money, Sex and Happiness: An Empirical Study", The Scandinavian Journal of Economics, 106 (3), pp. 393415. Retrieved from http://www.jstor.org.ezproxy.unal.edu.co/stable/3441116. 
(2004b), "Well-being Over Time in Britain and the USA", Journal of Public Economics, 88 (7-8), pp. 1359-1386, https://doi.org/10.1016/S00472727(02)00168-8.

вм (2012), World Development Indicators 2012, (2012 World Bank Publications, ed.), Washington.

Bradburn, Norman \& Noll, Edwuard (1969), The Structure of Psychological Well-being, Aldine Publishing Company. Retrieved from https://books.google. com.co/books?id=9h9-AAAAMAAJ.

Bravo, David \& Vásquez, Javier (2008), Microeconometría aplicada, Universidad de Chile, Santiago de Chile.

Brickman, Philip \& Campbell, Donald (1971), "Hedonic Relativism and Planning the Good Society".

Cameron, Colin \& Trivedi, Pravin (2005), Microeconometrics: Methods and Applications, University Press, Cambridge. Retrieved from https://books.google. com.co/books?id=ZFoGCWxC9ocC.

(2009), Microeconometrics Using Stata, Stata Press. Retrieved from https:// books.google.com.co/books?id=XPDTAAAAMAAJ.

Clark, Andrew \& Oswald, Andrew (1996), "Satisfaction and Comparison Income", Journal of Public Economics, 61 (3), pp. 359-381, https://doi.org/10.1016/00472727(95)01564-7.

Colburn, Forrest (2002), Latin America at the End of Politics, University Press, Princeton. Retrieved from https://books.google.com.co/books?id=qBCVB3mxск8c.

Cryder, Cynthia; Lerner, Jennifer; Gross, James \& Dahl, Ronald (2008), "Misery Is Not Miserly: Sad and Self-Focused Individuals Spend More", Psychological Science, 19 (6), pp. 525-530. Retrieved from http://www.jstor.org.ezproxy.unal. edu.co/stable/40064949.

Dolan, Paul; Peasgood, Tessa \& White, Mathew (2008), "Do we Really Know What Makes us Happy? A Review of the Economic Literature on the Factors Associated with Subjective Well-being”, Journal of Economic Psychology, 29 (1), pp. 94-122, https://doi.org/10.1016/j.joep.2007.09.001.

Easterlin, Richard (1973), “Does Money Buy Happiness?”, The Public Interest, (30), 3. (1974), "Does Economic Growth Improve the Human Lot? Some Empirical Evidence", Nations and Households in Economic Growth, 89, pp. 89-125. (1995), "Will Raising the Incomes of all Increase the Happiness of All?", Journal of Economic Behavior and Organization, 27 (1), pp. 35-47, https://doi. org/10.1016/0167-2681(95)00003-в.

(2006), "Life Cycle Happiness and its Sources. Intersections of Psychology, Economics, and Demography", Journal of Economic Psychology, 27 (4), pp. 463-482, https://doi.org/10.1016/j.joep.2006.05.002. 
Edgeworth, Francis Ysidro (2009), Mathematical Psychics: An Essay on the Application of Mathematics to the Moral Sciences, BiblioBazaar. Retrieved from https://books.google.com.co/books?id=xDxsenv6wewc.

Escobar, Modesto; Bernardi, Fabrizio y Fernández Macías, Enrique (2012), Análisis de datos con Stata, Centro de Investigaciones Sociológicas. Retrieved from https://books.google.com.co/books?id=CZDAZTPPM-wC.

Ferrer-i-Carbonell, Ada (2005), "Income and Well-being: An Empirical Analysis of the Comparison Income Effect", Journal of Public Economics, 89 (5-6), pp. 997-1019, https://doi.org/10.1016/j.jpubeco.2004.06.003.

FMI (2014), World economic outlook database, imf Washington. Retrieved from https://www.imf.org/external/pubs/ft/weo/2013/01/weodata/index.aspx.

Fuentes, Nicole y Rojas, Mariano (2001), "Economic Theory and Subjective Well-being: Mexico", Social Indicators Research, 53 (3), pp. 289-314, https://doi. org/10.1023/A:1007189429153.

Gerdtham, Ulf Göran y Johannesson, Magnus (2001), “The Relationship Between Happiness, Health, and Socio-economic Factors: Results Based on Swedish Microdata", Journal of Socio-Economics, 30 (6), pp. 553-557, https://doi. org/10.1016/S1053-5357(01)00118-4.

Gerstenblüth, Mariana; Melgar, Natalia y Rossi, Máximo (2013), "Ingreso y desigualdad. ¿Cómo afectan a la felicidad en América Latina?", Cuadernos de Economía, 32 (59), pp. 163-178.

Gilbert, Daniel (2006), Stumbling on Happiness, Knopf Doubleday Publishing Group. Retrieved from https://books.google.com.co/books?id=6h8jkuBC4ASC.

Guven, Cahit (2012), "Reversing the Question: Does Happiness Affect Consumption and Savings Behavior?”, Journal of Economic Psychology, 33 (4), pp. 701717, https://doi.org/10.1016/j.joep.2012.01.002.

Hallmann, Kirstin; Breuer, Christoph y Kühnreich, Benedikt (2013), "Happiness, Pride and Elite Sporting Success: What Population Segments Gain Most from National Athletic Achievements?", Sport Management Review, 16 (2), pp. 226235, https://doi.org/10.1016/j.smr.2012.07.001.

Hartog, Joop y Oosterbeek, Hessel (1998), "Health, Wealth and Happiness: Why Pursue a Higher Education?", Economics of Education Review, 17 (3), pp. 245256, https://doi.org/10.1016/S0272-7757(97)00064-2.

Haucap, Justus y Heimeshoff, Ulrich (2014), "The Happiness of Economists: Estimating the Causal Effect of Studying Economics on Subjective Well-being", International Review of Economics Education, 17, pp. 85-97, https://doi. org/10.1016/j.iree.2014.08.004.

Helliwell, John; Layard, Richard y Sachs, Jeffrey (2015), World Happiness Report 2015, Sustainable Development Solutions Network New York. Retrieved from http://worldhappiness.report/wp-content/uploads/sites/2/2015/04/whr15.pdf. 
Inglehart, Ronald; Foa, Roberto; Peterson, Christopher y Welzel, Christian (2008), "Development, Freedom, and Rising Happiness: A Global Perspective (19812007)", Perspectives on Psychological Science, 3 (4), pp. 264-285. Retrieved from http://www.jstor.org/stable/40212250.

Kahneman, Daniel y Deaton, Angus (2010), "High Income Improves Evaluation of Life But not Emotional Well-being", Proceedings of the National Academy of Sciences of the United States of America, 107 (38), pp. 16489-16493, https:// doi.org/10.1073/pnas.1011492107.

Kaun, David (2005), "Income and Happiness: Earning and Spending as Sources of Discontent", Journal of Socio-Economics, 34 (2), pp. 161-177, https://doi. org/10.1016/j.socec.2004.09.005.

Layard, Richard (2011), Happiness: Lessons from a New Science, 2a. ed., Penguin Books Limited. Retrieved from https://books.google.com.co/books?id=kumbtwctdkcc.

Lelkes, Orsolya (2006), “Tasting Freedom: Happiness, Religion and Economic Transition", Journal of Economic Behavior and Organization, 59 (2), pp. 173-194, https://doi.org/10.1016/j.jebo.2004.03.016.

Loewenstein, George; Krishnamurti, Tamar; Kopsic, Jessica y Mcdonald, Daniel (2015), “Does Increased Sexual Frequency Enhance Happiness?", Journal of Economic Behavior and Organization, 116, pp. 206-218, https://doi.org/10.1016/j. jebo.2015.04.021.

Loewenstein, George; O’Donoghue, Ted y Rabin, Matthew (2003), "Projection Bias in Predicting Future Utility", The Quarterly Journal of Economics, 118 (4), pp. 1209-1248, https://doi.org/10.1162/003355303322552784.

Lora, Eduardo (2008), Calidad de vida: más allá de los hechos, Banco Interamericano de Desarrollo, Washington. Retrieved from http://www.iadb.org/res/files/ dia2008_resumen.pdf.

Maslow, Abraham (1943), "A Theory of Human Motivation", Psychological Review, 50 (4), pp. 370-396, https://doi.org/10.1037/h0054346.

McBride, Michael (2010), "Money, Happiness, and Aspirations: An Experimental Study", Journal of Economic Behavior and Organization, 74 (3), pp. 262-276, https://doi.org/10.1016/j.jebo.2010.03.002.

Mookerjee, Rajen y Beron, Krista (2005), "Gender, Religion and Happiness", Journal of Socio-Economics, 34 (5), pp. 674-685, https://doi.org/10.1016/j. socec.2005.07.012.

OCDE y Santiso, Javier (2009), "América Latina en 2008-2009: la espuma de los días felices", Anuario Internacional СIDOB, (1), pp. 25-30. Retrieved from http:// www.raco.cat/index.php/Anuariocidob/article/view/164543/216518. 
ONU (2015), World Population Prospects. Key Findings and Advanced Tables. The 2015 Revision, esa/p/wp, 241, New York. Retrieved from http://esa.un.org/ unpd/wpp/Publications/Files/Key_Findings_wpp_2015.pdf.

Oswald, Andrew (1999), "A Non-Technical Introduction to the Economics of Happiness", University of Warwick, UK.

Oxford University (2016), Middle Age in English Oxford Dictionaries. Retrieved March 10, 2017, from https://en.oxforddictionaries.com/definition/us/middle_age.

Pawlowski, Tim; Downward, Paul y Rasciute, Simona (2014), "Does National Pride from International Sporting Success Contribute to Well-being? An International Investigation", Sport Management Review, 17 (2), pp. 121-132, https://doi. org/10.1016/j.smr.2013.06.007.

Peiró, Amado (2006), "Happiness, Satisfaction and Socio-economic Conditions: Some international Evidence, Journal of Socio-Economics, 35 (2), pp. 348-365, https://doi.org/10.1016/j.socec.2005.11.042.

Prinz, Aloys y Bünger, Björn (2012), "Balancing 'Full Life': An Economic Approach to the Route to Happiness", Journal of Economic Psychology, 33 (1), pp. 58-70, https://doi.org/10.1016/j.joep.2011.08.011.

Qari, Salmai (2014), "Marriage, Adaptation and Happiness: Are there Long-lasting Gains to Marriage?", Journal of Behavioral and Experimental Economics, 50, pp. 29-39. https://doi.org/10.1016/j.socec.2014.01.003.

Real Academia Española, (2005), Diccionario Panhispánico de Dudas, Academia de la Lengua Española, Alfaguara, Bogotá.

Rojas, Mariano (2016), Handbook of Happiness Research in Latin America. Handbook of Happiness Research in Latin America, Springer Netherlands, https:// doi.org/10.1007/978-94-017-7203-7.

Seligman, Martin (2002), Authentic Happiness: Using the New Positive Psychology to Realize Your Potential for Lasting Fulfillment, Free Press. Retrieved from https://books.google.com.co/books?id=3LoBCCOFMRGC.

Smith, Adam (1958), Investigación sobre la naturaleza y causas de la riqueza de las naciones, Fondo de Cultura Económica, México. Retrieved from https:// books.google.com.co/books?id=hty-upxzt0yc.

Stillman, Tyler; Fincham, Frank; Vohs, Kahleen; Lambert, Nathaniel y Phillips, Christa (2012), "The Material and Immaterial in Conflict: Spirituality Reduces Conspicuous Consumption", Journal of Economic Psychology, 33 (1), pp. 1-7, https://doi.org/10.1016/j.joep.2011.08.012.

Stutzer, Alois (2004), "The Role of Income Aspirations in Individual Happiness", Journal of Economic Behavior and Organization, 54 (1), pp. 89-109, https:// doi.org/10.1016/j.jebo.2003.04.003. 
Stutzer, Alois y Frey, Bruno (2006), "Does Marriage Make People Happy, or do Happy People Get Married?", Journal of Socio-Economics, 35 (2), pp. 326-347, https://doi.org/10.1016/j.socec.2005.11.043.

Triunfo, Patricia; Gerstenbluth, Mariana y Rossi, Maximo (2008), "Felicidad y salud: una aproximación al bienestar en el Río de la Plata", Estudios de Economía, 35 (1), pp. 65-78.

Tsui, Hsiao-Chien (2014), "What Affects Happiness: Absolute Income, Relative Income or Expected Income?”, Journal of Policy Modeling, 36 (6), pp. 994-1007, https://doi.org/10.1016/j.jpolmod.2014.09.005.

Veenhoven, Ruut (2000), "Freedom and Happiness: A Comparative Study in $46 \mathrm{Na}$ tions in the Early, 1990s", in Diener, Ed y Su, E. (eds.), Culture and subjective Well-being, MIT Press, Cambridge.

Verme, Paolo (2009), "Happiness, Freedom and Control", Journal of Economic Behavior and Organization, 71 (2), pp. 146-161, https://doi.org/10.1016/j. jebo.2009.04.008.

Winship, Christopher y Mare, Robert (1984), "Regression Models with Ordinal Variables”, American Sociological Review, 49 (4), pp. 512-525, https://doi. org/10.2307/2095465.

WVS (2015), "World Values Survey 1981-2014. Longitudinal Aggregate v. 20150418”, World Values Survey Association (Www.Worldvaluessurvey.Org), jdsystems, Madrid. Retrieved from http://www.worldvaluessurvey.org/wvsContents.jsp. 


\section{ANEXOS}

ANEXO I

Tabla A.1. Variables explicativas y sus categorías.

\begin{tabular}{|c|c|}
\hline Variable & Categorías \\
\hline Nivel ingresos & Nivel I, nivel II, nivel III, nivel IV y nivel V. \\
\hline Libertad elección (percepción) & Nivel I, nivel II, nivel III, nivel IV y nivel V. \\
\hline Condición laboral & $\begin{array}{l}\text { Tiempo completo, medio tiempo, independiente, } \\
\text { retirado, ama de casa, estudiante, desempleado } \\
\text { y otro. }\end{array}$ \\
\hline Estado civil & $\begin{array}{l}\text { Casado, unión libre, divorciado, separado, viudo } \\
\text { y soltero. }\end{array}$ \\
\hline Consumo (proporción del ingreso) & $\begin{array}{l}\text { Por encima del nivel de ingresos, igual al nivel de } \\
\text { ingresos y superior al nivel de ingresos. }\end{array}$ \\
\hline Nivel educativo & $\begin{array}{l}\text { Primaria incompleta o completa, secundaria incom- } \\
\text { pleta o completa, media vocacional incompleta o } \\
\text { completa, universidad incompleta o completa. }\end{array}$ \\
\hline Salud (subjetivo) & Malo, regular, bueno y muy bueno. \\
\hline Edad & $\begin{array}{l}18-20 \text { años, } 21-30,31-40,41-50,51-60,61-70,71- \\
80,81-90 \text { y } 91-99 .\end{array}$ \\
\hline Religión (importancia individual) & $\begin{array}{l}\text { Nada importante, poco importante, levemente } \\
\text { importante, muy importante. }\end{array}$ \\
\hline Sexo & 1=hombre, $2=$ =Mujer \\
\hline Mujer-ingresos & $\begin{array}{l}\text { Variable interactuada que captura las mujeres } \\
\text { pertenecientes a cada nivel de ingresos descritos } \\
\text { previamente. }\end{array}$ \\
\hline Tiempo libre (importancia individual) & $\begin{array}{l}\text { Nada importante, poco importante, levemente } \\
\text { importante, muy importante. }\end{array}$ \\
\hline Trabajo (importancia individual) & $\begin{array}{l}\text { Nada importante, poco importante, levemente } \\
\text { importante, muy importante. }\end{array}$ \\
\hline Familia (importancia individual) & $\begin{array}{l}\text { Nada importante, poco importante, levemente } \\
\text { importante, muy importante. }\end{array}$ \\
\hline Hijos & Desde ningún hijo (0) hasta ocho (8) hijos. \\
\hline Justificación de la riqueza & 1= inaceptable, 2 = justificable. \\
\hline Orgullo patrio & $\begin{array}{l}\text { Nada orgulloso, no tan orgulloso, levemente orgu- } \\
\text { lloso, muy orgulloso. }\end{array}$ \\
\hline Satisfacción con los ingresos del hogar & Nivel I, nivel II, nivel III, nivel IV y nivel V. \\
\hline
\end{tabular}

Fuente: elaboración del autor a partir de WVS-LONG WAVE 6. 
ECONOMÍA TEORÍA Y PRÁCTICA [ISSN: 2448-7481] • Nueva Época, año 27, número 50, enero-junio 2019 Oscar Mauricio Poveda Bermudez

ANEXO II

Tabla A.2. Tabulaciones felicidad y variables explicativas.

\begin{tabular}{|c|c|c|c|c|c|}
\hline Pais & Variable/Categoria & Infeliz & Poco Feliz & Feliz & Muy Feliz \\
\hline \multicolumn{6}{|c|}{ Nivel Ingresos } \\
\hline \multirow{5}{*}{ Colonbia } & Nvell & $1,83 \%$ & $12,80 \%$ & $32,32 \%$ & $53,05 \%$ \\
\hline & Nivell & $1,26 \%$ & $11,95 \%$ & $31,13 \%$ & $55,66 \%$ \\
\hline & Nivel II & $0,00 \%$ & $5,99 \%$ & $35,95 \%$ & $58,06 \%$ \\
\hline & Nwel N & $0,32 \%$ & $3,15 \%$ & $36,59 \%$ & $59,94 \%$ \\
\hline & Nivel V & $0,00 \%$ & $9,76 \%$ & $26,83 \%$ & $63,41 \%$ \\
\hline \multirow{5}{*}{ Brasil } & NvelI & $2,15 \%$ & $7,89 \%$ & $59,14 \%$ & $30,82 \%$ \\
\hline & Nvell & $0,34 \%$ & $8,19 \%$ & $60,41 \%$ & $31,06 \%$ \\
\hline & Nvel II & $0,40 \%$ & $6,14 \%$ & $58,02 \%$ & $35,45 \%$ \\
\hline & Nwel N & $1,09 \%$ & $4,35 \%$ & $50,54 \%$ & $44,02 \%$ \\
\hline & NvelV & $0,00 \%$ & $7,41 \%$ & $40,74 \%$ & $51,85 \%$ \\
\hline \multirow{5}{*}{ Mexico } & Nwel I & $0,22 \%$ & $6,28 \%$ & $27,80 \%$ & $65,70 \%$ \\
\hline & Nvel I & $0,26 \%$ & $4,40 \%$ & $27,72 \%$ & $67,62 \%$ \\
\hline & Nvel II & $0,36 \%$ & $4,35 \%$ & $25,36 \%$ & $69,93 \%$ \\
\hline & Nivel N & $1,20 \%$ & $4,19 \%$ & $22,16 \%$ & $72,46 \%$ \\
\hline & Nvel V & $1,23 \%$ & $2,47 \%$ & $17,28 \%$ & $79,01 \%$ \\
\hline \multicolumn{6}{|c|}{ Libertad de Elección (percepción) } \\
\hline \multirow{5}{*}{ Colombia } & Nvell & $5,56 \%$ & $33,33 \%$ & $33,33 \%$ & $27,78 \%$ \\
\hline & Nvel II & $2,56 \%$ & $15,38 \%$ & $33,33 \%$ & $48,72 \%$ \\
\hline & Nvel \| & $0,00 \%$ & $14,75 \%$ & $37,16 \%$ & $48,09 \%$ \\
\hline & Nwel N & $0,95 \%$ & $5,70 \%$ & $38,72 \%$ & $54,63 \%$ \\
\hline & Nvel V & $0,30 \%$ & $5,88 \%$ & $30,62 \%$ & $63,20 \%$ \\
\hline \multirow{5}{*}{ Brasil } & Nvell & $4,65 \%$ & $4,65 \%$ & $62,79 \%$ & $27,91 \%$ \\
\hline & Nvell I & $1,61 \%$ & $16,13 \%$ & $53,23 \%$ & $29,03 \%$ \\
\hline & Nwel II & $0,71 \%$ & $8,83 \%$ & $66,08 \%$ & $24,38 \%$ \\
\hline & Nwel N & $0,33 \%$ & $5,94 \%$ & $63,04 \%$ & $30,69 \%$ \\
\hline & Nvel V & $0,84 \%$ & $5,36 \%$ & $50,42 \%$ & $43,38 \%$ \\
\hline \multirow{5}{*}{ México } & Nivell & $0,00 \%$ & $7,69 \%$ & $23,08 \%$ & $69,23 \%$ \\
\hline & Nvel II & $0,00 \%$ & $18,75 \%$ & $18,75 \%$ & $62,50 \%$ \\
\hline & Nivel \| & $0,00 \%$ & $8,11 \%$ & $36,49 \%$ & $55,41 \%$ \\
\hline & Nwel N & $0,58 \%$ & $5,00 \%$ & $33,46 \%$ & $60,96 \%$ \\
\hline & Nvel V & $0,38 \%$ & $4,38 \%$ & $21,90 \%$ & $73,33 \%$ \\
\hline \multicolumn{6}{|c|}{ Consumo } \\
\hline \multirow{3}{*}{ Colombia } & Cons < hg & $0,00 \%$ & $3,93 \%$ & $33,93 \%$ & $62,14 \%$ \\
\hline & $C_{0 n}=h g$ & $0,62 \%$ & $8,23 \%$ & $34,32 \%$ & $56,83 \%$ \\
\hline & Cons > hg & $1,00 \%$ & $9,50 \%$ & $34,25 \%$ & $55,25 \%$ \\
\hline \multirow{3}{*}{ Brasil } & Cons $<\mathrm{hg}$ & $0,37 \%$ & $3,00 \%$ & $55,81 \%$ & $40,82 \%$ \\
\hline & $C_{0}=n g$ & $0,95 \%$ & $7,58 \%$ & $58,73 \%$ & $32,75 \%$ \\
\hline & Cons $>$ hg & $1,06 \%$ & $8,16 \%$ & $55,32 \%$ & $35,46 \%$ \\
\hline \multirow{3}{*}{ México } & Cons < ing & $0,27 \%$ & $3.25 \%$ & $23,04 \%$ & $73,44 \%$ \\
\hline & $C_{0 n}=\mathrm{hg}$ & $0,37 \%$ & $4,46 \%$ & $26,77 \%$ & $68,40 \%$ \\
\hline & Cons > hg & $0,48 \%$ & $7,35 \%$ & $27,96 \%$ & $64,22 \%$ \\
\hline
\end{tabular}

\begin{tabular}{|c|c|c|c|c|c|}
\hline Pais & Variable/Categoria & Infeliz & Poco Feliz & Feliz & Muy Feliz \\
\hline & & Edad & & & \\
\hline \multirow{8}{*}{ Colonbia } & $18-20$ & $0,00 \%$ & $6,11 \%$ & $35,88 \%$ & $58,02 \%$ \\
\hline & $21-30$ & $0,31 \%$ & $7,23 \%$ & $34,59 \%$ & $57,86 \%$ \\
\hline & $31-40$ & $0,71 \%$ & $4,61 \%$ & $33,33 \%$ & $61,35 \%$ \\
\hline & $41-50$ & $0,41 \%$ & $8,13 \%$ & $31,71 \%$ & $59,76 \%$ \\
\hline & $51-60$ & $1,59 \%$ & $11,11 \%$ & $39,68 \%$ & $47,62 \%$ \\
\hline & $61-70$ & $0,88 \%$ & $8,85 \%$ & $31,86 \%$ & $58,41 \%$ \\
\hline & $71-80$ & $0,00 \%$ & $17,07 \%$ & $26,83 \%$ & $56,10 \%$ \\
\hline & $81-90$ & $0,00 \%$ & $0,00 \%$ & $50,00 \%$ & $50,00 \%$ \\
\hline \multirow{9}{*}{ Brasil } & $18-20$ & $0,00 \%$ & $5,00 \%$ & $51,00 \%$ & $44,00 \%$ \\
\hline & $21-30$ & $0,72 \%$ & $4,30 \%$ & $62,01 \%$ & $32,97 \%$ \\
\hline & $31-40$ & $0,39 \%$ & $4,72 \%$ & $57,87 \%$ & $37,01 \%$ \\
\hline & $41-50$ & $0,77 \%$ & $8,81 \%$ & $57,85 \%$ & $32,57 \%$ \\
\hline & $51-60$ & $0,49 \%$ & $9,76 \%$ & $56,59 \%$ & $33,17 \%$ \\
\hline & $61-70$ & $4,10 \%$ & $7,38 \%$ & $56,56 \%$ & $31,97 \%$ \\
\hline & $71-80$ & $0,00 \%$ & $8,00 \%$ & $48,00 \%$ & $44,00 \%$ \\
\hline & $81-90$ & $0,00 \%$ & $13,33 \%$ & $46,67 \%$ & $40,00 \%$ \\
\hline & $91-99$ & $0,00 \%$ & $0,00 \%$ & $50,00 \%$ & $50,00 \%$ \\
\hline \multirow{9}{*}{ México } & $18-20$ & $0,00 \%$ & $2,40 \%$ & $28,37 \%$ & $69,23 \%$ \\
\hline & $21-30$ & $0,17 \%$ & $4,59 \%$ & $24,83 \%$ & $70,41 \%$ \\
\hline & $31-40$ & $0,25 \%$ & $4,30 \%$ & $26,58 \%$ & $68.86 \%$ \\
\hline & $41-50$ & $0,61 \%$ & $5,17 \%$ & $27,36 \%$ & $66,87 \%$ \\
\hline & $51-60$ & $0,71 \%$ & $10,00 \%$ & $28,57 \%$ & $60,71 \%$ \\
\hline & $61-70$ & $2,25 \%$ & $11,24 \%$ & $30,34 \%$ & $56,18 \%$ \\
\hline & $71-80$ & $0,00 \%$ & $8,70 \%$ & $17,39 \%$ & $73,91 \%$ \\
\hline & $81-90$ & $0,00 \%$ & $0,00 \%$ & $16,67 \%$ & $83,33 \%$ \\
\hline & $91-99$ & $0,00 \%$ & $0,00 \%$ & $0,00 \%$ & $100,00 \%$ \\
\hline \multicolumn{6}{|c|}{ Tiempo libre (importanoia) } \\
\hline \multirow{4}{*}{ Colonbia } & Nada importante & $4,17 \%$ & $16,67 \%$ & $20,83 \%$ & $58,33 \%$ \\
\hline & Poco importante & $0,59 \%$ & $11,76 \%$ & $33,53 \%$ & $54,12 \%$ \\
\hline & mportante & $0,64 \%$ & $6,17 \%$ & $42,34 \%$ & $50,85 \%$ \\
\hline & Muy importante & $0,45 \%$ & $7,42 \%$ & $29,09 \%$ & $63,03 \%$ \\
\hline \multirow{4}{*}{ Brasil } & Nada importanto & $4,17 \%$ & $16,67 \%$ & $37,50 \%$ & $41,67 \%$ \\
\hline & Poco importante & $0,78 \%$ & $14,84 \%$ & $54,69 \%$ & $29,69 \%$ \\
\hline & Importanto & $0,71 \%$ & $4,80 \%$ & $63,84 \%$ & $30,65 \%$ \\
\hline & Muy importante & $0,93 \%$ & $7,01 \%$ & $48,60 \%$ & $43,46 \%$ \\
\hline \multirow{4}{*}{ México } & Nada importante & $0,00 \%$ & $15,00 \%$ & $10,00 \%$ & $75,00 \%$ \\
\hline & Poco importante & $0,00 \%$ & $12,44 \%$ & $30,14 \%$ & $57,42 \%$ \\
\hline & Importante & $0,82 \%$ & $3,27 \%$ & $31,43 \%$ & $64,49 \%$ \\
\hline & Muy importante & $0,28 \%$ & $4,33 \%$ & $23,99 \%$ & $71,40 \%$ \\
\hline
\end{tabular}

Fuente: elaboración del autor a partir de wvs- 6. 
Tabla A.2. Continuación.

\begin{tabular}{|c|c|c|c|c|c|}
\hline Pais & Variable/Categoria & Infeliz & Poco Feliz & Feliz & Muy Feliz \\
\hline \multicolumn{6}{|c|}{ Salud (Subjetivo) } \\
\hline \multirow{4}{*}{ Colombia } & Malo & $9,09 \%$ & $36,36 \%$ & $40,91 \%$ & $13,64 \%$ \\
\hline & Regular & $1,80 \%$ & $17,63 \%$ & $33,09 \%$ & $47,48 \%$ \\
\hline & Bueno & $0,00 \%$ & $4,80 \%$ & $36,94 \%$ & $58,26 \%$ \\
\hline & Muy Bueno & $0,28 \%$ & $3,63 \%$ & $29,61 \%$ & $66,48 \%$ \\
\hline \multirow{4}{*}{ Brasil } & Malo & $10,00 \%$ & $20,00 \%$ & $55,00 \%$ & $15,00 \%$ \\
\hline & Regular & $1,57 \%$ & $13,21 \%$ & $58,18 \%$ & $27,04 \%$ \\
\hline & Bueno & $0,32 \%$ & $5,36 \%$ & $65,10 \%$ & $29,22 \%$ \\
\hline & Muy Bueno & $0,00 \%$ & $1,27 \%$ & $41,72 \%$ & $57,01 \%$ \\
\hline \multirow{4}{*}{ México } & Malo & $3,03 \%$ & $21,21 \%$ & $21,21 \%$ & $54,55 \%$ \\
\hline & Regular & $0,46 \%$ & $8,97 \%$ & $36,78 \%$ & $53,79 \%$ \\
\hline & Bueno & $0,24 \%$ & $4,82 \%$ & $26,94 \%$ & $68,00 \%$ \\
\hline & Muy Bueno & $0,41 \%$ & $1,45 \%$ & $16,53 \%$ & $81,61 \%$ \\
\hline \multicolumn{6}{|c|}{ Estado Civil } \\
\hline \multirow{6}{*}{ Colombia } & Casado & $0,51 \%$ & $4,34 \%$ & $35,71 \%$ & $59,44 \%$ \\
\hline & Union Libre & $1,03 \%$ & $7,69 \%$ & $33,59 \%$ & $57,69 \%$ \\
\hline & Divorciado & $0,00 \%$ & $12,00 \%$ & $36,00 \%$ & $52,00 \%$ \\
\hline & Separado & $0,00 \%$ & $13,48 \%$ & $37,08 \%$ & $49,44 \%$ \\
\hline & Viudo & $0,00 \%$ & $22,22 \%$ & $24,44 \%$ & $53,33 \%$ \\
\hline & Soltero & $0,52 \%$ & $7,83 \%$ & $33,68 \%$ & $57,96 \%$ \\
\hline \multirow{6}{*}{ Brasil } & Casado & $0,39 \%$ & $3,87 \%$ & $54,35 \%$ & $41,39 \%$ \\
\hline & Union Libre & $0,79 \%$ & $7,48 \%$ & $58,27 \%$ & $33,46 \%$ \\
\hline & Divorciado & $0,00 \%$ & $17,31 \%$ & $61,54 \%$ & $21,15 \%$ \\
\hline & Separado & $1,41 \%$ & $18,31 \%$ & $61,97 \%$ & $18,31 \%$ \\
\hline & Viudo & $2,41 \%$ & $10,84 \%$ & $59,04 \%$ & $27,71 \%$ \\
\hline & Soltero & $1,29 \%$ & $5,47 \%$ & $59,49 \%$ & $33,76 \%$ \\
\hline \multirow{6}{*}{ México } & Casado & $0,74 \%$ & $3,97 \%$ & $22,83 \%$ & $72,46 \%$ \\
\hline & Union Libre & $0,00 \%$ & $5,95 \%$ & $28,27 \%$ & $65,77 \%$ \\
\hline & Divorciado & $0,00 \%$ & $6,98 \%$ & $37,21 \%$ & $55,81 \%$ \\
\hline & Separado & $0,00 \%$ & $12,75 \%$ & $30,39 \%$ & $56,86 \%$ \\
\hline & Viudo & $0,00 \%$ & $4,92 \%$ & $34,43 \%$ & $60,66 \%$ \\
\hline & Soltero & $0,22 \%$ & $5,07 \%$ & $28,41 \%$ & $66,30 \%$ \\
\hline \multicolumn{6}{|c|}{ Sexo } \\
\hline \multirow{2}{*}{ Colombia } & Hombre & $0,45 \%$ & $6,80 \%$ & $36,10 \%$ & $56,65 \%$ \\
\hline & Mujer & $0,76 \%$ & $8,61 \%$ & $32,33 \%$ & $58,31 \%$ \\
\hline \multirow{2}{*}{ Brasi } & Honbre & $0,20 \%$ & $6,11 \%$ & $57,64 \%$ & $36,05 \%$ \\
\hline & Mujer & $1,25 \%$ & $7,15 \%$ & $57,21 \%$ & $34,38 \%$ \\
\hline \multirow{2}{*}{ México } & Honbre & $0,77 \%$ & $4,97 \%$ & $28,04 \%$ & $66,23 \%$ \\
\hline & Mujer & $0,00 \%$ & $5,47 \%$ & $24,78 \%$ & $69,75 \%$ \\
\hline
\end{tabular}

\begin{tabular}{|c|c|c|c|c|c|}
\hline \multirow[t]{2}{*}{ Pais } & Variable/Categoria & \multicolumn{2}{|c|}{ Infeliz Poco Feliz } & Feliz & \multirow[t]{2}{*}{ Muy Feliz } \\
\hline & \multicolumn{4}{|c|}{ Condición Laboral } & \\
\hline \multirow{8}{*}{ Colombia } & T. Completo & $0.28 \%$ & $4,52 \%$ & $34,18 \%$ & $61,02 \%$ \\
\hline & medio tiempo & $0,00 \%$ & $8,99 \%$ & $34,83 \%$ & $56,18 \%$ \\
\hline & independiente & $0,37 \%$ & $8,61 \%$ & $37,45 \%$ & $53,56 \%$ \\
\hline & retirado & $0,00 \%$ & $10,94 \%$ & $29,69 \%$ & $59,38 \%$ \\
\hline & ama de casa & $0,48 \%$ & $9,18 \%$ & $28,99 \%$ & $61,35 \%$ \\
\hline & estudiante & $0,00 \%$ & $3,77 \%$ & $41,51 \%$ & $54,72 \%$ \\
\hline & desempleado & $2,12 \%$ & $10,58 \%$ & $35,45 \%$ & $51,85 \%$ \\
\hline & otro & $0,99 \%$ & $6,93 \%$ & $32,67 \%$ & $59,41 \%$ \\
\hline \multirow{8}{*}{ Brasil } & T. Completo & $0,46 \%$ & $5,09 \%$ & $59,49 \%$ & $34,95 \%$ \\
\hline & modio tiempo & $0,00 \%$ & $2,15 \%$ & $56,99 \%$ & $40,86 \%$ \\
\hline & independiente & $0,00 \%$ & $7,19 \%$ & $51,08 \%$ & $41,73 \%$ \\
\hline & retirado & $2,07 \%$ & $10,88 \%$ & $54,92 \%$ & $32,12 \%$ \\
\hline & ama de casa & $2,40 \%$ & $5,77 \%$ & $57,69 \%$ & $34,13 \%$ \\
\hline & estudiante & $0.00 \%$ & $2,13 \%$ & $59,57 \%$ & $38,30 \%$ \\
\hline & desempleado & $0,00 \%$ & $10,71 \%$ & $58,93 \%$ & $30,36 \%$ \\
\hline & otro & $0,00 \%$ & $12,50 \%$ & $62,50 \%$ & $25,00 \%$ \\
\hline \multirow{8}{*}{ México } & T. Completo & $0,44 \%$ & $4,63 \%$ & $23,57 \%$ & $71,37 \%$ \\
\hline & medio tiempo & $0,00 \%$ & $7,49 \%$ & $28,34 \%$ & $64,17 \%$ \\
\hline & independiente & $1,08 \%$ & $4,69 \%$ & $28,52 \%$ & $65,70 \%$ \\
\hline & retirado & $0,00 \%$ & $8,62 \%$ & $22,41 \%$ & $68.97 \%$ \\
\hline & ama de casa & $0,00 \%$ & $5,58 \%$ & $24,25 \%$ & $70,17 \%$ \\
\hline & estudiante & $0,00 \%$ & $1,77 \%$ & $30,97 \%$ & $67,26 \%$ \\
\hline & desempleado & $0,85 \%$ & $5,56 \%$ & $31,20 \%$ & $62,39 \%$ \\
\hline & otro & $0,00 \%$ & $0,00 \%$ & $23,08 \%$ & $76,92 \%$ \\
\hline \multicolumn{6}{|c|}{ Nivel Educativo } \\
\hline \multirow{8}{*}{ Colombia } & Primaria incomp & $1,90 \%$ & $9,49 \%$ & $34,81 \%$ & $53,80 \%$ \\
\hline & Primaria completa & $1,26 \%$ & $9,43 \%$ & $32,08 \%$ & $57,23 \%$ \\
\hline & Secun incomp & $0,00 \%$ & $13,33 \%$ & $37,33 \%$ & $49,33 \%$ \\
\hline & Secun completa & $0,98 \%$ & $9,80 \%$ & $35,29 \%$ & $53,92 \%$ \\
\hline & Media voc. Incomp & $0.55 \%$ & $10,99 \%$ & $31,87 \%$ & $56,59 \%$ \\
\hline & Media voc. Comp & $0,36 \%$ & $5,40 \%$ & $32,37 \%$ & $61,87 \%$ \\
\hline & Universidad incomp & $0,00 \%$ & $4,71 \%$ & $32,94 \%$ & $62,35 \%$ \\
\hline & Universidad comp & $0,00 \%$ & $4,50 \%$ & $39,50 \%$ & $56,00 \%$ \\
\hline \multirow{8}{*}{ Brasil } & Pimaria incomp & $2,08 \%$ & $8,31 \%$ & $54,55 \%$ & $35,06 \%$ \\
\hline & Primaria completa & $0,62 \%$ & $6,83 \%$ & $63,98 \%$ & $28,57 \%$ \\
\hline & Secun incomp & $0,00 \%$ & $10,00 \%$ & $70,00 \%$ & $20,00 \%$ \\
\hline & Secun completa & $0,00 \%$ & $0,00 \%$ & $71,43 \%$ & $28,57 \%$ \\
\hline & Media voc. hcomp & $0,00 \%$ & $4,88 \%$ & $59,35 \%$ & $35,77 \%$ \\
\hline & Madia voc. Comp & $0,57 \%$ & $8,55 \%$ & $56,70 \%$ & $34,19 \%$ \\
\hline & Universidad inconp & $0,00 \%$ & $3,33 \%$ & $48,89 \%$ & $47,78 \%$ \\
\hline & Universidad comp & $0,00 \%$ & $2,86 \%$ & $59,29 \%$ & $37,86 \%$ \\
\hline
\end{tabular}

Fuente: elaboración del autor a partir de wVs- 6 . 
ECONOMÍA TEORÍA Y PRÁCTICA [ISSN: 2448-7481] • Nueva Época, año 27, número 50, enero-junio 2019 Oscar Mauricio Poveda Bermudez

Tabla A.2. Continuación.

\begin{tabular}{|c|c|c|c|c|c|c|c|c|c|c|c|}
\hline Pais & Variable/Categoria & Infeliz & Poco Feliz & Feliz & Muy Feliz & Pais & Variable/Categoria & Infeliz & Poco Feliz & Feliz & Muy Feliz \\
\hline \multicolumn{6}{|c|}{ Nivel Educativo (Continuación) } & \multicolumn{6}{|c|}{ Trabajo (Importancia) } \\
\hline \multirow{8}{*}{ México } & Primaria incomp & $0,50 \%$ & $12,38 \%$ & $22,77 \%$ & $64,36 \%$ & \multirow{4}{*}{ Colombia } & \multirow{3}{*}{$\begin{array}{l}\text { Nada importante } \\
\text { Poco importante } \\
\text { Importante }\end{array}$} & $0,00 \%$ & $12,50 \%$ & $37,50 \%$ & $50,00 \%$ \\
\hline & Primaria completa & $0,71 \%$ & $5,67 \%$ & $25,89 \%$ & $67,73 \%$ & & & $0,00 \%$ & $0,00 \%$ & $30,00 \%$ & $70,00 \%$ \\
\hline & Secun incomp & $1,09 \%$ & $5,43 \%$ & $32,61 \%$ & $60,87 \%$ & & & $0,67 \%$ & $9,43 \%$ & $39,39 \%$ & $50,51 \%$ \\
\hline & Secun completa & $0,00 \%$ & $4,90 \%$ & $28,73 \%$ & $66,37 \%$ & & My importante & $0,59 \%$ & $7,23 \%$ & $32,71 \%$ & $59,46 \%$ \\
\hline & Media voc. Incomp & $0,00 \%$ & $3,90 \%$ & $27,27 \%$ & $68,83 \%$ & \multirow{4}{*}{ Brasil } & Nada importante & $0,00 \%$ & $0,00 \%$ & $71,43 \%$ & $28,57 \%$ \\
\hline & Media voc. Comp & $0,00 \%$ & $3,58 \%$ & $27,24 \%$ & $69,18 \%$ & & Poco importante & $6,25 \%$ & $6,25 \%$ & $62,50 \%$ & $25,00 \%$ \\
\hline & Universidad incomp & $0,00 \%$ & $1,00 \%$ & $25,00 \%$ & $74,00 \%$ & & Importante & $1,14 \%$ & $6,38 \%$ & $61,28 \%$ & $31,21 \%$ \\
\hline & Universidad comp & $1,23 \%$ & $3,69 \%$ & $22,54 \%$ & $72,54 \%$ & & My importante & $0,61 \%$ & $7,02 \%$ & $55,08 \%$ & $37,29 \%$ \\
\hline \multicolumn{6}{|c|}{ Religión (Importancia) } & \multirow{4}{*}{ México } & Nada importante & $0,00 \%$ & $22,58 \%$ & $29,03 \%$ & $48,39 \%$ \\
\hline \multirow{4}{*}{ Colombia } & Nada importante & $0,00 \%$ & $10,00 \%$ & $40,00 \%$ & $50,00 \%$ & & Poco importante & $0,00 \%$ & $6,38 \%$ & $31,91 \%$ & $61,70 \%$ \\
\hline & Poco importante & $0,70 \%$ & $9,09 \%$ & $34,27 \%$ & $55,94 \%$ & & Importante & $0,65 \%$ & $3,90 \%$ & $28,57 \%$ & $66,88 \%$ \\
\hline & Importante & $0,85 \%$ & $7,91 \%$ & $41,53 \%$ & $49,72 \%$ & & My importante & $0,38 \%$ & $4,97 \%$ & $25,99 \%$ & $68,66 \%$ \\
\hline & My importante & $0,51 \%$ & $7,24 \%$ & $30,62 \%$ & $61,63 \%$ & \multicolumn{6}{|c|}{ Familia (importancia) } \\
\hline \multirow{4}{*}{ Brasil } & Nada importante & $0,00 \%$ & $8,33 \%$ & $66,67 \%$ & $25,00 \%$ & \multirow{4}{*}{ Colombia } & Nada importante & $0,00 \%$ & $33,33 \%$ & $0,00 \%$ & $66,67 \%$ \\
\hline & Poco importante & $2,17 \%$ & $14,13 \%$ & $56,52 \%$ & $27,17 \%$ & & \multirow{3}{*}{$\begin{array}{l}\text { Poco importante } \\
\text { Importante } \\
\text { My importante }\end{array}$} & $25,00 \%$ & $25,00 \%$ & $50,00 \%$ & $0,00 \%$ \\
\hline & Importante & $1,26 \%$ & $6,74 \%$ & $63,58 \%$ & $28,42 \%$ & & & $1,04 \%$ & $10,94 \%$ & $41,15 \%$ & $46,88 \%$ \\
\hline & My importante & $0,44 \%$ & $5,69 \%$ & $52,70 \%$ & $41,17 \%$ & & & $0,44 \%$ & $7,02 \%$ & $33,07 \%$ & $59,47 \%$ \\
\hline \multirow{4}{*}{ México } & Nada importante & $1,09 \%$ & $8,70 \%$ & $31,52 \%$ & $58,70 \%$ & \multirow{4}{*}{ Brasil } & \multirow{4}{*}{$\begin{array}{l}\text { Nada importante } \\
\text { Poco importante } \\
\text { Importante } \\
\text { Muy importante }\end{array}$} & $100,00 \%$ & $0,00 \%$ & $0,00 \%$ & $0,00 \%$ \\
\hline & Poco importante & $0,47 \%$ & $6,60 \%$ & $29,72 \%$ & $63,21 \%$ & & & $8,33 \%$ & $41,67 \%$ & $25,00 \%$ & $25,00 \%$ \\
\hline & Importante & $0,21 \%$ & $3,82 \%$ & $30,79 \%$ & $65,18 \%$ & & & $3,03 \%$ & $9,85 \%$ & $65,15 \%$ & $21,97 \%$ \\
\hline & My importante & $0,39 \%$ & $5,26 \%$ & $23,27 \%$ & $71,08 \%$ & & & $0,35 \%$ & $6,04 \%$ & $56,92 \%$ & $36,69 \%$ \\
\hline \multicolumn{6}{|c|}{ Mujer Ingresos } & \multirow{4}{*}{ México } & \multirow{4}{*}{$\begin{array}{l}\text { Nada importante } \\
\text { Poco importante } \\
\text { Importante } \\
\text { My importante }\end{array}$} & $0,00 \%$ & $0,00 \%$ & $0,00 \%$ & $0,00 \%$ \\
\hline \multirow{6}{*}{ Colonbia } & M ngresos I & $1,11 \%$ & $13,33 \%$ & $27,78 \%$ & $57,78 \%$ & & & $0,00 \%$ & $41,67 \%$ & $33,33 \%$ & $25,00 \%$ \\
\hline & M. hgresos II & $2,44 \%$ & $14,02 \%$ & $28,66 \%$ & $54,88 \%$ & & & $3,13 \%$ & $9,38 \%$ & $46,88 \%$ & $40,63 \%$ \\
\hline & M ngresos II & $0,00 \%$ & $6,50 \%$ & $36,18 \%$ & $57,32 \%$ & & & $0,34 \%$ & $4,89 \%$ & $26,00 \%$ & $68,77 \%$ \\
\hline & M. Ingresos N & $0,00 \%$ & $2,78 \%$ & $33,33 \%$ & $63,89 \%$ & \multicolumn{6}{|c|}{ Hijos } \\
\hline & M. hgresos V & $0,00 \%$ & $11,11 \%$ & $27,78 \%$ & $61,11 \%$ & & Sin hijos & $0,28 \%$ & $6,69 \%$ & $36,49 \%$ & $56,55 \%$ \\
\hline & Otros & $0,45 \%$ & $6,80 \%$ & $36,10 \%$ & $56,65 \%$ & & 1 hijo & $0,41 \%$ & $7,47 \%$ & $28,22 \%$ & $63,90 \%$ \\
\hline \multirow{6}{*}{ Brasil } & M ingresos I & $2,63 \%$ & $8,95 \%$ & $60,53 \%$ & $27,89 \%$ & & 2 hijos & $0,33 \%$ & $7,02 \%$ & $34,11 \%$ & $58,53 \%$ \\
\hline & M. hgresos II & $0,57 \%$ & $6,82 \%$ & $59,66 \%$ & $32,95 \%$ & & 3 hijos & $1,33 \%$ & $7,56 \%$ & $36,44 \%$ & $54,67 \%$ \\
\hline & M hgresos II & $0,67 \%$ & $6,35 \%$ & $57,86 \%$ & $35,12 \%$ & Colombia & 4 hijos & $2,13 \%$ & $12,77 \%$ & $31,91 \%$ & $53,19 \%$ \\
\hline & M. Ingresos N & $1,77 \%$ & $6,19 \%$ & $49,56 \%$ & $42,48 \%$ & & 5 hijos & $0,00 \%$ & $8,33 \%$ & $41,67 \%$ & $50,00 \%$ \\
\hline & M. Ingresos V & $0,00 \%$ & $10,53 \%$ & $36,84 \%$ & $52,63 \%$ & & 6 hijos & $0,00 \%$ & $10,34 \%$ & $48,28 \%$ & $41,38 \%$ \\
\hline & Otros & $0,20 \%$ & $6,11 \%$ & $57,64 \%$ & $36,05 \%$ & & 7 hijos & $0,00 \%$ & $18,18 \%$ & $9,09 \%$ & $72,73 \%$ \\
\hline & M ingresos I & $0,00 \%$ & $7,31 \%$ & $24,51 \%$ & $68,18 \%$ & & 80 más hijos & $0,00 \%$ & $5,56 \%$ & $27,78 \%$ & $66,67 \%$ \\
\hline & M. hgresos II & $0,00 \%$ & $4,22 \%$ & $27,71 \%$ & $68,07 \%$ & & & & & & \\
\hline Méxic & M hgresos III & $0,00 \%$ & $2,44 \%$ & $24,39 \%$ & $73,17 \%$ & & & & & & \\
\hline Then & M. Ingresos $N$ & $0,00 \%$ & $1,52 \%$ & $21,21 \%$ & $77,27 \%$ & & & & & & \\
\hline & M. hgresos V & $0,00 \%$ & $2,86 \%$ & $22,86 \%$ & $74,29 \%$ & & & & & & \\
\hline
\end{tabular}

Fuente: elaboración del autor a partir de wvs- 6. 
Tabla A.2. Continuación.

\begin{tabular}{|c|c|c|c|c|c|c|c|c|c|c|c|}
\hline Pais & Variable/Categoria & Infeliz & Poco Feliz & Feliz & Muy Feliz & Pais & Variable/Categoria & Infeliz & Poco Feliz & Feliz & Muy Feliz \\
\hline \multicolumn{6}{|c|}{ Hijos (Continuación) } & \multicolumn{6}{|c|}{ Orgullo Patrio } \\
\hline \multirow{9}{*}{ Brasil } & Sin hijos & $0,32 \%$ & $4,78 \%$ & $60,19 \%$ & $34,71 \%$ & \multirow{4}{*}{ Colombia } & Para nada & $0,00 \%$ & $0,00 \%$ & $0,00 \%$ & $100,00 \%$ \\
\hline & 1 hijo & $0,38 \%$ & $6,46 \%$ & $52,85 \%$ & $40,30 \%$ & & Muy poco & $0,00 \%$ & $16,22 \%$ & $45,95 \%$ & $37,84 \%$ \\
\hline & 2 hijos & $0,97 \%$ & $6,47 \%$ & $56,31 \%$ & $36,25 \%$ & & Levemente & $0,90 \%$ & $5,43 \%$ & $49,77 \%$ & $43,89 \%$ \\
\hline & 3 hijos & $2,05 \%$ & $5,64 \%$ & $57,95 \%$ & $34,36 \%$ & & Totalmente & $0,56 \%$ & $7,89 \%$ & $30,61 \%$ & $60,94 \%$ \\
\hline & 4 hjos & $0,00 \%$ & $14,14 \%$ & $58,59 \%$ & $27,27 \%$ & \multirow{4}{*}{ Brasil } & Para nada & $2,53 \%$ & $6,33 \%$ & $58,23 \%$ & $32,91 \%$ \\
\hline & 5 hijos & $3,57 \%$ & $7,14 \%$ & $53,57 \%$ & $35,71 \%$ & & Muy poco & $1,40 \%$ & $10,75 \%$ & $59,35 \%$ & $28,50 \%$ \\
\hline & 6 hijos & $0,00 \%$ & $10,00 \%$ & $70,00 \%$ & $20,00 \%$ & & Levemente & $0,54 \%$ & $6,70 \%$ & $62,86 \%$ & $29,89 \%$ \\
\hline & 7 hjos & $0,00 \%$ & $7,14 \%$ & $57,14 \%$ & $35,71 \%$ & & Tota'mente & $0,68 \%$ & $4,97 \%$ & $49,44 \%$ & $44,92 \%$ \\
\hline & 80 más hijos & $0,00 \%$ & $16,67 \%$ & $77,78 \%$ & $5,56 \%$ & \multirow{4}{*}{ México } & Para nada & $0,00 \%$ & $5,00 \%$ & $40,00 \%$ & $55,00 \%$ \\
\hline \multirow{9}{*}{ México } & Sin hijos & $0,22 \%$ & $3,79 \%$ & $25,84 \%$ & $\overline{70,16 \%}$ & & Muy poco & $0,00 \%$ & $15,94 \%$ & $33,33 \%$ & $50,72 \%$ \\
\hline & 1 hijo & $0,00 \%$ & $7,04 \%$ & $24,65 \%$ & $68,31 \%$ & & Levemente & $0,00 \%$ & $2,40 \%$ & $40,87 \%$ & $56,73 \%$ \\
\hline & 2 hijos & $1,03 \%$ & $4,64 \%$ & $26,03 \%$ & $68,30 \%$ & & Totalmente & $0,47 \%$ & $5,12 \%$ & $23,92 \%$ & $70,50 \%$ \\
\hline & 3 hijos & $0,00 \%$ & $3,46 \%$ & $29,56 \%$ & $66,98 \%$ & \multicolumn{6}{|c|}{ Satisfacción con Ingresos Hogar } \\
\hline & 4 hijos & $1,16 \%$ & $7,51 \%$ & $26,01 \%$ & $65,32 \%$ & \multirow{5}{*}{ Colombia } & NivelI & $4,08 \%$ & $22,45 \%$ & $29,59 \%$ & $43,88 \%$ \\
\hline & 5 hjos & $0,00 \%$ & $3,70 \%$ & $30,86 \%$ & $65,43 \%$ & & Nivel II & $1,52 \%$ & $17,42 \%$ & $34,85 \%$ & $46,21 \%$ \\
\hline & 6 hijos & $0,00 \%$ & $8,00 \%$ & $30,00 \%$ & $62,00 \%$ & & Nivel III & $0,30 \%$ & $8,06 \%$ & $38,51 \%$ & $53,13 \%$ \\
\hline & 7 hịos & $0,00 \%$ & $19,05 \%$ & $9,52 \%$ & $71,43 \%$ & & Nivel N & $0,00 \%$ & $3,44 \%$ & $37,10 \%$ & $59,46 \%$ \\
\hline & 80 más hijos & $0,00 \%$ & $10,53 \%$ & $21,05 \%$ & $68,42 \%$ & & NivelV & $0,28 \%$ & $4,55 \%$ & $27,84 \%$ & $67,33 \%$ \\
\hline \multicolumn{6}{|c|}{ Justificación Riqueza } & \multirow[b]{3}{*}{ Brasil } & Nivell & $2,72 \%$ & $9,52 \%$ & $63,27 \%$ & $24,49 \%$ \\
\hline \multirow{2}{*}{ Colombia } & haceptable & $0,66 \%$ & $10,56 \%$ & $34,98 \%$ & $53,80 \%$ & & Nivel II & $2,07 \%$ & $10,34 \%$ & $65,52 \%$ & $22,07 \%$ \\
\hline & Justificable & $0,59 \%$ & $6,86 \%$ & $33,99 \%$ & $58,57 \%$ & & Nivel III & $0,84 \%$ & $9,22 \%$ & $59,50 \%$ & $30,45 \%$ \\
\hline
\end{tabular}

Fuente: elaboración del autor a partir de wvs- 6. 
ECONOMÍA TEORÍA Y PRÁCTICA [ISSN: 2448-7481] • Nueva Época, año 27, número 50, enero-junio 2019

Oscar Mauricio Poveda Bermudez

\section{ANEXO III}

Tabla A.3. Coeficientes - Regresión Lineal.

\begin{tabular}{|c|c|c|c|c|c|c|c|}
\hline Variable/Categoria & Colombia & Brasil & México & Variable/Categoria & Colombia & Brasil & México \\
\hline \multicolumn{4}{|c|}{ Libertad de Elección (percepción) } & \multicolumn{4}{|c|}{ Hijos (Continuación) } \\
\hline \multirow[t]{2}{*}{ Nivel II } & $0.462^{*}$ & 0.0312 & -0.134 & 2 hijos & -0.0927 & $0.228^{*}$ & -0.154 \\
\hline & $(0.252)$ & $(0.123)$ & $(0.149)$ & & $(0.229)$ & $(0.128)$ & $(0.122)$ \\
\hline \multirow[t]{2}{*}{ Nivel IIII } & $0.530^{* *}$ & -0.0180 & -0.131 & \multicolumn{4}{|c|}{ Orgullo Patrio } \\
\hline & $(0.228)$ & $(0.0985)$ & $(0.0980)$ & Muy poco & $-0.578^{* * *}$ & 0.0269 & -0.166 \\
\hline \multirow[t]{2}{*}{ Nivel N } & $0.549 * *$ & 0.0277 & -0.117 & & $(0.161)$ & $(0.0960)$ & $(0.148)$ \\
\hline & $(0.224)$ & $(0.0985)$ & $(0.0899)$ & Levemente & $-0.524^{* * *}$ & 0.0413 & -0.0382 \\
\hline \multirow[t]{2}{*}{ Nivel V } & $0.648^{* * *}$ & 0.137 & -0.0386 & & $(0.130)$ & $(0.0463)$ & $(0.129)$ \\
\hline & $(0.223)$ & $(0.0961)$ & $(0.0866)$ & Totalmente & $-0.390^{* * *}$ & $0.153^{* * *}$ & 0.0340 \\
\hline \multicolumn{4}{|c|}{ Estado Civil } & & $(0.123)$ & $(0.0494)$ & $(0.125)$ \\
\hline \multirow[t]{2}{*}{ Casado } & 0.112 & $0.250^{* \star *}$ & $0.152^{*}$ & Satisfacción c & on Ingreso & s Hogar & \\
\hline & $(0.116)$ & $(0.0857)$ & $(0.0907)$ & Nivel I & $-0.331^{* *}$ & $-0.260^{* * * *}$ & $-0.123^{* *}$ \\
\hline \multicolumn{3}{|c|}{ Salud (Subjetivo) } & & & $(0.0928)$ & $(0.0664)$ & $(0.0605)$ \\
\hline \multirow[t]{2}{*}{ Regular } & $0.560 \cdots$ & 0.169 & $-0.289^{* *}$ & Nivel II & $-0.215^{\cdots}$ & $-0.256^{\ldots *}$ & $-0.232 *$ \\
\hline & $(0.191)$ & $(0.118)$ & $(0.0407)$ & & $(0.0783)$ & $(0.0593)$ & $(0.0661)$ \\
\hline \multirow[t]{2}{*}{ Bueno } & $0.774^{* * *}$ & $0.272^{* *}$ & $-0.143^{\star * *}$ & Nivel III & $-0.104^{* *}$ & $-0.157^{\star * *}$ & $-0.144^{* * *}$ \\
\hline & $(0.188)$ & $(0.114)$ & $(0.0296)$ & & $(0.0502)$ & $(0.0490)$ & $(0.0430)$ \\
\hline \multirow[t]{2}{*}{ Muy Bueno } & $0.833^{* \ldots *}$ & $0.542^{* \ldots *}$ & 0.0312 & Nivel N & -0.0631 & $-0.124^{\ldots *}$ & -0.0360 \\
\hline & $(0.190)$ & $(0.117)$ & $(0.123)$ & & $(0.0435)$ & $(0.0456)$ & $(0.0341)$ \\
\hline \multicolumn{4}{|c|}{ Religión (Importancia) } & \multicolumn{4}{|c|}{ Controles adicionales } \\
\hline \multirow[t]{2}{*}{ Muy importante } & $0.0471^{* *}$ & $0.0841^{* * *}$ & $0.0301^{*}$ & Nivel de ingresos & Si & Si & Si \\
\hline & $(0.0238)$ & $(0.0231)$ & $(0.0176)$ & Condición laboral & Si & $\mathrm{Si}$ & $\mathrm{Si}$ \\
\hline \multicolumn{4}{|c|}{ Familia (importancia) } & Consumo & Si & $\mathrm{Si}$ & Si \\
\hline \multirow[t]{2}{*}{ Poco importante } & -0.841 & $1.431^{\cdots}$ & 0.119 & Nivel educativo & Sí & $\mathrm{Si}$ & Si \\
\hline & $(0.675)$ & $(0.261)$ & $(0.120)$ & Edad & Sí & Si & Si \\
\hline \multirow[t]{2}{*}{ Importante } & 0.0380 & $1.786^{\star \cdots}$ & 0.322 & Género & Sí & $\mathrm{Si}$ & Si \\
\hline & $(0.509)$ & $(0.152)$ & $(0.254)$ & Justificación riqueza & Si & Si & Si \\
\hline \multirow[t]{3}{*}{ Muy importante } & 0.146 & $1.896^{* * *}$ & $0.612^{* \star *}$ & Tiempo Libre (importancia) & Si & $\mathrm{Si}$ & $\mathrm{Si}$ \\
\hline & $(0.507)$ & $(0.146)$ & $(0.226)$ & Trabajo (importancia) & Si & $\mathrm{Si}$ & $\mathrm{Si}$ \\
\hline & Hijos & & & $\mathrm{R}^{\wedge} 2$ & 0.166 & 0.222 & 0.131 \\
\hline \multirow[t]{2}{*}{1 hijo } & -0.0401 & $0.248^{*}$ & -0.144 & Raiz ECM & 0.620 & 0.577 & 0.571 \\
\hline & $(0.232)$ & $(0.131)$ & $(0.126)$ & Observaciones & 1324 & 1288 & 1802 \\
\hline
\end{tabular}

Fuente: elaboración del autor a partir de wVs- 6. Un asterisco indica que la estimación es estadísticamente significativa a un nivel de significancia del 10 por ciento. Dos asteriscos a una significancia del 5 por ciento y tres asteriscos a una significancia del 1 por ciento, El valor en paréntesis indica el error estándar. 
En esta realización, donde el nivel de felicidad reportado es transformado a variable binomial ${ }^{32}$ y definido como variable dependiente, las variables independientes se sustentan en la revisión de literatura expuesta previamente, de forma tal que, la forma funcional es:

$$
\begin{aligned}
\text { Felicidad }_{i}= & \beta_{0}+\beta_{1} \text { Nivel_ingresos }_{i}+\beta_{2} \text { Libertad_eleccion }_{i}+\beta_{3} \text { Condicion_laboral }_{i} \\
& +\beta_{4} \text { Estado_civil }_{i}+\beta_{5} \text { Consumo }_{i}+\beta_{6} \text { Nivel_educativo }_{i}+\beta_{7} \text { Salud }_{i}+\beta_{8} \text { Hijos }_{i} \\
& +\beta_{9} \text { Religión }_{i}+\beta_{10} \text { Familia }_{i}+\beta_{11} \text { Edad }_{i}+\beta_{12} \text { Orgullo_patrio }_{i}+\beta_{13} \text { Género }_{i} \\
& +\beta_{14} \text { Tiempo_libre }_{i}+\beta_{15} \text { Satisfaccion_ingresos_hogar }_{i}+\beta_{16} \text { Trabajo }_{i} \\
& +\beta_{17} \text { Justificar_riqueza }_{i}+\varepsilon_{i}
\end{aligned}
$$

Además, se define un sujeto base de comparación idéntico al definido para la metodología logística ordenada; se encuentra que los colombianos elevan su probabilidad de reportar ser felices a medida que aumenta su percepción de libertad de elección. Lo anterior es apreciable, ya que las personas pertenecientes al nivel II y al nivel V de libertad de elección tienen 46 y 64.8 puntos porcentuales más de probabilidad de reportar ser felices en comparación con alguien con nula libertad de elección, respectivamente.

Lo mismo se repite para Brasil respecto al estado de salud, donde las personas con un estado de salud bueno y muy bueno tienen 27.2 y 54.2 puntos porcentuales más de probabilidad de reportar ser feliz, respectivamente, ambos en comparación con alguien con un mal estado de salud. Para el caso de México considerar a la familia como muy importante, eleva la probabilidad de reportar ser feliz en 61.2, en comparación con alguien quien considere a la familia como nada importante.

Finalmente, indicadores de bondad de ajuste como el R-cuadrado no ofrece un buen indicio de ajuste puesto que las variables explicativas incluidas en el modelo no explican ni en una tercera parte a la variable dependiente, para ningún país. De igual forma la raíz del error cuadrático medio, cuyo resultado indica las unidades en las que falla la predicción de la especificación, en términos de la variable dependiente, tampoco ofrece un criterio acertado para determinar la conveniencia de esta metodología.

${ }^{32}$ Tomará los valores de uno si se es feliz y cero si no se es feliz ( $1=$ feliz, $0=$ infeliz). 
ECONOMÍA TEORÍA y PRÁCTICA [ISSN: 2448-7481] • Nueva Época, año 27, número 50, enero-junio 2019 Oscar Mauricio Poveda Bermudez

ANEXO IV

Tabla A.4. Efectos marginales - Metodología logística multinomial.

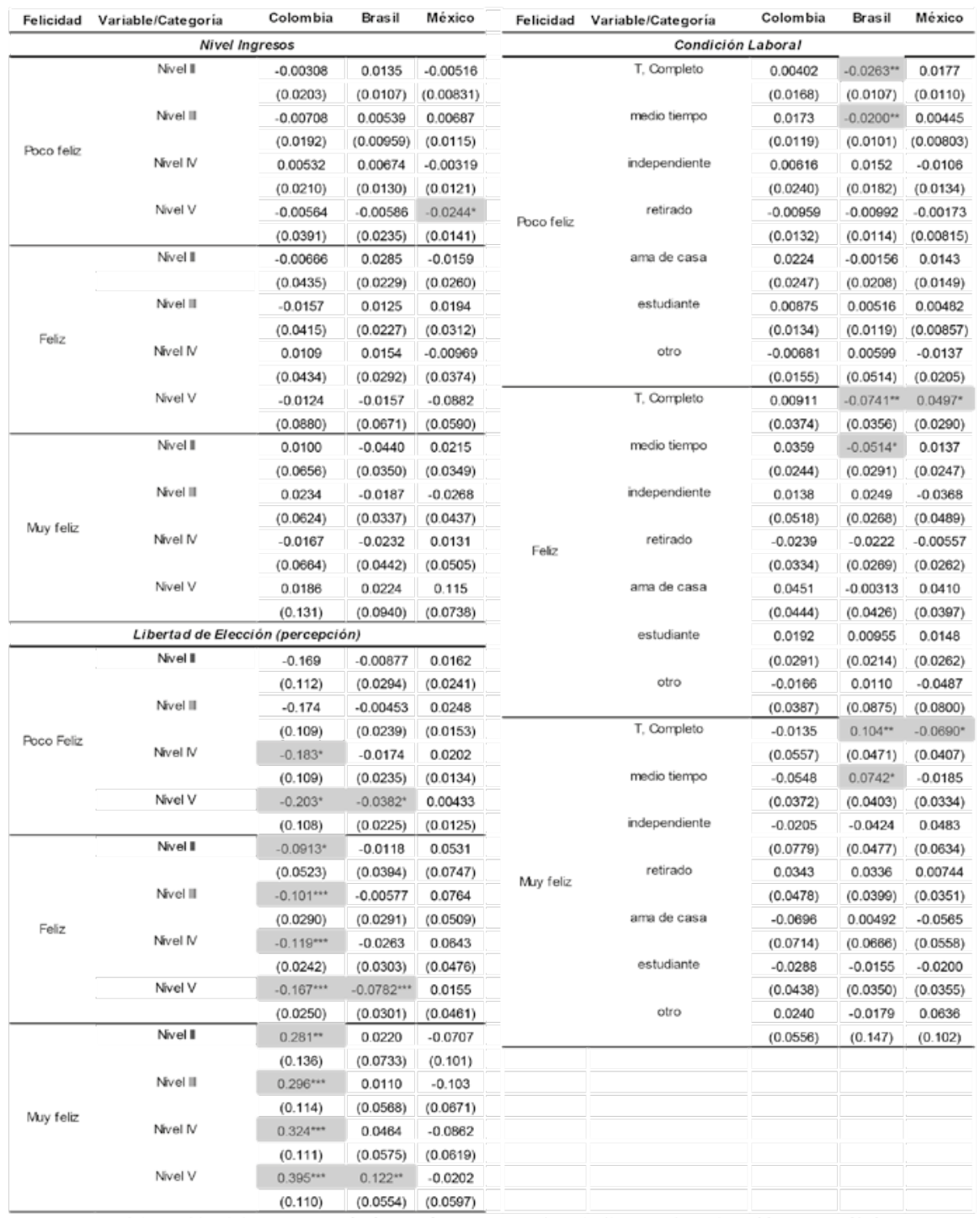

Fuente: elaboración del autor a partir de wVs- 6. Un asterisco indica que la estimación es estadísticamente significativa a un nivel de significancia del 10 por ciento. Dos asteriscos a una significancia del 5 por ciento y tres asteriscos a una significancia del 1 por ciento. El valor en paréntesis indica el error estándar. 
Tabla A.4. Continuación.

\begin{tabular}{|c|c|c|c|c|c|c|c|c|c|}
\hline Felicidad & Variable/Categoria & Colombia & Brasil & México & Felicidad & Variable/Categoria & Colombia & Brasil & México \\
\hline & \multicolumn{2}{|c|}{ Estado Civil } & & & \multicolumn{5}{|c|}{ Nivel Educativo } \\
\hline \multirow{10}{*}{ Poco Felz } & Casado & 0.0159 & $0.0244^{-1}$ & $0.0166^{* *}$ & \multirow{14}{*}{ Poco Feliz } & \multirow[t]{2}{*}{ Primaria completa } & 0.00447 & 0.00674 & -0.00669 \\
\hline & \multirow{3}{*}{ Union Libre } & $(0.0103)$ & $(0.00982)$ & $(0.00686)$ & & & $(0.0144)$ & $(0.0119)$ & $(0.0104)$ \\
\hline & & 0.0304 & $0.0539^{* \prime}$ & $0.0316^{*}$ & & \multirow[t]{2}{*}{ Socun incomp } & $0.0422^{*}$ & 0.0787 & -0.000943 \\
\hline & & $(0.0308)$ & $(0.0254)$ & $(0.0181)$ & & & $(0.0232)$ & $(0.0617)$ & $(0.0131)$ \\
\hline & \multirow[t]{2}{*}{ Dvorciado } & 0.0274 & $0.0660^{\cdots \cdots}$ & $0.0325^{*}$ & & \multirow[t]{2}{*}{ Secun completa } & $0.0379^{\circ}$ & 0.00618 & -0.00166 \\
\hline & & $(0.0190)$ & $(0.0252)$ & $(0.0150)$ & & & $(0.0209)$ & $(0.0213)$ & $(0.0103)$ \\
\hline & \multirow[t]{2}{*}{ Separado } & 0.0461 & $0.0417^{*}$ & 0.00791 & & \multirow[t]{2}{*}{ Media voc, hcomp } & 0.0205 & -0.0118 & -0.00468 \\
\hline & & $(0.0417)$ & $(0.0242)$ & $(0.0126)$ & & & $(0.0156)$ & $(0.0112)$ & $(0.0126)$ \\
\hline & \multirow[t]{2}{*}{ Viudo } & 0.0111 & $0.0289 \cdots$ & $0.0306^{\cdots *}$ & & \multirow[t]{2}{*}{ Modia voc, Comp } & 0.00918 & 0.0113 & -0.00484 \\
\hline & & $(0.0127)$ & $(0.00971)$ & $(0.0110)$ & & & $(0.0135)$ & $(0.0104)$ & $(0.0108)$ \\
\hline \multirow{10}{*}{ Feliz } & \multirow[t]{2}{*}{ Casado } & 0.0372 & $0.0662^{\cdots \cdots}$ & $0.0543^{\cdots *}$ & & \multirow[t]{4}{*}{ Universidad incomp } & 0.00867 & $-0.0227^{*}$ & -0.0185 \\
\hline & & $(0.0235)$ & $(0.0231)$ & $(0.0208)$ & & & $(0.0153)$ & $(0.0117)$ & $(0.0128)$ \\
\hline & \multirow[t]{2}{*}{ Union Libre } & 0.0648 & $0.106^{\cdots \cdots}$ & $0.0931^{*}$ & & & $0.0319^{\circ}$ & 0.00563 & -0.00608 \\
\hline & & $(0.0544)$ & $(0.0261)$ & $(0.0432)$ & & & $(0.0172)$ & $(0.0126)$ & $(0.0118)$ \\
\hline & \multirow[t]{2}{*}{ Divorciado } & $0.0595^{\circ}$ & $0.114^{\cdots \cdots}$ & $0.0950^{\prime \cdots *}$ & \multirow{14}{*}{ Foliz } & Primaria completa & 0.0118 & 0.0140 & -0.0201 \\
\hline & & $(0.0358)$ & $(0.0218)$ & $(0.0351)$ & & & $(0.0377)$ & $(0.0241)$ & $(0.0308)$ \\
\hline & \multirow[t]{2}{*}{ Separado } & 0.0892 & $0.0929^{\prime \cdots}$ & 0.0276 & & Secun incormp & $0.0875^{*}$ & $0.0726^{\cdots *}$ & -0.00271 \\
\hline & & $(0.0592)$ & $(0.0332)$ & $(0.0419)$ & & & $(0.0420)$ & $(0.0171)$ & $(0.0376)$ \\
\hline & Viudo & 0.0268 & $0.0744 \cdots$ & $0.0907^{* \cdots}$ & & Secun completa & $0.0807^{* *}$ & 0.0129 & -0.00481 \\
\hline & & $(0.0299)$ & $(0.0216)$ & $(0.0277)$ & & & $(0.0405)$ & $(0.0420)$ & $(0.0295)$ \\
\hline \multirow{10}{*}{ My Feliz } & \multirow[t]{2}{*}{ Casado } & -0.0545 & $.0 .0940^{\cdots}$ & $.0 .0723^{\cdots}$ & & Media voc, incomp & 0.0485 & -0.0311 & -0.0139 \\
\hline & & $(0.0345)$ & $(0.0337)$ & $(0.0279)$ & & & $(0.0362)$ & $(0.0309)$ & $(0.0374)$ \\
\hline & Union Libre & -0.0980 & $-0.167^{\cdots}$ & $.0 .127^{* \prime}$ & & Media voc, Comp & 0.0234 & 0.0221 & -0.0143 \\
\hline & & $(0.0879)$ & $(0.0533)$ & $(0.0625)$ & & & $(0.0347)$ & $(0.0203)$ & $(0.0315)$ \\
\hline & Dvorciado & -0.0894 & $-0.190^{\cdots \cdots}$ & $-0.130^{\circ *}$ & & Universidad incomp & 0.0222 & $-0.0698^{*}$ & -0.0609 \\
\hline & & $(0.0562)$ & $(0.0476)$ & $(0.0509)$ & & & $(0.0390)$ & $(0.0415)$ & $(0.0424)$ \\
\hline & Separado & -0.140 & $-0.141^{* *}$ & -0.0361 & & Universidad comp & $0.0704^{\circ}$ & 0.0118 & -0.0182 \\
\hline & & $(0.105)$ & $(0.0800)$ & $(0.0555)$ & & & $(0.0371)$ & $(0.0258)$ & $(0.0350)$ \\
\hline & Viudo & -0.0389 & $-0.107^{\cdots \cdots}$ & $-0.124 \cdots$ & & Primaria complota & -0.0166 & -0.0217 & 0.0274 \\
\hline & & $(0.0437)$ & $(0.0320)$ & $(0.0390)$ & & & $(0.0533)$ & $(0.0378)$ & $(0.0421)$ \\
\hline & & & & & & Secun incorrp & $-0.134^{* *}$ & $-0.165^{* *}$ & 0.00374 \\
\hline & $C_{0}=h g$ & 0.00975 & 0.000119 & -0.000497 & & & $(0.0665)$ & $(0.0834)$ & $(0.0517)$ \\
\hline Pocofelz & & $(0.0102)$ & $(0.00907)$ & $(0.00670)$ & & Secun completa & $-0.122^{\circ}$ & -0.0200 & 0.00662 \\
\hline & Cons $>\mathrm{hg}$ & 0.00293 & 0.000484 & 0.00544 & & & $(0.0628)$ & $(0.0665)$ & $(0.0406)$ \\
\hline & & $(0.0111)$ & $(0.0109)$ & $(0.00735)$ & My Felz & Media voc, incomp & -0.0708 & 0.0446 & 0.0189 \\
\hline & $C_{n}=n g$ & 0.0217 & 0.000256 & .0 .00156 & & & $(0.0529)$ & $(0.0435)$ & $(0.0511)$ \\
\hline Feliz & & $(0.0233)$ & $(0.0195)$ & $(0.0210)$ & & Media voc, Comp & -0.0334 & -0.0351 & 0.0196 \\
\hline . & Cons $>\mathrm{hg}$ & 0.00684 & 0.00104 & 0.0164 & & & $(0.0493)$ & $(0.0320)$ & $(0.0432)$ \\
\hline & & $(0.0259)$ & $(0.0234)$ & $(0.0224)$ & & Universidad incomp & -0.0316 & $0.0957^{*}$ & 0.0809 \\
\hline & $C_{0}=h g$ & -0.0324 & -0.000392 & 0.00210 & & & $(0.0556)$ & $(0.0544)$ & $(0.0561)$ \\
\hline Myy feliz & & $(0.0343)$ & $(0.0300)$ & $(0.0283)$ & & Universidad comp & $-0.105^{*}$ & -0.0183 & 0.0248 \\
\hline & Cons > hg & -0.0100 & -0.00160 & -0.0223 & & & $(0.0554)$ & $(0.0402)$ & $(0.0477)$ \\
\hline
\end{tabular}

Fuente: elaboración del autor a partir de wvs- 6. Un asterisco indica que la estimación es estadísticamente significativa a un nivel de significancia del 10 por ciento. Dos asteriscos a una significancia del 5 por ciento y tres asteriscos a una significancia del 1 por ciento. El valor en paréntesis indica el error estándar. 
ECONOMÍA TEORÍA y PRÁCTICA [ISSN: 2448-7481] • Nueva Época, año 27, número 50, enero-junio 2019 Oscar Mauricio Poveda Bermudez

Tabla A.4. Continuación.

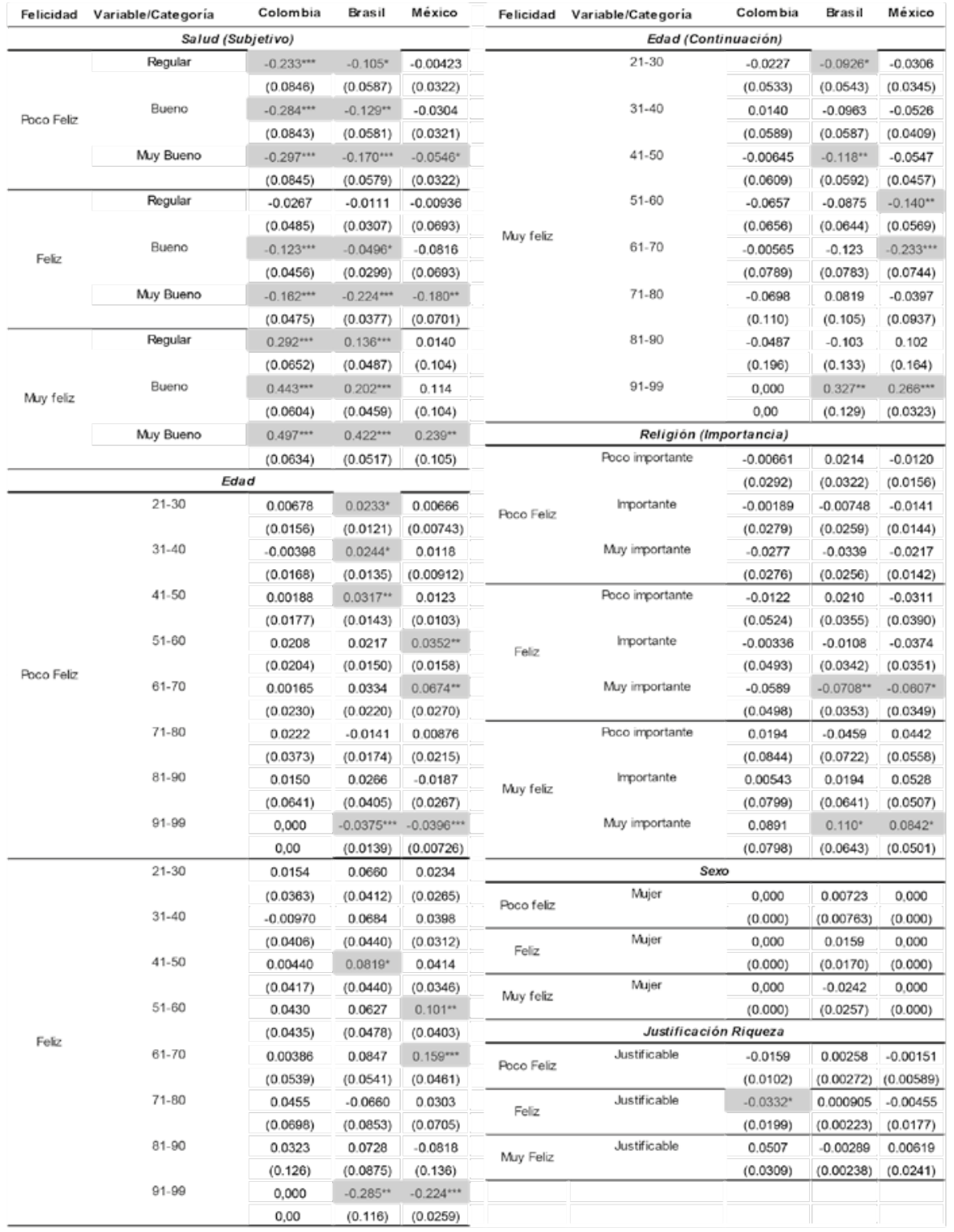

Fuente: elaboración del autor a partir de wVs- 6. Un asterisco indica que la estimación es estadísticamente significativa a un nivel de significancia del 10 por ciento. Dos asteriscos a una significancia del 5 por ciento y tres asteriscos a una significancia del 1 por ciento. El valor en paréntesis indica el error estándar. 
Tabla A.4. Continuación.

\begin{tabular}{|c|c|c|c|c|c|c|c|c|c|}
\hline Felicidad & Variable/Categoria & Colombia & Brasil & Móxico & Felicidad & Variable/Categoria & Colombia & Brasill & México \\
\hline \multicolumn{4}{|c|}{ Tiempo Iibre (importancia) } & & \multicolumn{5}{|c|}{ Satisfacción con Ingresos Hogar (Continuación) } \\
\hline \multirow{6}{*}{ Poco fellz } & Poco importante & 0.0345 & 0.0388 & $0.0382^{* *}$ & \multirow{8}{*}{ Muy Felz } & \multirow[t]{2}{*}{ Nivel I } & 0.0753 & -0.0136 & -0.0832 \\
\hline & & $(0.0318)$ & $(0.0314)$ & $(0.0159)$ & & & $(0.0737)$ & $(0.0431)$ & $(0.0544)$ \\
\hline & importante & 0.0374 & 0.0108 & $0.0268^{\circ}$ & & \multirow[t]{2}{*}{ Nivel III } & $0.130 *$ & 0.0535 & -0.0290 \\
\hline & \multirow{3}{*}{ Muy importante } & $(0.0300)$ & $(0.0274)$ & $(0.0139)$ & & & $(0.0652)$ & (0.0391) & $(0.0444)$ \\
\hline & & 0.0153 & 0.00240 & 0.0160 & & \multirow[t]{2}{*}{ Nivel $N$} & $0.170 \cdots$ & $0.0771^{*}$ & 0.0537 \\
\hline & & $(0.0295)$ & $(0.0277)$ & $(0.0135)$ & & & $(0.0650)$ & $(0.0412)$ & $(0.0420)$ \\
\hline \multirow{6}{*}{ Foliz } & \multirow[t]{2}{*}{ Poco importante } & 0.0863 & 0.0698 & $0.125^{* *}$ & & \multirow[t]{2}{*}{ Nvel V } & $0.231^{\cdots}$ & $0.173^{\cdots}$ & $0.104^{* *}$ \\
\hline & & $(0.0946)$ & $(0.0782)$ & $(0.0620)$ & & & $(0.0660)$ & $(0.0455)$ & $(0.0433)$ \\
\hline & inportante & 0.0919 & 0.0268 & 0.0948 & \multicolumn{4}{|c|}{ Mijos } & \\
\hline & & $(0.0925)$ & $(0.0773)$ & $(0.0599)$ & \multirow{16}{*}{ Poco Feliz } & 1 hijo & -0.0135 & 0.000 & $0.0162^{*}$ \\
\hline & Muy importante & 0.0433 & 0.00660 & 0.0614 & & & $(0.0127)$ & 0,00 & $(0.00940)$ \\
\hline & & $(0.0922)$ & $(0.0783)$ & $(0.0588)$ & & 2 hijos & 0.000347 & 0,000 & $0.0187^{*}$ \\
\hline \multirow{6}{*}{ Mry feliz } & \multirow[t]{2}{*}{ Poco importante } & -0.124 & -0.115 & $-0.166^{* *}$ & & & $(0.0138)$ & 0.00 & (0.00973) \\
\hline & & $(0.129)$ & $(0.112)$ & $(0.0783)$ & & 3 hilos & 0.00662 & 0.000 & $0.0192^{*}$ \\
\hline & Inportante & -0.133 & -0.0391 & $-0.124^{*}$ & & & $(0.0164)$ & 0,00 & $(0.0105)$ \\
\hline & & $(0.125)$ & $(0.108)$ & $(0.0747)$ & & 4 hijos & 0.0108 & 0,000 & 0.0156 \\
\hline & Muy importante & -0.0599 & -0.00934 & -0.0787 & & & $(0.0216)$ & 0.00 & $(0.0126)$ \\
\hline & & $(0,124)$ & $(0.110)$ & $(0.0732)$ & & 5 hijos & 0.0114 & 0,000 & 0.00991 \\
\hline & Trabajo & rtancia) & & & & & $(0.0251)$ & 0,00 & $(0.0152)$ \\
\hline & Poco importante & -0.0395 & 0.00258 & $-0.0713^{*}$ & & 6 hijos & 0.00813 & 0.000 & 0.00842 \\
\hline & & $(0.0773)$ & $(0.00272)$ & $(0.0422)$ & & & $(0.0290)$ & 0.00 & $(0.0156)$ \\
\hline Poco Felizz & Importante & -0.0127 & 0.000905 & -0.0649 & & 7 hijos & -0.0260 & 0.000 & -0.000473 \\
\hline & & $(0.0638)$ & $(0.00223)$ & $(0.0403)$ & & & $(0.0440)$ & 0.00 & $(0.0258)$ \\
\hline & Muy importante & -0.0306 & -0.00289 & $-0.0702^{*}$ & & 8 o mas hijos & $-0.0410^{*}$ & 0,000 & -0.00263 \\
\hline & & $(0.0635)$ & $(0.00238)$ & $(0.0396)$ & & & $(0.0249)$ & 0,00 & (0.0185) \\
\hline & Poco importante & -0.0810 & 0.0170 & $-0.143^{* *}$ & & 1 hijo & -0.0328 & 0,000 & $0.0516^{\circ}$ \\
\hline & & $(0.153)$ & $(0.0179)$ & $(0.0669)$ & & & $(0.0307)$ & 0,00 & $(0.0295)$ \\
\hline Feliz & Importante & -0.0216 & 0.00609 & $-0.124^{*}$ & & 2 hijos & 0.000765 & 0.000 & $0.0588^{*}$ \\
\hline reve & & $(0.0997)$ & $(0.0153)$ & (0.0537) & & & $(0.0305)$ & 0,00 & $(0.0307)$ \\
\hline & Muy importante & -0.0589 & -0.0207 & $-0.140^{\cdots *}$ & & 3 hijos & 0.0140 & 0,000 & $0.0599^{*}$ \\
\hline & & $(0.0994)$ & $(0.0149)$ & $(0.0487)$ & & & $(0.0347)$ & 0,00 & $(0.0331)$ \\
\hline & Poco importante & 0.124 & -0.0482 & $0.221^{*}$ & & 4 hijos & 0.0223 & 0,000 & 0.0502 \\
\hline & & $(0.236)$ & $(0.0533)$ & $(0.110)$ & Feliz & & $(0.0431)$ & 0,00 & $(0.0391)$ \\
\hline Mry feliz & inportante & 0.0355 & -0.0187 & $0.195^{* *}$ & & 5 hijos & 0.0234 & 0,000 & 0.0331 \\
\hline & & $(0.170)$ & $(0.0487)$ & $(0.0967)$ & & & $(0.0493)$ & 0.00 & $(0.0490)$ \\
\hline & Muy importante & 0.0924 & 0.0807 & $0.217^{* *}$ & & 6 hijos & 0.0170 & 0,000 & 0.0285 \\
\hline & & $(0.169)$ & $(0.0510)$ & $(0.0916)$ & & & $(0.0588)$ & 0.00 & $(0.0510)$ \\
\hline & Satisfacción c & gresos Hog & & & & 7 hijos & -0.0691 & 0,000 & -0.00172 \\
\hline & Nivel II & -0.0309 & 0.00592 & 0.0237 & & & $(0.137)$ & 0,00 & $(0.0936)$ \\
\hline & & $(0.0316)$ & $(0.0187)$ & (0.0158) & & 8 o mús hijos & -0.122 & 0,000 & -0.00971 \\
\hline & Nivel al & $-0.0493^{*}$ & -0.0194 & 0.00763 & & & $(0.0891)$ & 0,00 & $(0.0691)$ \\
\hline Poco Fellz & & $(0.0288)$ & (0.0152) & (0.0115) & & 1 hijo & 0,048 & 0,017 & $-0.0692^{*}$ \\
\hline 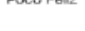 & Nivel N & $-0.0613^{* *}$ & $-0.0263^{\circ}$ & -0.0127 & & & $(0,04)$ & $(0,02)$ & $(0.0395)$ \\
\hline & & $(0.0288)$ & $(0.0154)$ & $(0.0104)$ & & 2 hilos & $-0,001$ & 0,006 & $-0.0791^{\circ}$ \\
\hline & Nivel V & $-0.0767 \cdots$ & $-0.0478 \cdots$ & $-0.0230^{* *}$ & & & $(0,05)$ & $(0,02)$ & $(0.0411)$ \\
\hline & & $(0.0286)$ & $(0.0150)$ & $(0.0105)$ & & 3 hijos & $-0,021$ & -0.021 & $-0.0807^{*}$ \\
\hline & Nivel II & -0.0413 & 0.00670 & 0.0575 & & & $(0,05)$ & $(0,01)$ & $(0.0443)$ \\
\hline & & $(0.0395)$ & $(0.0214)$ & $(0.0375)$ & & 4 hijos & -0.034 & 0,029 & -0.0671 \\
\hline & Nivel in & $-0.0759^{\circ-}$ & -0.0312 & 0.0207 & Muy Felz & & $(0,07)$ & $(0,03)$ & $(0.0526)$ \\
\hline Feliz & & $(0.0342)$ & $(0.0219)$ & $(0.0319)$ & & 5 hijos & $-0,036$ & 0,012 & -0.0439 \\
\hline & Nivel N & $-0.104 \cdots$ & $-0.0469^{\circ}$ & -0.0400 & & & $(0,08)$ & $(0,03)$ & $(0.0653)$ \\
\hline & & $(0.0344)$ & $(0.0240)$ & $(0.0308)$ & & 6 hijos & $-0,026$ & -0.057 & -0.0376 \\
\hline & Nivel V & $-0.147^{\cdots}$ & $-0.119^{\cdots}$ & $-0.0789^{*}$ & & & $(0,09)$ & $(0,03)$ & $(0.0679)$ \\
\hline & & $(0.0366)$ & $(0.0306)$ & $(0.0323)$ & & 7 hijos & 0.097 & -0.048 & 0.00223 \\
\hline & & & & & & & $(0,19)$ & $(0.0533)$ & $(0.122)$ \\
\hline & & & & & & 80 más hijos & 0.166 & -0.0187 & 0.0126 \\
\hline & & & & & & & $(0.115)$ & $(0.0487)$ & $(0.0891)$ \\
\hline
\end{tabular}

Fuente: elaboración del autor a partir de wVs- 6 . Un asterisco indica que la estimación es estadísticamente significativa a un nivel de significancia del 10 por ciento. Dos asteriscos a una significancia del 5 por ciento y tres asteriscos a una significancia del 1 por ciento. El valor en paréntesis indica el error estándar. 
Esta especificación, donde la variable explicada - nivel de felicidad reportado- tiene las cuatro categorías originales y se define un sujeto base de comparación idéntico al definido en la metodología logística ordenada, indica que la probabilidad de reportar ser feliz o muy feliz aumenta a medida que aumenta la libertad de elección en el caso colombiano. Al respecto, las personas con una leve libertad de elección (nivel II) tienen un incremento de 28.1 puntos porcentuales en la probabilidad de reportar ser feliz en comparación con alguien con nula libertad de elección, esta probabilidad aumenta en 39.5 puntos porcentuales para las personas con plena libertad de elección.

El estado de salud se asocia positivamente con la probabilidad de reportar ser feliz en Colombia y Brasil, ya que las personas con un buen estado de salud tienen un incremento en la probabilidad de reportar ser muy felices de 49.7 puntos porcentuales para Colombia y de 42.2 puntos para Brasil; ambos en comparación con alguien con un mal estado de salud.

Estar satisfecho con los ingresos del hogar aumenta la probabilidad de reportar ser muy feliz en los tres países de estudio. Esto se evidencia en que las personas totalmente satisfechas con este nivel tienen 23.1, 17.3 y 10.4 puntos porcentuales más de probabilidad de reportar ser muy felices en comparación con alguien totalmente insatisfecho con los ingresos del hogar para Colombia, Brasil y México, respectivamente. 


\section{ANEXO V}

Tabla A.5. Coeficientes - Metodología logística ordenada.

\begin{tabular}{|c|c|c|c|c|c|c|c|}
\hline \multirow{2}{*}{\multicolumn{2}{|c|}{$\begin{array}{r}\text { Variable/Categoría Colombia } \\
\text { Nivel Ingresos } \\
\end{array}$}} & \multirow{2}{*}{ Brasil } & \multirow[t]{2}{*}{ México } & \multirow{2}{*}{\multicolumn{2}{|c|}{$\begin{array}{r}\text { Variable/Categoria Colombia } \\
\text { Estado Civil } \\
\end{array}$}} & \multirow{3}{*}{$\begin{array}{l}\text { Brasil } \\
0.555^{* * *}\end{array}$} & \multirow[t]{2}{*}{ México } \\
\hline & & & & & & & \\
\hline \multirow[t]{2}{*}{ Nivel II } & 0,04 & $-0,490^{*}$ & 0,06 & Casado & 0,22 & & $0,642^{* * *}$ \\
\hline & $(0,31)$ & $(0,29)$ & $(0,14)$ & & $(0,21)$ & $(0,20)$ & $(0,20)$ \\
\hline \multirow[t]{2}{*}{ Nivel III } & 0,08 & $-0,24$ & 0,01 & Union Libre & $-0,05$ & 0,07 & 0,23 \\
\hline & $(0,29)$ & $(0,28)$ & $(0,17)$ & & $(0,19)$ & $(0,21)$ & $(0,21)$ \\
\hline \multirow[t]{2}{*}{ Nivel N } & $-0,09$ & 0,01 & 0,15 & Divorciado & $-0,16$ & $-0,41$ & $-0,04$ \\
\hline & $(0,31)$ & $(0,36)$ & $(0,21)$ & & $(0,41)$ & $(0,37)$ & $(0,35)$ \\
\hline \multirow[t]{2}{*}{ Nivel V } & 0,05 & 0,26 & 0,31 & Separado & $-0,17$ & $-0,47$ & $-0,06$ \\
\hline & $(0,61)$ & $(0,65)$ & $(0,35)$ & & $(0,29)$ & $(0,32)$ & $(0,29)$ \\
\hline \multicolumn{4}{|c|}{ Libertad de Elección (percepción) } & Viudo & $-0,31$ & $-0,09$ & 0,46 \\
\hline \multirow[t]{2}{*}{ Nivel II } & $1,449^{*}$ & 0,17 & $-0,35$ & & $(0,53)$ & $(0,38)$ & $(0,34)$ \\
\hline & $(0,78)$ & $(0,43)$ & $(0,54)$ & & Consumo & & \\
\hline \multirow[t]{2}{*}{ Nivel III } & $1,562^{* *}$ & 0,06 & $-0,55$ & Con $=$ lng & $-0,20$ & $-0,02$ & 0,02 \\
\hline & $(0,71)$ & $(0,34)$ & $(0,37)$ & & $(0,16)$ & $(0,16)$ & $(0,15)$ \\
\hline \multirow[t]{2}{*}{ Nivel N } & $1,674^{\star *}$ & 0,26 & $-0,46$ & Cons $>$ Ing & $-0,09$ & $-0,01$ & $-0,11$ \\
\hline & $(0,70)$ & $(0,34)$ & $(0,35)$ & & $(0,18)$ & $(0,20)$ & $(0,16)$ \\
\hline \multirow[t]{2}{*}{ Nivel V } & $2,001^{* * *}$ & $0,630^{*}$ & $-0,11$ & \multicolumn{4}{|c|}{ Nivel Educativo } \\
\hline & $(0,69)$ & $(0,33)$ & $(0,34)$ & \multirow[t]{2}{*}{ Primaria completa } & $-0,03$ & $-0,13$ & 0,14 \\
\hline \multicolumn{4}{|c|}{ Condición Laboral } & & $(0,26)$ & $(0,21)$ & $(0,22)$ \\
\hline \multirow[t]{2}{*}{ T, Completo } & 0,14 & 0,08 & 0,11 & Secun incomp & $-0,572^{\star}$ & $-1,097^{\star}$ & 0,02 \\
\hline & $(0,20)$ & $(0,20)$ & $(0,19)$ & & $(0,31)$ & $(0,63)$ & $(0,27)$ \\
\hline \multirow[t]{2}{*}{ medio tiempo } & 0,12 & $0,597^{\star \star}$ & $-0,24$ & Secun completa & $-0,540^{*}$ & $-0,15$ & 0,03 \\
\hline & $(0,29)$ & $(0,27)$ & $(0,23)$ & & $(0,30)$ & $(0,38)$ & $(0,21)$ \\
\hline \multirow[t]{2}{*}{ independiente } & $-0,10$ & $0,511^{* *}$ & 0,00 & Media voc, Incomp & $-0,30$ & 0,21 & 0,11 \\
\hline & $(0,21)$ & $(0,25)$ & $(0,20)$ & & $(0,26)$ & $(0,23)$ & $(0,27)$ \\
\hline \multirow[t]{2}{*}{ retirado } & 0,02 & $-0,13$ & 0,36 & Media voc, Comp & $-0,13$ & $-0,23$ & 0,10 \\
\hline & $(0,38)$ & $(0,31)$ & $(0,39)$ & & $(0,24)$ & $(0,18)$ & $(0,23)$ \\
\hline \multirow[t]{2}{*}{ ama de casa } & 0,31 & 0,29 & 0,14 & Universidad incomp & $-0,08$ & $0,480^{*}$ & 0,42 \\
\hline & $(0,25)$ & $(0,25)$ & $(0,21)$ & & $(0,27)$ & $(0,28)$ & $(0,32)$ \\
\hline \multirow[t]{2}{*}{ estudiante } & $-0,23$ & 0,09 & $-0,18$ & Universidad comp & $-0,461^{*}$ & $-0,17$ & 0,12 \\
\hline & $(0,34)$ & $(0,38)$ & $(0,29)$ & & $(0,27)$ & $(0,23)$ & $(0,25)$ \\
\hline \multirow[t]{2}{*}{ otro } & 0,26 & $-0,07$ & 0,45 & & & & \\
\hline & $(0,28)$ & $(0,88)$ & $(0,63)$ & & & & \\
\hline
\end{tabular}

Fuente: elaboración del autor a partir de wvs- 6. Un asterisco indica que la estimación es estadísticamente significativa a un nivel de significancia del 10 por ciento. Dos asteriscos a una significancia del 5 por ciento y tres asteriscos a una significancia del 1 por ciento. El valor en paréntesis indica el error estándar. 
ECONOMÍA TEORÍA Y PRÁCTICA [ISSN: 2448-7481] • Nueva Época, año 27, número 50, enero-junio 2019

Tabla A.5. Continuación.

\begin{tabular}{|c|c|c|c|c|c|c|c|}
\hline Variable/Categoría & Colombia & Brasil & México & Variable/Categoría & Colombia & Brasil & México \\
\hline \multicolumn{4}{|c|}{ Salud (Subjetivo) } & \multicolumn{3}{|c|}{ Sexo } & \\
\hline Regular & $1,562^{* * *}$ & $1,037^{\star \star}$ & 0,09 & Mujer & 0,19 & $-0,28$ & $-0,326^{* *}$ \\
\hline \multirow{3}{*}{ Bueno } & $(0,52)$ & $(0,48)$ & $(0,48)$ & & $(0,38)$ & $(0,30)$ & $(0,14)$ \\
\hline & $2,191^{* * *}$ & $1,381^{* * *}$ & 0,58 & \multicolumn{4}{|c|}{ M ujer Ingresos } \\
\hline & $(0,51)$ & $(0,47)$ & $(0,47)$ & $\mathrm{M}$, Ingresos \| & $-0,31$ & 0,40 & $-0,13$ \\
\hline \multirow[t]{3}{*}{ Muy Bueno } & $2,419^{* * *}$ & $2,453^{* * *}$ & $1,286^{* \cdots}$ & & $(0,44)$ & $(0,38)$ & $(0,28)$ \\
\hline & $(0,52)$ & $(0,49)$ & $(0,48)$ & \multirow[t]{2}{*}{ M, Ingresos III } & $-0,37$ & 0,20 & 0,36 \\
\hline & Edad & & & & $(0,41)$ & $(0,35)$ & $(0,33)$ \\
\hline \multirow[t]{2}{*}{$21-30$} & $-0,22$ & $-0,532^{*}$ & $-0,18$ & $\mathrm{M}$, Ingresos $\mathrm{N}$ & 0,08 & $-0,25$ & 0,20 \\
\hline & $(0,25)$ & $(0,28)$ & $(0,20)$ & & $(0,44)$ & $(0,45)$ & $(0,41)$ \\
\hline \multirow[t]{2}{*}{$31-40$} & $-0,11$ & $-0,518^{*}$ & $-0,31$ & $\mathrm{M}$, Ingresos V & $-0,42$ & $-0,26$ & $-0,83$ \\
\hline & $(0,28)$ & $(0,31)$ & $(0,23)$ & & $(0,89)$ & $(0,90)$ & $(0,67)$ \\
\hline \multirow[t]{2}{*}{$41-50$} & $-0,21$ & $-0,614^{*}$ & $-0,32$ & \multicolumn{3}{|c|}{ Tiempo Iibre (importancia) } & \\
\hline & $(0,29)$ & $(0,32)$ & $(0,26)$ & Poco importante & $-0,62$ & $-0,61$ & $-0,915^{*}$ \\
\hline \multirow[t]{2}{*}{$51-60$} & $-0,51$ & $-0,45$ & $-0,738^{* *}$ & & $(0,64)$ & $(0,60)$ & $(0,50)$ \\
\hline & $(0,31)$ & $(0,34)$ & $(0,30)$ & Importante & $-0,63$ & $-0,18$ & $-0,71$ \\
\hline \multirow[t]{2}{*}{$61-70$} & $-0,22$ & $-0,68$ & $-1,186^{\star \star \star}$ & & $(0,62)$ & $(0,57)$ & $(0,49)$ \\
\hline & $(0,38)$ & $(0,43)$ & $(0,37)$ & Muy importante & $-0,34$ & 0,00 & $-0,47$ \\
\hline \multirow[t]{2}{*}{$71-80$} & $-0,52$ & 0,57 & $-0,24$ & & $(0,62)$ & $(0,58)$ & $(0,48)$ \\
\hline & $(0,52)$ & $(0,54)$ & $(0,51)$ & \multicolumn{3}{|c|}{ Trabajo (Importancia) } & \\
\hline \multirow[t]{2}{*}{$81-90$} & $-0,43$ & $-0,50$ & 0,70 & \multirow[t]{2}{*}{ Poco importante } & 0,39 & 0,41 & $1,066^{\star}$ \\
\hline & $(0,80)$ & $(0,73)$ & $(1,34)$ & & $(1,15)$ & $(0,83)$ & $(0,55)$ \\
\hline \multirow[t]{2}{*}{$91-99$} & 0,00 & $2,286^{* * *}$ & $13,49^{* * *}$ & Importante & 0,13 & 0,47 & $0,938^{* *}$ \\
\hline & 0,00 & $(0,82)$ & $(1,09)$ & & $(0,82)$ & $(0,61)$ & $(0,46)$ \\
\hline \multicolumn{4}{|c|}{ Religión (Importancia) } & \multirow[t]{2}{*}{ Muy importante } & 0,32 & 0,33 & $1,052^{* *}$ \\
\hline \multirow[t]{2}{*}{ Poco importante } & 0,04 & $-0,31$ & 0,23 & & $(0,82)$ & $(0,61)$ & $(0,43)$ \\
\hline & $(0,38)$ & $(0,45)$ & $(0,28)$ & \multicolumn{3}{|c|}{ Familia (importancia) } & \\
\hline \multirow[t]{2}{*}{ mportante } & $-0,06$ & 0,08 & 0,26 & Poco importante & $-2,02$ & 0,00 & $-1,865^{\star \star *}$ \\
\hline & $(0,36)$ & $(0,39)$ & $(0,25)$ & & $(2,31)$ & 0,00 & $(0,59)$ \\
\hline \multirow[t]{4}{*}{ Muy importante } & 0,30 & 0,58 & $0,432^{*}$ & Importante & 0,20 & 0,00 & $-0,943^{* * *}$ \\
\hline & $(0,36)$ & $(0,39)$ & $(0,25)$ & \multirow{3}{*}{ Muy importante } & $(1,58)$ & 0,00 & $(0,35)$ \\
\hline & & & & & 0,55 & 0,00 & 0,00 \\
\hline & & & & & $(1,58)$ & 0,00 & 0,00 \\
\hline
\end{tabular}

Fuente: elaboración del autor a partir de wVs- 6. Un asterisco indica que la estimación es estadísticamente significativa a un nivel de significancia del 10 por ciento. Dos asteriscos a una significancia del 5 por ciento y tres asteriscos a una significancia del 1 por ciento. El valor en paréntesis indica el error estándar. 
Tabla A.5. Continuación.

\begin{tabular}{|c|c|c|c|c|c|c|c|}
\hline \multicolumn{3}{|c|}{ Hijos } & \multirow[b]{2}{*}{$-0,372^{*}$} & \multicolumn{4}{|c|}{ Orgullo Patrio } \\
\hline 1 hijo & 0,24 & 0,13 & & Muy poco & $-13,11^{\star * *}$ & $-0,27$ & $-0,50$ \\
\hline \multirow{3}{*}{2 hijos } & $(0,21)$ & $(0,20)$ & $(0,22)$ & & $(1,13)$ & $(0,31)$ & $(0,50)$ \\
\hline & 0,02 & 0,12 & $-0,405^{\star}$ & Levemente & $-12,91^{* * \star}$ & $-0,10$ & $-0,15$ \\
\hline & $(0,21)$ & $(0,20)$ & $(0,23)$ & & $(1,10)$ & $(0,27)$ & $(0,45)$ \\
\hline \multirow[t]{2}{*}{3 hijos } & $-0,07$ & 0,03 & $-0,438^{*}$ & \multirow[t]{2}{*}{ Totalmente } & $-12,43^{* * * *}$ & 0,44 & 0,23 \\
\hline & $(0,25)$ & $(0,24)$ & $(0,25)$ & & $(1,08)$ & $(0,28)$ & $(0,44)$ \\
\hline \multirow[t]{2}{*}{4 hijos } & $-0,12$ & $-0,39$ & $-0,35$ & \multicolumn{4}{|c|}{ Satisfacción con Ingresos Hogar } \\
\hline & $(0,31)$ & $(0,29)$ & $(0,29)$ & Nivel II & 0,34 & $-0,07$ & $-0,40$ \\
\hline \multirow[t]{2}{*}{5 hijos } & $-0,09$ & $-0,04$ & $-0,21$ & & $(0,33)$ & $(0,26)$ & $(0,26)$ \\
\hline & $(0,35)$ & $(0,37)$ & $(0,36)$ & Nivel III & $0,610^{* *}$ & 0,32 & $-0,15$ \\
\hline \multirow[t]{2}{*}{6 hijos } & $-0,06$ & $-0,57$ & $-0,19$ & & $(0,30)$ & $(0,23)$ & $(0,22)$ \\
\hline & $(0,43)$ & $(0,53)$ & $(0,38)$ & Nivel $\mathrm{N}$ & $0,731^{\star *}$ & $0,436^{*}$ & 0,28 \\
\hline \multirow[t]{2}{*}{7 hijos } & 0,60 & $-0,40$ & 0,04 & & $(0,29)$ & $(0,24)$ & $(0,21)$ \\
\hline & $(0,98)$ & $(0,82)$ & $(0,72)$ & Nivel V & $1,032^{* \star *}$ & $0,931^{\ldots * x}$ & $0,551^{\star \star}$ \\
\hline \multirow[t]{2}{*}{8 o más hijos } & 1,10 & $-1,091^{\star *}$ & 0,10 & & $(0,30)$ & $(0,25)$ & $(0,22)$ \\
\hline & $(0,78)$ & $(0,53)$ & $(0,54)$ & & & & \\
\hline \multicolumn{4}{|c|}{ Justificación Riqueza } & & & & \\
\hline \multirow[t]{2}{*}{ Justificable } & $0,243^{*}$ & 0,13 & 0,03 & & & & \\
\hline & $(0,15)$ & $(0,15)$ & $(0,13)$ & & & & \\
\hline
\end{tabular}

Fuente: elaboración del autor a partir de wVs- 6 . Un asterisco indica que la estimación es estadísticamente significativa a un nivel de significancia del 10 por ciento. Dos asteriscos a una significancia del 5 por ciento y tres asteriscos a una significancia del 1 por ciento. El valor en paréntesis indica el error estándar. 
ECONOMÍA TEORÍA Y PRÁCTICA [ISSN: 2448-7481] • Nueva Época, año 27, número 50, enero-junio 2019 Oscar Mauricio Poveda Bermudez

\section{ANEXO VI}

Tabla A.6. Efectos marginales - Metodología logística ordenada.

\begin{tabular}{|c|c|c|c|c|c|c|c|c|c|}
\hline Felicidad & Variable/Categoria & Colombia & Brasil & México & Felicidad & Variable/Categoría & Colombia & Brasil & México \\
\hline \multicolumn{5}{|c|}{ Nivel Ingresos } & \multicolumn{5}{|c|}{ Libertad de Elección (percepción) (continuación) } \\
\hline \multirow{8}{*}{ Infeliz } & \multirow[t]{2}{*}{ Nivel II } & 0,00 & 0,00 & 0,00 & \multirow{2}{*}{\multicolumn{2}{|c|}{ Nivel II }} & $-0,18$ & $-0,011$ & 0,015 \\
\hline & & $(0,00)$ & $(0,00)$ & $(0,00)$ & & & $(0,11)$ & $(0,03)$ & $(0,02)$ \\
\hline & \multirow[t]{2}{*}{ Nivel III } & 0,00 & 0,00 & 0,00 & \multirow{6}{*}{ Poco feliz } & \multirow[t]{2}{*}{ Nivel III } & $-0,184^{*}$ & $-0,004$ & 0,025 \\
\hline & & $(0,00)$ & $(0,00)$ & $(0,00)$ & & & $(0,11)$ & $(0,02)$ & $(0,02)$ \\
\hline & \multirow[t]{2}{*}{ Nivel $N$} & 0,00 & 0,00 & 0,00 & & \multirow[t]{2}{*}{ Nivel $N$} & $-0,192^{*}$ & $-0,017$ & 0,020 \\
\hline & & $(0,00)$ & $(0,00)$ & $(0,00)$ & & & $(0,11)$ & $(0,02)$ & $(0,01)$ \\
\hline & \multirow[t]{2}{*}{ Nivel V } & 0,00 & 0,00 & 0,00 & & \multirow[t]{2}{*}{ NivolV } & $-0,212^{*}$ & $-0,036$ & 0,004 \\
\hline & & $(0,00)$ & $(0,00)$ & $(0,00)$ & & & $(0,11)$ & $(0,02)$ & $(0,01)$ \\
\hline \multirow{8}{*}{ Poco feliz } & \multirow[t]{2}{*}{ Nivel II } & 0,00 & $0,0279^{*}$ & 0,00 & \multirow{8}{*}{ Feliz } & \multirow[t]{2}{*}{ Nivel II } & $-0,09$ & $-0,016$ & 0,049 \\
\hline & & $(0,02)$ & $(0,02)$ & $(0,01)$ & & & $(0,05)$ & $(0,04)$ & $(0.07)$ \\
\hline & \multirow[t]{2}{*}{ Nivel III } & 0,00 & 0,01 & 0,00 & & \multirow[t]{2}{*}{ Nivel III } & $-0,103^{* \ldots}$ & $-0,006$ & 0,077 \\
\hline & & $(0,02)$ & $(0,01)$ & $(0,01)$ & & & $(0,03)$ & $(0,03)$ & $(0,05)$ \\
\hline & \multirow[t]{2}{*}{ Nivel N } & 0,01 & 0,00 & $-0,01$ & & \multirow[t]{2}{*}{ Nivel N } & $-0,119^{* *}$ & $-0,027$ & 0,064 \\
\hline & & $(0,02)$ & $(0,02)$ & $(0,01)$ & & & $(0,03)$ & $(0,03)$ & $(0,05)$ \\
\hline & \multirow[t]{2}{*}{ Nivel V } & 0,00 & $-0,01$ & $-0,01$ & & \multirow[t]{2}{*}{ Nivel V } & $-0,167 \cdots$ & $-0,0740^{* *}$ & 0,015 \\
\hline & & $(0,04)$ & $(0,03)$ & $(0,01)$ & & & $(0,03)$ & $(0,03)$ & $(0,05)$ \\
\hline \multirow{8}{*}{ Foliz } & \multirow[t]{2}{*}{ Nivel II } & $-0,01$ & 0,06 & $-0,01$ & & Nivel II & $0,286^{* *}$ & 0,029 & $-0,065$ \\
\hline & & $(0,04)$ & $(0,03)$ & $(0,02)$ & & & $(0,13)$ & $(0,07)$ & $(0,10)$ \\
\hline & Nivel li: & $-0,01$ & 0,03 & 0,00 & & Nivel III & $0,311 \cdots$ & 0.010 & $-0,104$ \\
\hline & & $(0,04)$ & $(0,04)$ & $(0,02)$ & My foliz & & $(0,11)$ & $(0,06)$ & $(0,07)$ \\
\hline & Nivel N & 0,01 & 0,00 & $-0,02$ & overy torie & Nivel N & $0,336^{\cdots \cdots}$ & 0.046 & $-0,085$ \\
\hline & & $(0,04)$ & $(0,05)$ & $(0,03)$ & & & $(0,11)$ & $(0,06)$ & $(0,06)$ \\
\hline & Nivel V & $-0,01$ & $-0,04$ & $-0,04$ & & Nivel V & $0,406^{\cdots}$ & $0,115^{* *}$ & $-0,020$ \\
\hline & & $(0,09)$ & $(0,10)$ & $(0,05)$ & & & $(0,11)$ & $(0,06)$ & $(0,06)$ \\
\hline & Nivel II & 0,01 & $-0,0889^{*}$ & 0,01 & & Condicion & Laboral & & \\
\hline & & $(0,06)$ & $(0,05)$ & $(0,03)$ & & $\mathrm{T}$, Completo & 0,000 & $-0,00356^{\circ}$ & 0,001 \\
\hline & Nivel III & 0,02 & $-0,04$ & 0,00 & & & $(0,00)$ & $(0,00)$ & $(0,00)$ \\
\hline Muy feliz & & $(0,06)$ & $(0,05)$ & $(0,03)$ & & medio tiempo & 0,002 & $-0,00308^{*}$ & 0,000 \\
\hline & Nivel N & $-0,02$ & 0,00 & 0,03 & & & $(0,00)$ & $(0,00)$ & $(0,00)$ \\
\hline & & $(0,07)$ & $(0,07)$ & $(0,04)$ & & independiente & 0.001 & 0.002 & -0.001 \\
\hline & Nivel V & 0,01 & 0,05 & 0,06 & & & $(0,00)$ & $(0,00)$ & $(0,00)$ \\
\hline & & $(0,13)$ & $(0,13)$ & $(0,06)$ & Infeliz & retirado & $-0,001$ & $-0,002$ & 0,000 \\
\hline & Libertad de Elecci & ión (percep & ción) & & & & $(0,00)$ & $(0,00)$ & $(0,00)$ \\
\hline & Nivel II & $-0,02$ & $-0,002$ & 0,001 & & ama do casa & 0,003 & 0,000 & 0,001 \\
\hline & & $(0,02)$ & $(0,00)$ & $(0,00)$ & & & $(0,00)$ & $(0,00)$ & $(0,00)$ \\
\hline & Nivel III & $-0,02$ & $-0,001$ & 0,002 & & estudiante & 0,001 & 0,001 & 0,000 \\
\hline Infeliz & & $(0,02)$ & $(0,00)$ & $(0,00)$ & & & $(0,00)$ & $(0,00)$ & $(0,00)$ \\
\hline & Nivel N & $-0,03$ & $-0,003$ & 0,002 & & otro & $-0,001$ & 0,001 & $-0,001$ \\
\hline & & $(0,02)$ & $(0,00)$ & $(0,00)$ & & & $(0,00)$ & $(0,01)$ & $(0,00)$ \\
\hline
\end{tabular}

Fuente: elaboración del autor a partir de WVs- 6 . Un asterisco indica que la estimación es estadísticamente significativa a un nivel de significancia del 10 por ciento. Dos asteriscos a una significancia del 5 por ciento y tres asteriscos a una significancia del 1 por ciento. El valor en paréntesis indica el error estándar. 
Tabla A.6. Continuación.

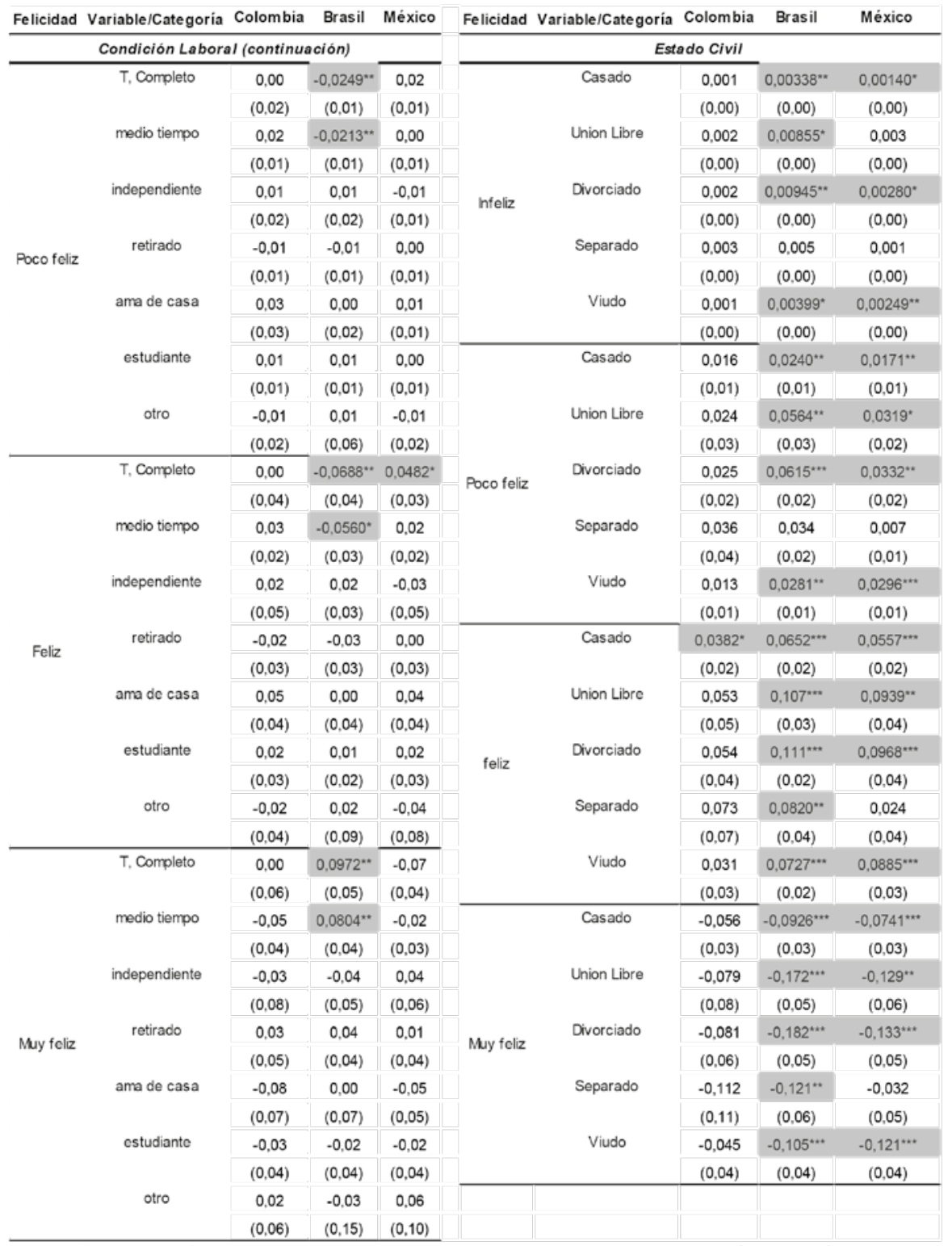

Fuente: elaboración del autor a partir de wvs- 6 . Un asterisco indica que la estimación es estadísticamente significativa a un nivel de significancia del 10 por ciento. Dos asteriscos a una significancia del 5 por ciento y tres asteriscos a una significancia del 1 por ciento. El valor en paréntesis indica el error estándar. 
ECONOMÍA TEORÍA y PRÁCTICA [ISSN: 2448-7481] • Nueva Época, año 27, número 50, enero-junio 2019 Oscar Mauricio Poveda Bermudez

Tabla A.6. Continuación.

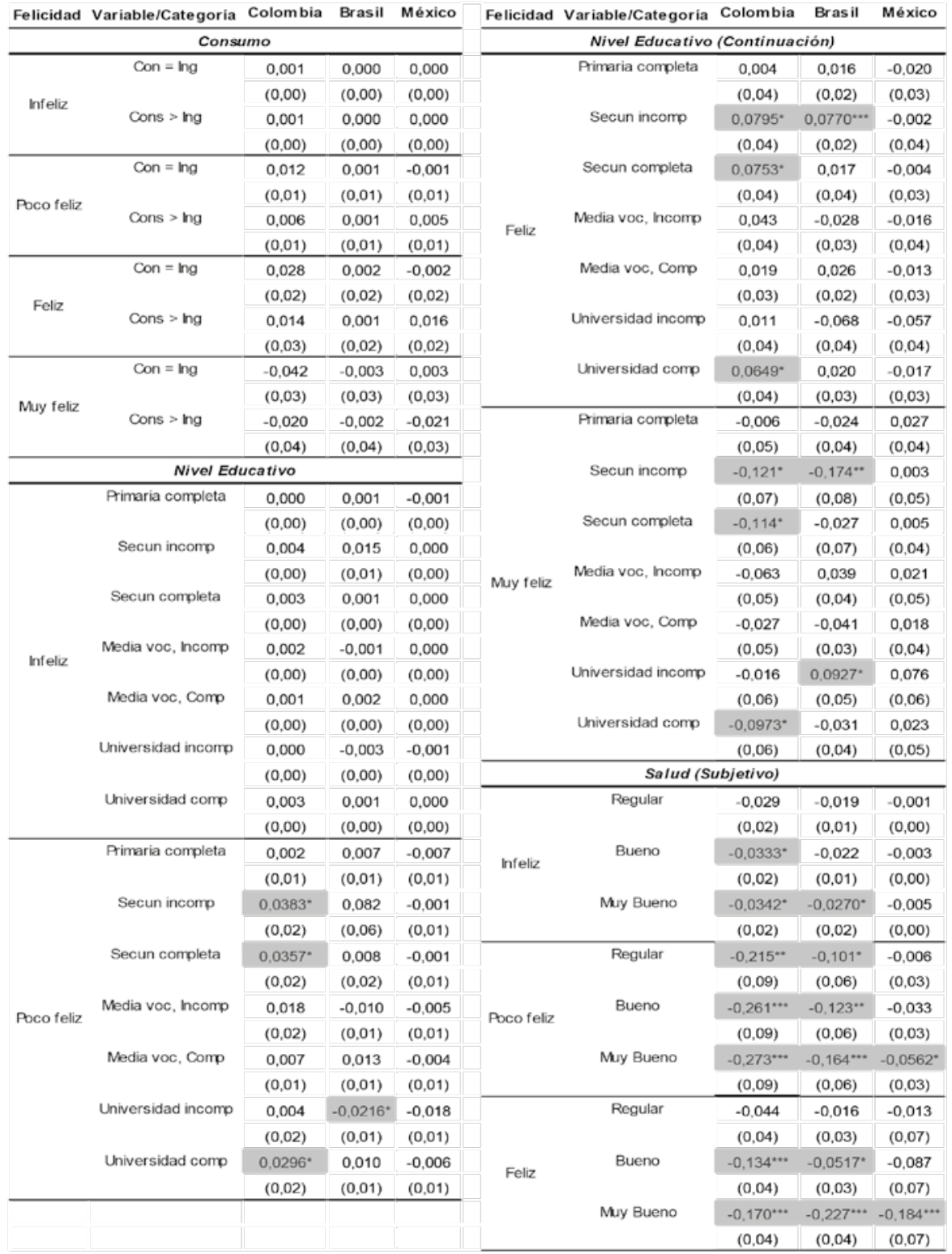

Fuente: elaboración del autor a partir de wvs- 6. Un asterisco indica que la estimación es estadísticamente significativa a un nivel de significancia del 10 por ciento. Dos asteriscos a una significancia del 5 por ciento y tres asteriscos a una significancia del 1 por ciento. El valor en paréntesis indica el error estándar. 
Tabla A.6. Continuación.

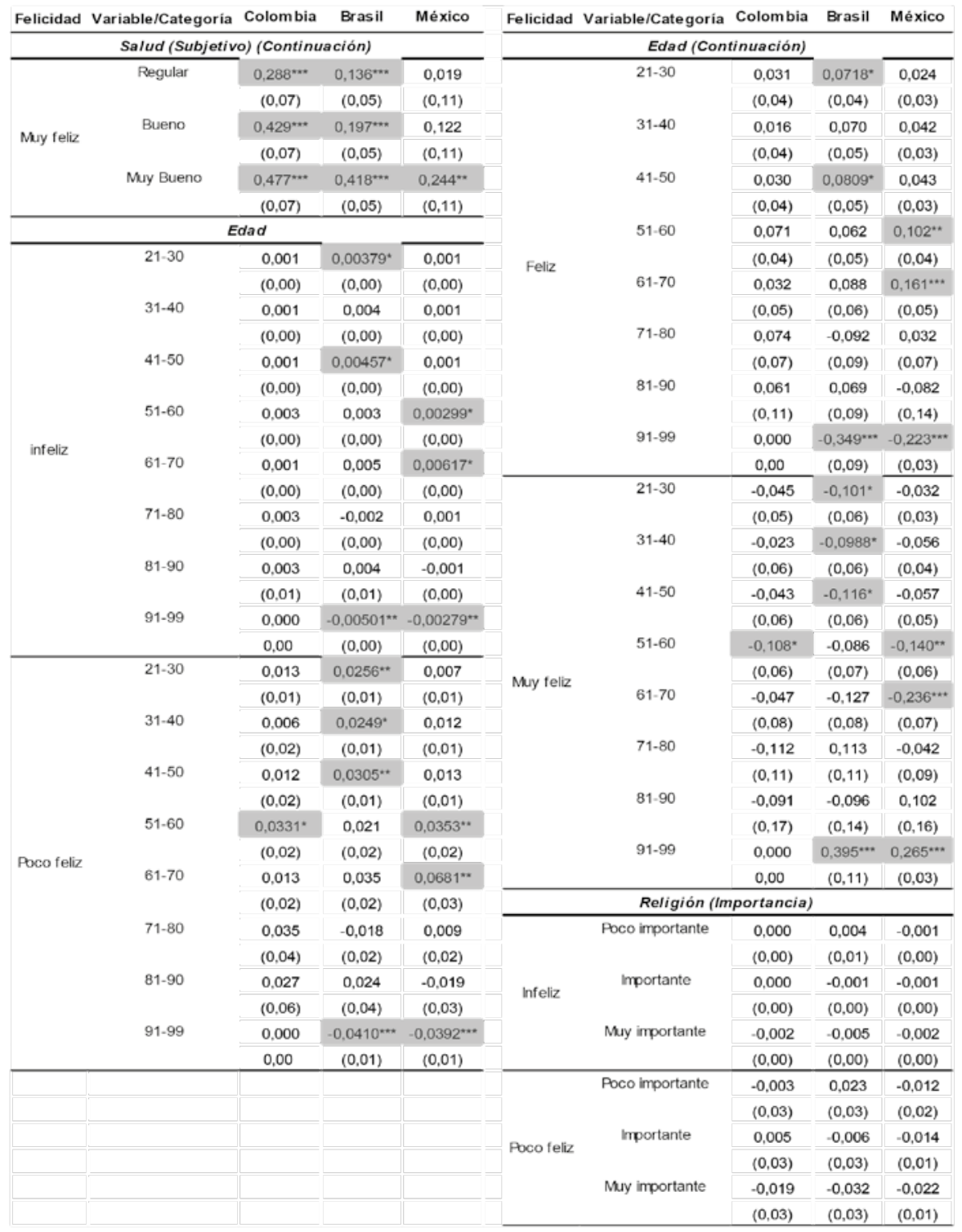

Fuente: elaboración del autor a partir de wVS- 6 . Un asterisco indica que la estimación es estadísticamente significativa a un nivel de significancia del 10 por ciento. Dos asteriscos a una significancia del 5 por ciento y tres asteriscos a una significancia del 1 por ciento. El valor en paréntesis indica el error estándar. 
ECONOMÍA TEORÍA Y PRÁCTICA [ISSN: 2448-7481] • Nueva Época, año 27, número 50, enero-junio 2019 Oscar Mauricio Poveda Bermudez

Tabla A.6. Continuación.

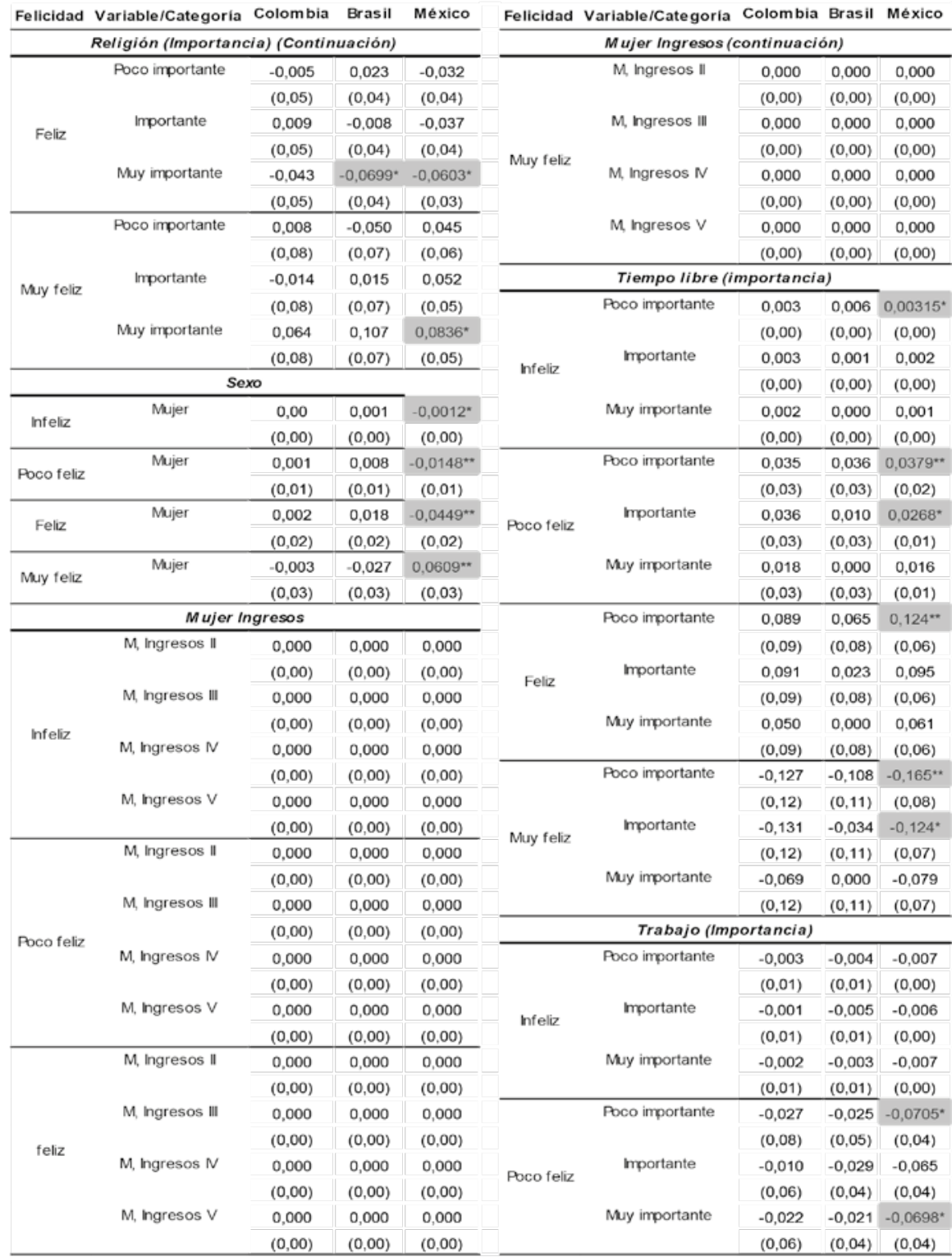

Fuente: elaboración del autor a partir de wVs- 6. Un asterisco indica que la estimación es estadísticamente significativa a un nivel de significancia del 10 por ciento. Dos asteriscos a una significancia del 5 por ciento y tres asteriscos a una significancia del 1 por ciento. El valor en paréntesis indica el error estándar. 
Tabla A.6. Continuación.

\begin{tabular}{|c|c|c|c|c|c|c|c|c|c|}
\hline \multirow{2}{*}{ Felicidad } & Variable/Categoria & Colombia & Brasil & \multirow[t]{2}{*}{ México } & Felicidad & Variable/Categoria & Colombia & Brasil & México \\
\hline & \multicolumn{3}{|c|}{ Trabajo (Importancia) (Continuación) } & & \multicolumn{5}{|c|}{ Orgullo Patrio } \\
\hline \multirow{6}{*}{ Feliz } & \multirow[t]{2}{*}{ Poco importante } & $-0,055$ & $-0,042$ & $-0,142^{* *}$ & \multirow{6}{*}{ Infeliz } & \multirow[t]{2}{*}{ Muy poco } & $0,0104^{* *}$ & 0.003 & 0,003 \\
\hline & & $(0,16)$ & $(0,09)$ & $(0,07)$ & & & $(0,00)$ & $(0,00)$ & $(0,00)$ \\
\hline & \multirow[t]{2}{*}{ Importante } & $-0,018$ & $-0,050$ & $-0,124^{*-}$ & & \multirow[t]{2}{*}{ Levemente } & $0,00856^{\cdots \cdots}$ & 0,001 & 0,001 \\
\hline & & $(0,11)$ & $(0,05)$ & $(0,05)$ & & & $(0,00)$ & $(0,00)$ & $(0,00)$ \\
\hline & \multirow[t]{2}{*}{ Muy importante } & -0.044 & -0.033 & $-0,140^{\cdots} \cdots$ & & \multirow[t]{2}{*}{ Totalmente } & $0,00542^{\cdots}$ & $-0,003$ & -0.001 \\
\hline & & $(0,11)$ & $(0,05)$ & $(0,05)$ & & & $(0,00)$ & $(0,00)$ & $(0,00)$ \\
\hline \multirow{6}{*}{ Muy feliz } & \multirow[t]{2}{*}{ Poco importante } & 0,084 & 0,071 & $0.219^{* *}$ & \multirow{6}{*}{ Poco feliz } & \multirow[t]{4}{*}{ Muy poco } & $0,122^{* *}$ & 0,017 & 0,031 \\
\hline & & $(0,25)$ & $(0,14)$ & $(0,11)$ & & & $(0,03)$ & $(0,02)$ & $(0,03)$ \\
\hline & \multirow[t]{2}{*}{ Importante } & 0,029 & 0,083 & $0,195^{* *}$ & & & $0,105^{\cdots}$ & 0,006 & 0,008 \\
\hline & & $(0,18)$ & $(0,10)$ & $(0,10)$ & & & $(0,01)$ & $(0,02)$ & $(0,02)$ \\
\hline & \multirow[t]{2}{*}{ Muy importante } & 0,068 & 0.058 & $0,216^{* *}$ & & \multirow[t]{2}{*}{ Totalmente } & $0,0716^{* * *}$ & $-0,021$ & -0.011 \\
\hline & & $(0,18)$ & $(0,10)$ & $(0,09)$ & & & $(0,01)$ & $(0,02)$ & $(0,02)$ \\
\hline & Familia (imp & portancia) & & & & Muy poco & $0,421^{\cdots}$ & 0.029 & 0,070 \\
\hline & Poco importante & 0,051 & 0,000 & 0,000 & & & $(0,04)$ & $(0,03)$ & $(0,07)$ \\
\hline & & $(0,09)$ & $(0, \infty 0)$ & $(0,00)$ & Foliz & Levemente & $0,397^{\cdots}$ & 0.011 & 0,021 \\
\hline Infeliz & Importante & $-0,002$ & 0,000 & $-0,013$ & reliz & & $(0,03)$ & $(0,03)$ & $(0,06)$ \\
\hline Intenz & & $(0,01)$ & $(0,00)$ & $(0,01)$ & & Totalmente & $0,330^{\cdots}$ & $-0,0596^{*}$ & $-0,032$ \\
\hline & Muy importante & $-0,004$ & 0,000 & $-0,018$ & & & $(0,02)$ & $(0,03)$ & $(0,06)$ \\
\hline & & $(0,01)$ & $(0,00)$ & $(0,01)$ & & Muy poco & $-0,554 \cdots$ & $-0,048$ & $-0,104$ \\
\hline & Poco importante & 0,280 & 0,000 & 0.000 & & & $(0,07)$ & $(0,06)$ & $(0,10)$ \\
\hline & & $(0,31)$ & $(0,00)$ & $(0,00)$ & & Levemente & $-0,510^{\cdots \cdots}$ & $-0,018$ & -0.029 \\
\hline Poco feliz & Importante & $-0,017$ & 0,000 & $-0,104$ & Muy tele & & $(0,04)$ & $(0,05)$ & $(0,09)$ \\
\hline Foco tell & & $(0,14)$ & $(0,00)$ & $(0,09)$ & & Totalmente & $-0,407^{* \cdots}$ & 0,084 & 0,044 \\
\hline & Muy importante & -0.041 & 0,000 & $-0,165^{* *}$ & & & $(0,02)$ & $(0,05)$ & $(0,09)$ \\
\hline & & $(0,14)$ & $(0,00)$ & $(0,08)$ & & Satisfacción cor & n Ingresos f & Hogar & \\
\hline & Poco importante & 0,010 & 0,000 & 0.000 & & Nivel II & $-0,003$ & 0.001 & 0,002 \\
\hline & & $(0,27)$ & $(0,00)$ & $(0,00)$ & & & $(0,00)$ & $(0,00)$ & $(0,00)$ \\
\hline Feliz & Importante & $-0,026$ & 0,000 & $-0,0716^{*}$ & & Nivel III & $-0,005$ & $-0,003$ & 0,001 \\
\hline & & $(0,19)$ & $(0,00)$ & $(0,04)$ & nfeliz & & $(0,00)$ & $(0,00)$ & $(0,00)$ \\
\hline & Muy importante & -0.075 & 0,000 & $-0,200^{\cdots}$ & & Nivel N & $-0,005$ & $-0,004$ & $-0,001$ \\
\hline & & $(0,19)$ & $(0,00)$ & $(0,02)$ & & & $(0,00)$ & $(0,00)$ & $(0,00)$ \\
\hline & Poco importante & $-0,342$ & 0,000 & 0,000 & & Nivel V & $-0,00684^{*}$ & $-0,00693^{* *}$ & $-0,00183^{*}$ \\
\hline & & $(0,39)$ & $(0,00)$ & $(0,00)$ & & & $(0,00)$ & $(0,00)$ & $(0,00)$ \\
\hline Mury feliz & Importante & 0,044 & 0,000 & 0,188 & & Nivel II & $-0,030$ & 0.005 & 0,024 \\
\hline & & $(0,35)$ & $(0,00)$ & $(0,13)$ & & & $(0,03)$ & $(0,02)$ & $(0,02)$ \\
\hline & Muy importante & 0,120 & 0,000 & $0,382^{\cdots}$ & & Nivel III & $-0,0502^{*}$ & $-0,021$ & 0,008 \\
\hline & & $(0,35)$ & $(0,00)$ & $(0,11)$ & Phco feliz & & $(0,03)$ & $(0,02)$ & $(0,01)$ \\
\hline & Justificación & Riqueza & & & Focotera & Nivel N & $-0,0579 *$ & $-0,0265^{*}$ & $-0,013$ \\
\hline Infeliz & Justificable & $-0,002$ & $-0,001$ & 0,000 & & & $(0,03)$ & $(0,02)$ & $(0,01)$ \\
\hline inrenz & & $(0,00)$ & $(0,00)$ & $(0,00)$ & & Nivel V & $-0,0743^{\cdots}$ & $-0,0482^{\cdots \cdots}$ & $-0,0227^{* *}$ \\
\hline Poco feli & Justificable & -0.016 & $-0,007$ & -0.001 & & & $(0,03)$ & $(0,01)$ & $(0,01)$ \\
\hline Poco feli & & $(0,01)$ & $(0,01)$ & $(0,01)$ & & Nivel II & $-0,042$ & 0,006 & 0,058 \\
\hline Feliz & Justificable & $-0,0342^{*}$ & $-0,015$ & $-0,004$ & & & $(0,04)$ & $(0,02)$ & $(0,04)$ \\
\hline renz & & $(0,02)$ & $(0,02)$ & $(0,02)$ & & Nivel III & $-0,0801^{* *}$ & $-0,033$ & 0,022 \\
\hline Muy foliz & Justificable & $0,0520^{*}$ & 0,023 & 0.006 & Feliz & & $(0,03)$ & $(0,02)$ & $(0,03)$ \\
\hline Tuy reiz & & $(0,03)$ & $(0,03)$ & $(0,02)$ & & Nivel N & $-0,0982^{* \cdots}$ & $-0,0472^{* *}$ & -0.040 \\
\hline & & & & & & & $(0,03)$ & $(0,02)$ & $(0,03)$ \\
\hline & & & & & & Nivel V & $-0,144^{\cdots}$ & $-0,120^{* \ldots}$ & $-0,0781^{* *}$ \\
\hline & & & & & & & $(0,04)$ & $(0,03)$ & $(0,03)$ \\
\hline
\end{tabular}

Fuente: elaboración del autor a partir de wVS- 6 . Un asterisco indica que la estimación es estadísticamente significativa a un nivel de significancia del 10 por ciento. Dos asteriscos a una significancia del 5 por ciento y tres asteriscos a una significancia del 1 por ciento. El valor en paréntesis indica el error estándar. 
ECONOMÍA TEORÍA Y PRÁCTICA [ISSN: 2448-7481] • Nueva Época, año 27, número 50, enero-junio 2019 Oscar Mauricio Poveda Bermudez

Tabla A.6. Continuación.

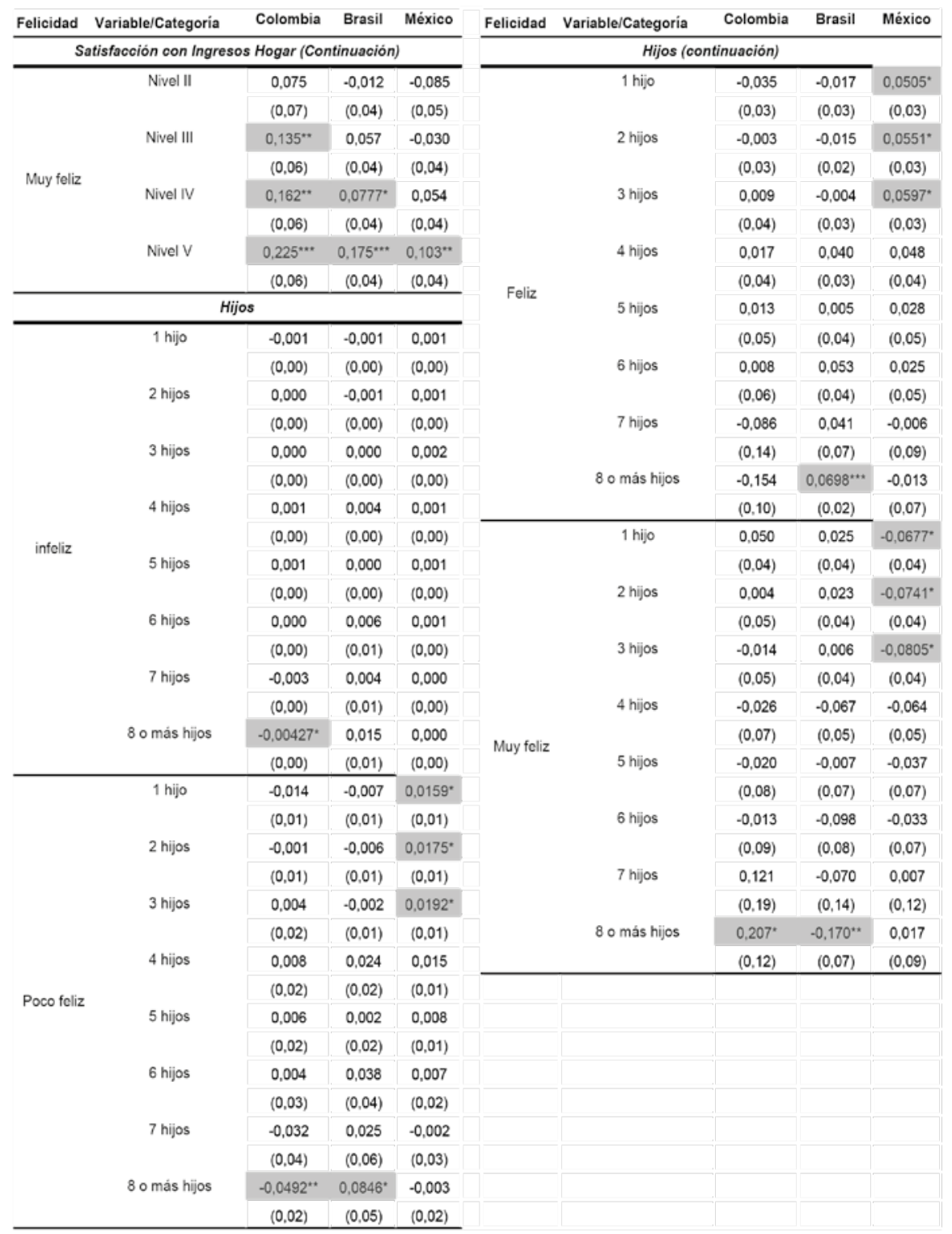

Fuente: elaboración del autor a partir de wVS- 6 . Un asterisco indica que la estimación es estadísticamente significativa a un nivel de significancia del 10 por ciento. Dos asteriscos a una significancia del 5 por ciento y tres asteriscos a una significancia del 1 por ciento. El valor en paréntesis indica el error estándar. 